\title{
CVIT expert consensus document on primary percutaneous coronary intervention (PCI) for acute myocardial infarction (AMI) update 2022
}

\author{
Yukio Ozaki $^{1} \cdot$ Hironori Hara ${ }^{2,3} \cdot$ Yoshinobu Onuma $^{2} \cdot$ Yuki Katagiri $^{4} \cdot$ Tetsuya Amano $^{5} \cdot$ Yoshio Kobayashi $^{6}$. \\ Takashi Muramatsu $^{1} \cdot$ Hideki Ishii $^{7} \cdot$ Ken Kozuma $^{8} \cdot$ Nobuhiro Tanaka $^{9} \cdot$ Hitoshi Matsuo $^{10} \cdot$ Shiro Uemura ${ }^{11}$. \\ Kazushige Kadota ${ }^{12}$. Yutaka Hikichi' ${ }^{13}$. Kenichi Tsujita ${ }^{14}$. Junya Ako ${ }^{15}$. Yoshihisa Nakagawa ${ }^{16}$. Yoshihiro Morino ${ }^{17}$. \\ Ichiro Hamanaka ${ }^{18}$. Nobuo Shiode ${ }^{19}$. Junya Shite ${ }^{20}$. Junko Honye ${ }^{21}$. Tetsuo Matsubara ${ }^{22} \cdot$ Kazuya Kawai $^{23}$. \\ Yasumi Igarashi ${ }^{24}$. Atsunori Okamura ${ }^{25}$. Takayuki Ogawa ${ }^{26}$. Yoshisato Shibata ${ }^{27}$. Takafumi Tsuji ${ }^{28}$. Junji Yajima ${ }^{29}$. \\ Kaoru Iwabuchi ${ }^{30}$. Nobuo Komatsu ${ }^{31}$. Teruyasu Sugano ${ }^{32}$. Masaru Yamaki ${ }^{33}$. Shinichiro Yamada ${ }^{34}$. \\ Hiroaki Hirase $\mathrm{e}^{35}$. Yuusuke Miyashita ${ }^{36}$. Fuminobu Yoshimachi ${ }^{37}$. Masakazu Kobayashi ${ }^{1}$. Jiro Aoki ${ }^{38}$. \\ Hirotaka Oda ${ }^{39}$. Yoshiaki Katahira ${ }^{40} \cdot \mathrm{Kinzo} \mathrm{Ueda}^{41} \cdot$ Masami Nishino $^{42} \cdot$ Koichi Nakao $^{43} \cdot$ Ichiro Michishita $^{44}$. \\ Takafumi Ueno ${ }^{45}$. Taku Inohara ${ }^{46}$. Shun Kohsaka ${ }^{46}$. Tevfik F. Ismail ${ }^{1,47}$. Patrick W. Serruys ${ }^{2,48}$. Masato Nakamura ${ }^{49}$. \\ Hiroyoshi Yokoi ${ }^{50}$ - Yuji Ikari ${ }^{51}$. The Task Force on Primary Percutaneous Coronary Intervention (PCI) of the \\ Japanese Cardiovascular Interventional Therapeutics (CVIT)
}

Received: 15 November 2021 / Accepted: 15 November 2021 / Published online: 12 January 2022

(c) The Author(s) 2022

\begin{abstract}
Primary Percutaneous Coronary Intervention (PCI) has significantly contributed to reducing the mortality of patients with ST-segment elevation myocardial infarction (STEMI) even in cardiogenic shock and is now the standard of care in most of Japanese institutions. The Task Force on Primary PCI of the Japanese Association of Cardiovascular Interventional and Therapeutics (CVIT) society proposed an expert consensus document for the management of acute myocardial infarction (AMI) focusing on procedural aspects of primary PCI in 2018. Updated guidelines for the management of AMI were published by the European Society of Cardiology (ESC) in 2017 and 2020. Major changes in the guidelines for STEMI patients included: (1) radial access and drug-eluting stents (DES) over bare-metal stents (BMS) were recommended as a Class I indication, (2) complete revascularization before hospital discharge (either immediate or staged) is now considered as Class IIa recommendation. In 2020, updated guidelines for Non-ST-Elevation Myocardial Infarction (NSTEMI) patients, the followings were changed: (1) an early invasive strategy within $24 \mathrm{~h}$ is recommended in patients with NSTEMI as a Class I indication, (2) complete revascularization in NSTEMI patients without cardiogenic shock is considered as Class IIa recommendation, and (3) in patients with atrial fibrillation following a short period of triple antithrombotic therapy, dual antithrombotic therapy (e.g., DOAC and single oral antiplatelet agent preferably clopidogrel) is recommended, with discontinuation of the antiplatelet agent after 6 to 12 months. Furthermore, an aspirin-free strategy after PCI has been investigated in several trials those have started to show the safety and efficacy. The Task Force on Primary PCI of the CVIT group has now proposed the updated expert consensus document for the management of AMI focusing on procedural aspects of primary PCI in 2022 version.
\end{abstract}

Keywords ST-segment elevation acute myocardial infarction (STEMI) · Non-ST-segment elevation acute coronarysyndrome (NSTE-ACS) · Percutaneous coronary intervention (PCI) · Thrombus aspiration, Optical coherencetomography $(\mathrm{OCT}) \cdot$ Dual antiplatelet therapy (DAPT)

Yukio Ozaki

yukio.ozaki7@gmail.com

Extended author information available on the last page of the article

\section{Introduction}

In ST-segment elevation myocardial infarction (STEMI), primary PCI has been shown to contribute to the reduction of cardiac events, lead to earlier discharge, and is even effective in patients with cardiogenic shock [1-19]. It is now a 
standard of care in Japan. While there are a high number of available facilities providing primary PCI in Japan, there are no guidelines focusing on procedural aspect of standardized care, which may further improve the quality of our practice.

Updated guidelines for the management of acute myocardial infarction (AMI) were published by European Society of Cardiology (ESC) in 2017 and 2020 [20, 21]. Major changes in the guidelines for STEMI patients include recommendations for: (1) radial access and drug-eluting stent (DES) over bare-metal stent (BMS) as a Class I indication; and (2) complete revascularization before hospital discharge (either immediate or staged) as a Class IIa recommendation. Primary PCI is consistently recommended in the updated guidelines as well as the previous guidelines [22]. In the guidelines for NSTEMI patients, the followings were changed: (1) an early invasive strategy within $24 \mathrm{~h}$ is recommended in patients with NSTEMI as a Class I indication; (2) complete revascularization in NSTEMI patients without cardiogenic shock is considered as Class IIa recommendation; and (3) in patients with atrial fibrillation, following a short period of triple antithrombotic therapy (up to 1 week from the acute event), dual antithrombotic therapy (e.g., DOAC and single oral antiplatelet agent preferably clopidogrel) is recommended, with cessation of the antiplatelet after 6 to 12 months [21].

However, lags in device approval and differences in available medical therapy and mechanical support may prevent direct application of European guidelines to the Japanese population (Tables 1 and 2). Therefore, the Task Force on PCI of the Japanese CVIT society summarized the consensus for the management of AMI, mainly focusing on procedural aspects.

\section{Specific differences between Japan and Europe}

Glycoprotein (GP) IIb/IIIa inhibitors are not available in Japan whereas thrombus aspiration is still a choice of strategy of treatment of AMI.

Currently preferred oral P2Y12 inhibitors in acute coronary syndrome in Europe are prasugrel and ticagrelor. Until recently, ticagrelor was not available in Japan, which was approved in 2016 and put on the market in February, 2017, with a 7-year lag from the approval in Europe. In addition, dose difference in P2Y12 inhibitors between Japan and Europe may cause different antithrombotic benefit/bleeding risk profile. Intravenous cangrelor and subcutaneous selatogrel are not approved in Japan, while its use may be considered in patients not pre-treated with oral P2Y12 inhibitors at the time of PCI or in those who are considered unable to absorb oral agents.

LV assist devices and ECMO are increasingly popular managing patients with cardiogenic shock in Europe although they have not been sufficiently evaluated in clinical trials, while the use of IABP has not met prior expectations of benefit [23, 24]. In contrast, in Japan, left ventricular assist devices (LVADs: i.e., intra-cardiac axial flow pumps and arterial-venous extracorporeal membrane oxygenation) are not widely available, and we continue to largely rely on intra-aortic balloon pumps as a mechanical support.

Regarding intravascular imaging devices, intravascular ultrasound (IVUS) and optical coherence tomography (OCT) during PCI are routinely reimbursed in Japan. In contrast to the situation in Europe, their use is not restricted in selected cases such as unprotected left main lesions or stent failure.

In terms of data derived from Japanese population, there are several registries and databases including patients with AMI in Japan such as J-MINUET [25-28], PACIFIC [29], Tokyo CCU network registry [30], JAMIR [31-35], and JROAD [36-38]. CVIT has been working on the J-PCI registry [39-42], the largest database of patients who underwent PCI in Japan. The current demographics, lesion and procedural characteristics in patients with AMI in Japan can be identified in the J-PCI registry including 253,228 patients treated in 1113 institutions from January 2019 to December 2019 (Tables 3 and 4).

Table 1 Major differences in available medication and mechanical devices

\begin{tabular}{|c|c|c|}
\hline & Europe & Japan \\
\hline Glycoprotein IIb/IIIa inhibitors & Tirofiban, eptifibatide, and abciximab are available & GP IIb/IIIa inhibitors are not available \\
\hline P2Y12 inhibitors & $\begin{array}{l}\text { The preferred P2Y12 inhibitors are prasugrel [ } 60 \mathrm{mg} \text { loading } \\
\text { dose and } 10 \mathrm{mg} \text { maintenance dose once daily per os (p.o.)] } \\
\text { or ticagrelor (180 mg p.o. loading dose and } 90 \mathrm{mg} \text { mainte- } \\
\text { nance dose twice daily) }\end{array}$ & $\begin{array}{l}\text { Both prasugrel and ticagrelor are available, but } \\
\text { the dose in prasugrel is different. [ } 20 \mathrm{mg} \text { load- } \\
\text { ing dose and } 3.75 \mathrm{mg} \text { maintenance dose once } \\
\text { daily per os] }\end{array}$ \\
\hline Mechanical LV assist devices & $\begin{array}{l}\text { Intra-cardiac axial flow pump (i.e., Impella) and intra-aortic } \\
\text { balloon pump are available }\end{array}$ & $\begin{array}{l}\text { Intra-aortic balloon pumps are still in use. Intra- } \\
\text { cardiac axial flow pumps are used in selected } \\
\text { institutions but are not widely available }\end{array}$ \\
\hline
\end{tabular}


Table 2 Major CE-approved DES and their availability in Japan

\begin{tabular}{|c|c|c|c|c|}
\hline DES & Stent platform & Polymer coating & Drug & $\begin{array}{l}\text { Avail- } \\
\text { ability in } \\
\text { Japan }\end{array}$ \\
\hline \multicolumn{5}{|c|}{ Based on durable polymer coatings } \\
\hline DESyne Nx & Cobalt-chrome & PBMA & Novolimus & No \\
\hline Promus element & Platinum-chrome & PBMA and PVDF-HFP & Everolimus & Yes \\
\hline Resolute & Cobalt-chrome & PBMA, PHMA, PVP, and PVA & Zotarolimus & Yes \\
\hline STENTYS & Nitinol & PSU and PVP & Paclitaxel & No \\
\hline Xience & Cobalt-chrome & PBMA and PVDF-HFP & Everolimus & Yes \\
\hline \multicolumn{5}{|c|}{ Based on biodegradable polymer coatings } \\
\hline Axxess & Nitinol & PDLLA & Biolimus A9 & No \\
\hline Biomatrix & Stainless steel & PDLLA & Biolimus A9 & No \\
\hline BioMime & Cobalt-chrome & PLLA and PLGA & Sirolimus & No \\
\hline Combo & Stainless steel & $\begin{array}{l}\text { PDLLA and PLGA + Additional } \\
\text { coating with anti-CD34 }\end{array}$ & Sirolimus & No \\
\hline DESyne BD & Cobalt-chrome & PLLA & Novolimus & No \\
\hline Infinnium & Stainless steel & PLLA, PLGA, PCL, and PVP & Paclitaxel & No \\
\hline MiStent & Cobalt-chrome & PLGA & Crystalline sirolimus & No \\
\hline Nobori & Stainless steel & PDLLA & Biolimus A9 & Yes \\
\hline Orsiro & Cobalt-chrome & PLLA & Sirolimus & Yes \\
\hline Supralimus core & Cobalt-chrome & PLLA, PLGA, PCL, and PVP & Sirolimus & No \\
\hline Synergy & Platinum-chrome & PLGA & Everolimus & Yes \\
\hline Ultimaster & Cobalt-chrome & PDLLA and PCL & Sirolimus & Yes \\
\hline Yukon choice PC & Stainless steel & PDLLA & Sirolimus & No \\
\hline Supraflex Cruz & Cobalt-chrome & PLLA, PLGA, and PVP & Sirolimus & No \\
\hline BuMA supreme & Cobalt-chrome & PLGA & Sirolimus & No \\
\hline \multicolumn{5}{|l|}{ Polymer-free } \\
\hline Amazonia Pax & Cobalt-chrome & - & Paclitaxel & No \\
\hline BioFreedom & Stainless steel & - & Biolimus A9 & Yes \\
\hline Cre8 & Cobalt-chrome & - & Sirolimus & No \\
\hline Yukon Choice PF & Stainless steel & - & Sirolimus & No \\
\hline
\end{tabular}

$P B M A$ polyn-butyl methacrylate, $P C L$ poly-caprolactone, $P D L L A$ poly-D,L-lactic acid, $P H M A$ poly-hexyl methacrylate, $P L C L$ poly-L-lactideco-caprolactone, $P L G A$ poly-D,L-lactide-co-glycolide, $P L L A$ poly-L-lactic acid, $P V P$ polyvinylpyrrolidone, $P V A$ polyvinyl acetate, $P V D F-H F P$ poly-vinylidene fluoride-co-hexafluoropropylene, $P S U$ polysulphone

\section{Primary $\mathrm{PCl}$ in STEMI, early invasive vs. conservative strategy in NSTEMI}

In ST-segment elevation myocardial infarction, primary PCI has been shown to contribute high revascularization success rates, less cardiac events, earlier discharge, and is even effective in patients with cardiogenic shock [1-19] and consistently recommended by European [20], American [43], and Japanese guidelines.

Meta-analysis based on individual patient data from three studies that compared a routine invasive against a selective invasive strategy revealed lower rates of death and myocardial infarction at 5 -year follow-up $(\mathrm{HR}=0.81,95 \% \mathrm{CI}$ $0.71-0.93 ; p=0.002)$, with the most pronounced difference in high-risk patients [44]. Age, diabetes, previous myocardial infarction, ST-segment depression, hypertension, body mass index $\left(<25 \mathrm{~kg} / \mathrm{m}^{2}\right.$ or $\left.>35 \mathrm{~kg} / \mathrm{m}^{2}\right)$ and treatment strategy were found to be independent predictors of death and myocardial infarction during follow-up. The results supported a routine invasive strategy but highlight the importance of risk stratification in the decision-making process as is recommended in the present guidelines [21,23].

However, in the ICTUS trial, in which 1,200 patients with Non-ST-Elevation Acute Coronary Syndrome (NSTEACS) (NSTE-ACS) and an elevated cardiac troponin T were randomized to an early invasive strategy versus a selective invasive strategy, 10-year death or spontaneous MI was not statistically different between the 2 groups (33.8\% vs. $29.0 \%$, HR 1.12, 95\% CI 0.97-1.46; $p=0.11$ ). In addition, the 15-year follow-up of the FRISC-II study showed a significant 18-month postponement of the occurrence of death or next MI and 37 months postponement of re-hospitalization 
Table 3 Demographics of patients with STEMI and NSTEMI from J-PCI registry

\begin{tabular}{|c|c|c|c|c|}
\hline & $\begin{array}{l}\text { Overall MI } \\
(N=59,020)\end{array}$ & $\begin{array}{l}\text { STEMI } \\
(n=44,329)\end{array}$ & $\begin{array}{l}\text { NSTEMI } \\
(n=14,691)\end{array}$ & $p$ value \\
\hline Age (years), mean (SD) & $69.86(12.84)$ & $69.49(12.94)$ & 70.95 (12.49) & $<0.001$ \\
\hline Female & $14,200(24.1)$ & $10,686(24.1)$ & $3514(23.9)$ & 0.654 \\
\hline Cardiogenic shock & $6798(11.5)$ & $5570(12.6)$ & $1228(8.4)$ & $<0.001$ \\
\hline \multicolumn{5}{|l|}{ Risk factors } \\
\hline Smoker (current and within $1 \mathrm{yr}$ ) & $21,763(36.9)$ & $16,720(37.7)$ & $5043(34.3)$ & $<0.001$ \\
\hline Diabetes mellitus & $21,525(36.5)$ & $15,547(35.1)$ & $5978(40.7)$ & $<0.001$ \\
\hline Hypertension & $40,711(69.0)$ & $29,828(67.3)$ & $10,883(74.1)$ & $<0.001$ \\
\hline Hypercholesterolemia & $34,823(59.0)$ & $25,546(57.6)$ & $9277(63.1)$ & $<0.001$ \\
\hline \multicolumn{5}{|l|}{ History of: } \\
\hline Previous MI & $7008(11.9)$ & $4344(9.8)$ & $2664(18.1)$ & $<0.001$ \\
\hline Peripheral vascular disease & $2184(3.7)$ & $1331(3.0)$ & $853(5.8)$ & $<0.001$ \\
\hline Previous PCI & $9365(15.9)$ & $5871(13.2)$ & $3494(23.8)$ & $<0.001$ \\
\hline Previous CABG & $824(1.4)$ & $384(0.9)$ & $440(3.0)$ & $<0.001$ \\
\hline Heart failure & $4503(7.6)$ & $2650(6.0)$ & $1853(12.6)$ & $<0.001$ \\
\hline Renal insufficiency & $10,506(17.8)$ & $7219(16.3)$ & $3287(22.4)$ & $<0.001$ \\
\hline Hemodialysis & $1745(3.0)$ & $958(2.2)$ & $787(5.4)$ & $<0.001$ \\
\hline Chronic lung disease (COPD) & $1453(2.5)$ & $1023(2.3)$ & $430(2.9)$ & $<0.001$ \\
\hline \multicolumn{5}{|l|}{ Door to balloon time } \\
\hline Min, median (IQR: 25th, 75th) & NA & $70(54,90)$ & NA & NA \\
\hline \multicolumn{5}{|c|}{ Antiplatelet prescribed before or at procedure } \\
\hline \multicolumn{5}{|l|}{ Type of antiplatelet agent } \\
\hline Aspirin & $47,403(80.3)$ & $35,165(79.3)$ & $12,238(83.3)$ & $<0.001$ \\
\hline Clopidogrel & $7283(12.3)$ & $4488(10.1)$ & $2795(19.0)$ & $<0.001$ \\
\hline Prasugrel & $36,465(61.8)$ & $27,990(63.1)$ & $8475(57.7)$ & $<0.001$ \\
\hline Ticagrelor & $65(0.1)$ & $34(0.1)$ & $31(0.2)$ & $<0.001$ \\
\hline \multicolumn{5}{|l|}{ Dual antiplatelet therapy } \\
\hline Aspirin + clopidogrel & $6736(11.4)$ & $4145(9.4)$ & $2591(17.6)$ & $<0.001$ \\
\hline Aspirin + ticagrelor & $60(0.1)$ & $30(0.1)$ & $30(0.2)$ & $<0.001$ \\
\hline Aspirin + prasugrel & $35,912(60.8)$ & $27,566(62.2)$ & $8346(56.8)$ & $<0.001$ \\
\hline Single antiplatelet therapy & $5574(9.4)$ & $4039(9.1)$ & $1535(10.4)$ & $<0.001$ \\
\hline \multicolumn{5}{|c|}{ Oral anticoagulant prescribed before or at procedure } \\
\hline Warfarin & $887(1.5)$ & $615(1.4)$ & $272(1.9)$ & $<0.001$ \\
\hline DOAC & $1442(2.4)$ & $924(2.1)$ & $518(3.5)$ & $<0.001$ \\
\hline In-hospital mortality & $3097(5.2)$ & $2526(5.7)$ & $571(3.9)$ & $<0.001$ \\
\hline
\end{tabular}

Data are counts (percentage) unless otherwise specified.

$C A B G$ coronary artery bypass grafting, IQR interquartile range, $M I$ myocardial infarction, NSTEMI non-ST-elevation myocardial infarction, $P C I$ percutaneous coronary intervention, STEMI ST-elevation myocardial infarction

for ischemic heart disease, but similar mortality with either strategy [45].

Although the long-term benefit of an early invasive strategy is unclear, the timing of angiography and revascularization should be based on patient risk profile, considering the significant difference between early and delayed strategies in short-term outcome.

In the VERDICT trial, 2147 patients with NSTE-ACS were randomized to invasive coronary angiography within $12 \mathrm{~h}$ or standard invasive care within 48-72 h [46]. Overall, early invasive coronary angiography did not improve the primary endpoint at 5 years (all-cause death, nonfatal AMI, hospital admission for refractory myocardial ischemia, or hospital admission for heart failure; HR 0.92, 95\% CI 0.78-1.08). However, in patients with a GRACE risk score $>140$, early invasive coronary angiography significantly reduced the primary endpoint (HR $0.81,95 \%$ CI 0.66-0.99). In addition, early invasive coronary angiography had some benefits in patients with troponin elevation (i.e., 
Table 4 Lesion and procedural characteristics in STEMI and NSTEMI from J-PCI registry

\begin{tabular}{|c|c|c|c|c|}
\hline & $\begin{array}{l}\text { Overall MI } \\
(N=59,020)\end{array}$ & $\begin{array}{l}\text { STEMI } \\
(n=44,329)\end{array}$ & $\begin{array}{l}\text { NSTEMI } \\
(n=14,691)\end{array}$ & $p$ value \\
\hline \multicolumn{5}{|l|}{ Lesion characteristics } \\
\hline \multicolumn{5}{|l|}{ Lesion location: } \\
\hline LAD/left main & $31,371(53.2)$ & $23,961(54.1)$ & $7410(50.4)$ & $<0.001$ \\
\hline LCX & $11,704(19.8)$ & $6625(14.9)$ & $5079(34.6)$ & $<0.001$ \\
\hline RCA & $22,586(38.3)$ & $18,194(41.0)$ & $4392(29.9)$ & $<0.001$ \\
\hline Bypass graft & $159(0.3)$ & $74(0.2)$ & $85(0.6)$ & $<0.001$ \\
\hline Restenotic lesion & $2824(4.8)$ & $1830(4.1)$ & $994(6.8)$ & $<0.001$ \\
\hline \multicolumn{5}{|l|}{ Procedure details } \\
\hline Approach & & & & $<0.001$ \\
\hline Transfemoral & $15,425(26.1)$ & $12,305(27.8)$ & $3120(21.2)$ & \\
\hline Transradial & $41,859(70.9)$ & $30,831(69.6)$ & $11,028(75.1)$ & \\
\hline Others (e.g., brachial) & $1736(2.9)$ & $1193(2.7)$ & $543(3.7)$ & \\
\hline Thrombus aspiration & $24,915(42.2)$ & $22,042(49.7)$ & $2873(19.6)$ & $<0.001$ \\
\hline Distal protection & $3114(5.3)$ & $2638(6.0)$ & $476(3.2)$ & $<0.001$ \\
\hline \multicolumn{5}{|l|}{ Stent characteristics } \\
\hline DES & $50,572(85.7)$ & $38,435(86.7)$ & $12,137(82.6)$ & $<0.001$ \\
\hline \multicolumn{5}{|l|}{ Mechanical assist device } \\
\hline IABP & $6367(10.8)$ & $5128(11.6)$ & $1239(8.4)$ & $<0.001$ \\
\hline PCPS & $1589(2.7)$ & $1285(2.9)$ & $304(2.1)$ & $<0.001$ \\
\hline Impella & $263(0.4)$ & $222(0.5)$ & $41(0.3)$ & 0.001 \\
\hline \multicolumn{5}{|l|}{ TIMI flow post-procedure } \\
\hline Flow 3 & $57,964(98.2)$ & $43,596(98.3)$ & $14,368(97.8)$ & $<0.001$ \\
\hline
\end{tabular}

Data are counts (percentage)

$B M S$ bare-metal stent, $D E S$ drug-eluting stent, $L A D$ left anterior descending artery, $L C x$ left circumflex artery, $\mathrm{MI}=$ myocardial infarction, $N S T E M I$ non ST-elevation myocardial infarction, $R C A$ right coronary artery, STEMI ST-elevation myocardial infarction, TIMI thrombolysis in Myocardial Infarction
NSTEMI) and ST-T change (HR 0.85, 95\% CI 0.71-1.01; and HR $0.80,95 \%$ CI $0.63-1.01$, respectively).

GRACE risk score was applied to the patients with acute coronary syndrome (ACS) in the Tokyo CCU (cardiovascular care unit) Network Database. A total of 9,460 patients with ACS hospitalized at 67 Tokyo CCUs were retrospectively reviewed and there was a strong correlation between the GRACE risk score and in-hospital mortality for patients with STEMI or NSTEMI $(r=0.99, p<0.001)$; however, the correlation was not significant for patients with unstable angina $(r=0.35, p=0.126)$. We recommend the use of the GRACE score to identify high-risk patients with AMI [47].

Recently a chronic kidney disease (CKD) study from J-MINUET examining the impact of CKD on long-term outcomes in 3,281 Japanese patients with AMI demonstrated that 3-year mortality and MACE significantly deteriorated from $5.09 \%$ and $15.8 \%$ in no CKD through $16.3 \%$ and $38.2 \%$ in moderate CKD to $36.7 \%$ and $57.9 \%$ in severe CKD, respectively $(p<0.0001)$ [48]. CKD remains a useful predictor of in-hospital and 3-year mortality as well as MACE after AMI in the modern PCI and medical therapy era [48].

In cases of cardiac arrest without STEMI, the COACT (Coronary angiography after cardiac arrest) trial compared immediate angiography with an intent to revascularize with delayed angiography in patients who successfully resuscitated after out-of-hospital cardiac arrest and had no signs of STEMI [49]. Immediate angiography did not reduce death, compared to delayed angiography [50].

\section{Recommendations}

Primary PCI of the infarct-related artery (IRA) is indicated in STEMI.

\section{In case of NSTEMI}

Urgent coronary angiography $(<2 \mathrm{~h})$ is recommended in patients at very high risk (refractory angina, ST changes in 
more than 6 leads, with associated heart failure, mechanical complication, cardiogenic shock, life-threatening arrhythmias, or hemodynamic instability).

An early invasive strategy $(<24 \mathrm{~h})$ is recommended in patients with an established NSTEMI diagnosis.

\section{Practical recommendation for primary $\mathrm{PCl}$}

\section{a. Loading dose DAPT}

Prasugrel and ticagrelor reduce ischemic events and mortality in ACS patients compared to clopidogrel and are recommended by current guidelines [20,21, 51].

In TRITON-TIMI 38, 13,608 patients with ACS with scheduled PCI were randomized to either prasugrel or clopidogrel. Prasugrel therapy was associated with significantly reduced rates of ischemic events, including stent thrombosis, but with an increased risk of major bleeding, including fatal bleeding. Overall mortality did not differ significantly between the treatment groups [51]. In the Japanese population, the PRASFIT-ACS study was conducted to confirm the efficacy and safety of prasugrel at loading/ maintenance doses of 20/3.75 mg [52]. Japanese patients $(n=1363)$ with ACS undergoing PCI were randomized to either prasugrel (20 mg for loading $/ 3.75 \mathrm{mg}$ for maintenance) or clopidogrel (300 mg for loading/75 mg for maintenance). The incidence of MACE at 24 weeks was $9.4 \%$ in the prasugrel group and $11.8 \%$ in the clopidogrel group (risk reduction $23 \%$, hazard ratio $0.77,95 \%$ confidence interval $0.56-1.07$ ). The incidence of non-coronary artery bypass graft-related major bleeding was similar in both groups (1.9\% vs. $2.2 \%)$. The results were similar to TRITON-TIMI 38 with a low risk of clinically serious bleeding in Japanese ACS patients.

Regarding ticagrelor, clinical outcomes in a large realworld post-ACS population were studied in a Swedish prospective cohort study of 45,073 ACS patients who were discharged on ticagrelor $(N=11,954)$ or clopidogrel $(N=33,119)$ [53]. The risk of the primary outcome (composite of all-cause death, readmission with $\mathrm{Ml}$ or stroke) with ticagrelor vs. clopidogrel was $11.7 \%$ vs. $22.3 \%$ [adjusted HR (HR) 0.85 (95\% Cl: 0.78-0.93)], risk of death $5.8 \%$ vs. $12.9 \%$ (adjusted HR 0.83 [0.75-0.921], and risk of MI $6.1 \%$ vs. $10.8 \%$ (adjusted HR 0.89 [0.78-1.011] at 24 months. Re-admission rates for bleeding with ticagrelor versus clopidogrel were similar. Both ticagrelor and clopidogrel post-ACS was associated with a lower risk of death, Ml, or stroke, as well as death alone. Risk of bleeding was higher with ticagrelor [53]. These real-world outcomes are consistent with the results of the landmark
PLATO (Platelet Inhibition and Patient Outcomes) trial [54].

The ISAR-REACT 5 trial compared prasugrel plus aspirin vs. ticagrelor plus aspirin in 4,018 ACS patients [55]. The trial demonstrated that treatment with prasugrel, compared to ticagrelor, significantly reduced the composite rate of death, MI, or stroke (6.9\% vs. $9.3 \%, p=0.006)$ without any increase in bleeding complications ( $4.8 \%$ vs. $5.4 \%, p=0.46$ ).

Both prasugrel and ticagrelor are available for clinical use in Japan. The recommended dose of prasugrel is the same as in Europe and United Sates of America, while the dose of prasugrel was reduced according to the PLASFIT-ACS study in Japan [52] (EU: $60 \mathrm{mg}$ loading dose and $10 \mathrm{mg}$ maintenance dose once daily; Japan: $20 \mathrm{mg}$ loading dose and $3.75 \mathrm{mg}$ maintenance dose once daily) (Table 1).

\section{Recommendations}

A potent $\mathrm{P} 2 \mathrm{Y} 12$ inhibitor (prasugrel or ticagrelor) as well as clopidogrel especially in patients having OAC or DOAC are recommended before or at latest at the time of PCI.

Recommended dose of prasugrel: $20 \mathrm{mg}$ loading dose and $3.75 \mathrm{mg}$ maintenance dose once daily per os (p.o.).

Recommended dose of ticagrelor: $180 \mathrm{mg}$ p.o. loading dose and $90 \mathrm{mg}$ maintenance dose twice daily.

\section{b. Anticoagulation during PCI}

According to the 2017 ESC STEMI and 2020 ESC NSTEACS Guidelines, routine use of unfractionated heparin (UFH) is recommended as a class I recommendation and routine use of enoxaparin or bivalirudin during primary PCI is a class IIa or IIb recommendation [20, 21].

There has been no placebo-controlled trial evaluating UFH in primary PCI, but there is a large body of experience with this agent. Dosage should follow standard recommendations for PCI (i.e., initial bolus $70-100 \mathrm{U} / \mathrm{kg}$ ). There are no robust data recommending the use of activated clotting time to tailor dose or monitor UFH, and if activated clotting time is used, it should not delay recanalization of the artery.

An intravenous bolus of enoxaparin $0.5 \mathrm{mg} / \mathrm{kg}$ was compared with UFH in the ATOLL randomized trial including 910 STEMI patients [56]. The primary composite endpoint of 30-day death, MI, procedural failure, or major bleeding was not significantly reduced by enoxaparin (17\% relative risk reduction, $p=0.063$ ), but there was a reduction in the composite main secondary endpoint of death, recurrent MI or ACS, or urgent revascularization. Importantly, there was no evidence of increased bleeding following the use of enoxaparin over UFH. In a meta-analysis of 23 PCI trials $(30,966$ patients, $33 \%$ primary $\mathrm{PCI})$, enoxaparin was associated with a significant reduction in death compared 
to UFH. This effect was particularly significant in the primary PCI context and was associated with a reduction in major bleeding [57]. In Japan, enoxaparin is approved only for subcutaneous administration and is practically difficult to use during PCI.

A meta-analysis comparing bivalirudin with UFH with or without planned use of GP IIb/IIIa inhibitors in patients with STEMI trials showed no mortality advantage with bivalirudin and a reduction in the risk of major bleeding, but at the cost of an increased risk of acute stent thrombosis [58]. In the recent MATRIX trial including 7213 ACS patients (56\% with STEMI), bivalirudin did not reduce the incidence of the primary endpoint (composite of death, MI, or stroke) compared to UFH. Bivalirudin was associated with lower total and cardiovascular mortality, lower bleeding, and more definite stent thrombosis [59]. A post hoc analysis suggested that prolonging bivalirudin with a full-PCI dose after PCI was associated with the lowest risk of ischemic and bleeding events, which is in accordance with the current labeling of the drug [59]. Bivalirudin could be considered in STEMI, especially in patients at high bleeding risk [60-62]. Bivalirudin is recommended for patients with heparin-induced thrombocytopenia.

After the publication of the 2017 ESC guidelines, the VALIDATE-SWEDEHEART (Bivalirudin versus Heparin in ST-Segment and Non-ST-Segment Elevation Myocardial Infarction in Patients on Modern Antiplatelet Therapy in the Swedish Web System for Enhancement and Development of Evidence-based Care in Heart Disease Evaluated according to Recommended Therapies Registry Trial) multicenter, randomized, registry-based trial was published [63]. Patients with either ST-segment elevation MI $(N=3005)$ or non-ST-segment elevation MI $(N=3001)$ undergoing $\mathrm{PCI}$ and receiving a potent $\mathrm{P} 2 \mathrm{Y} 12$ inhibitor (ticagrelor, prasugrel, or cangrelor) without the planned use of glycoprotein IIb/IIIa inhibitors were randomly assigned to receive bivalirudin or heparin during PCI, performed predominantly with the use of radial artery access. The primary composite endpoint (death from any cause, MI, or major bleeding during 180 days of followup) occurred in $12.3 \%$ of the patients in the bivalirudin group and in $12.8 \%$ in the heparin group (HR 0.96, 95\% CI 0.83 to $1.10 ; p=0.54)$. The results were consistent between patients with ST-segment elevation MI and those with non-ST-segment elevation MI and across other major subgroups. There was no difference between groups in MI, major bleeding, definite stent thrombosis or mortality. This study shows overall clinical non-inferiority for use of bivalirudin or heparin during PCI for ACS, along with increased cost with use of bivalirudin. Thus, the use of bivalirudin during PCI was downgraded to a class IIb recommendation. Consistent with these findings, the current uptake of bivalirudin in Europe is very low. Bivalirudin remains unavailable in Japan with no evaluation by clinical trials.

Glycoprotein (GP) IIb/IIIa inhibitors are the strongest antiplatelet agents currently available in Europe and in the US, but remain unavailable in Japan. There are three different compounds, namely abciximab, tirofiban, and eptifibatide. However, procedural use of abciximab plus unfractionated heparin (UFH) showed no benefit compared to bivalirudin [60]. In Japan, JEPPORT a randomized placebocontrolled trial $(n=973)$, abciximab did not show efficacy in reducing the primary endpoint (30-day post-PCI coronary events: death, MI or urgent revascularization) [64]. However, using GP IIb/IIIa inhibitors as bail-out therapy in the event of angiographic evidence of a large thrombus, slow or no reflow, and other thrombotic complications is reasonable, as recommended in 2017 ESC guidelines [20], although this strategy has not been tested in a randomized trial. Overall, there is no evidence to recommend the routine use of GP IIb/ IIIa inhibitors for primary PCI.

\section{Recommendations}

Anticoagulation is recommended for all the patients in addition to antiplatelet therapy during primary PCI.

Routine use of UFH is recommended.

\section{c. Approach (femoral vs. radial)}

Over recent years, several studies have provided robust evidence in favor of the radial approach as the default access site in ACS patients undergoing primary PCI by experienced radial operators $[65,66]$. In the Minimizing Adverse Hemorrhagic Events by TRansradial Access Site and Systemic Implementation of angioX (MATRIX) program, patients were randomized to radial or femoral access, stratified by STEMI (2,001 radial, 2,009 femoral) and NSTE-ACS (2,196 radial, 2,198 femoral). MACE occurred in 121 (6.1\%) STEMI patients with radial access vs. 126 $(6.3 \%)$ patients with femoral access [rate ratio $(\mathrm{RR})=0.96$, 95\% CI $=0.75-1.24 ; p=0.76]$ and in $248(11.3 \%)$ NSTEACS patients with radial access vs. $303(13.9 \%)$ with femoral access $(\mathrm{RR}=0.80,95 \% \mathrm{CI}=0.67-0.96 ; p=0.016)$ (Pint $=0.25)$. MACE occurred in $142(7.2 \%)$ STEMI patients with radial access and in $165(8.3 \%)$ patients with femoral access $(\mathrm{RR}=0.86,95 \% \mathrm{CI}=0.68-1.08 ; p=0.18)$ and in $268(12.2 \%)$ NSTE-ACS patients with radial access compared with $321(14.7 \%)$ with femoral access $(\mathrm{RR}=0.82$, 95\% CI $=0.69-0.97 ; p=0.023)\left(\mathrm{P}_{\text {int }}=0.76\right)$. All-cause mortality and access site-actionable bleeding favored radial access irrespective of ACS type $\left(P_{\text {interaction }}=0.11\right.$ and $P_{\text {interaction }}=0.36$, respectively) [67]. Radial as compared with femoral access was shown to have consistent benefit across the whole spectrum of patients with ACS, resulting 
in upgrading of the recommendation to a class I indication in the 2017 and 2020 ESC guidelines.

In Japan, the TEMPURA trial randomized patients with AMI undergoing primary PCI to transradial coronary intervention (TRI) group $(n=77)$ and transfemoral coronary intervention (TFI) group $(n=72)$ [68]. The success rate of reperfusion and the incidence of in-hospital MACE were similar in both groups $(96.1 \%$ and $5.2 \%$ vs. $97.1 \%$ and $8.3 \%$ in TRI and TFI groups, respectively). In a substudy of PRASFIT-ACS including ACS patients with prasugrel, rates of periprocedural bleeding, bleeding not related to CABG, and puncture site bleeding were consistently lower in the TRI group than in the TFI group [69]. More recently, in a report from the CREDO-Kyoto AMI registry was published [70]. 3662 STEMI patients who had primary PCI by TRI $(\mathrm{N}=471)$ or TFI $(N=3191)$ were analyzed. The prevalence of hemodynamically compromised patients (Killip II-IV) was significantly less in TRI group than in TFI group (19 vs. $25 \%, p=0.002$ ). Cumulative 5 -year incidences of death/ $\mathrm{MI} /$ stroke and major bleeding were not significantly different between the TRI and TFI groups ( 26.7 vs. $25.9 \%$, $\log$-rank $p=0.91$, and 11.3 vs. $11.5 \%, \log$-rank $p=0.71$, respectively). After adjustment for confounders, the risks of the TRI or TFI group were not significant for both death/ $\mathrm{MI} /$ stroke [Hazard ratio (HR) 1.15, 95\% confidence interval (CI) $0.83-1.59, p=0.41]$ and major bleeding (HR 1.29, 95\% CI $0.77-2.15, p=0.34$ ), leading to the conclusion that clinical outcomes of transradial approach were not different from those of transfemoral approach in primary PCI for STEMI in the real-world practice.

\section{Recommendations}

Radial access is recommended over femoral access if performed by an experienced radial operator.

\section{d. Thrombus aspiration}

While it has been well recognized that thrombus formation caused by plaque rupture, plaque erosion and calcified nodule play a crucial role in the mechanism of ACS, the reduction of thrombus burden can theoretically be effective therapy for AMI [71-75]. However, in the guidelines released by the European Society of Cardiology in 2017 on the management of patients with STEMI, routine thrombus aspiration was downgraded from IIa to III (not recommended).

A pooled analysis of individual patient data from three large randomized trials (TAPAS [Thrombus Aspiration During Percutaneous Coronary Intervention in Acute Myocardial Infarction], TASTE [Thrombus Aspiration in ST-Elevation Myocardial Infarction in Scandinavia], and TOTAL [Trial of Routine Aspiration Thrombectomy With
PCI Versus PCI Alone in Patients With STEMI]) provided novel insights about thrombus aspiration for ST-elevation MI [76]. By including 18,306 patients, the study did not show a significant reduction in cardiovascular death when thrombus aspiration was compared with standard therapy. There were also no differences between thrombus aspiration and no thrombus aspiration with respect to stroke or transient ischemic attack, recurrent MI, stent thrombosis, heart failure or target vessel revascularization [77]. Although routine use of mechanical thrombus aspiration is no longer recommended, prior safety concerns regarding the risk of stroke could not be confirmed. However, because a trend toward reduced cardiovascular death and increased stroke or transient ischemic attack was found in the subgroup of patients with high thrombus burden, future studies may want to investigate improved thrombus aspiration technologies in this high-risk subgroup.

In contrast to the studies mentioned above, earlier studies had shown a potential benefit for thrombus aspiration in primary PCI $[78,79]$.

\section{Evidence from Japan}

There are several studies in Japan showing the benefit of thrombus aspiration in primary PCI.

In the VAMPIRE study, patients with STEMI were randomized to primary PCI with $(n=180)$ or without $(n=175)$ upfront thrombus aspiration [80]. There was a trend towards a lower incidence of slow or no reflow (primary endpoint defined as a Thrombolysis In Myocardial Infarction flow grade $<3$ ) in patients treated with aspiration versus conventional primary PCI (12.4\% vs. $19.4 \%$, $p=0.07)$. The rate of myocardial blush grade 3 was higher in the aspiration group ( $46.0 \%$ vs. $20.5 \%, p<0.001)$. Aspiration was most effective in patients presenting after $6 \mathrm{~h}$ of symptoms onset (slow flow rate: $8.1 \%$ vs. $37.6 \%, p=0.01$ ). Patients presenting late after STEMI appear to benefit the most from thrombectomy.

In an observational study $(n=3913)$ by Nakatani et al. [81], thrombus aspiration was associated with a lower 30-day mortality rate in selected patients with high TIMI risk scores, an age $>$ or $=70$ years, diabetes mellitus, or stenting adjusted for baseline characteristics.

In the latest guidelines of Japanese Circulation Society, thrombus aspiration in primary PCI was recommended as a class IIa indication with level of evidence B. Accordingly, thrombus aspiration is performed frequently in primary PCI in Japan. A comparison of specifications of aspiration device is tabulated in Table 5. From a practical view point, aspiration performance, trackability, and pushability are of importance when choosing an aspiration catheter [82]. 


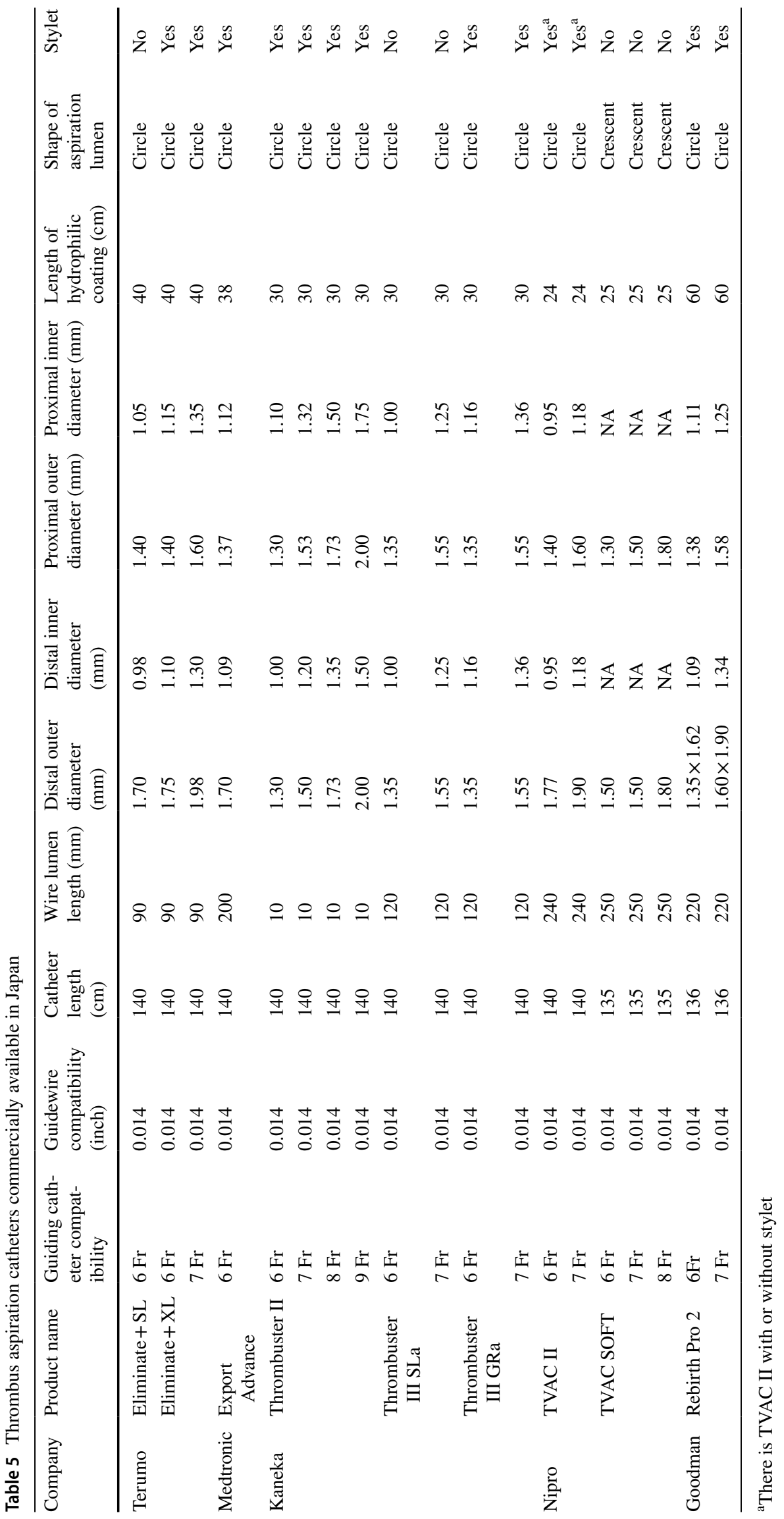


Anzai et al. reported that thrombus aspiration facilitates direct stenting without increasing the cost of treatment [83]. Thrombus aspiration can be considered followed by direct stenting, which will be discussed later.

\section{Recommendations}

Thrombus aspiration can be considered in primary PCI in the absence of GP IIb/IIIa inhibitors.

\section{e. Distal protection}

The benefit of distal protection using filter device or occlusion balloon has not been confirmed [84, 85]. However, the use of distal protection devices can be considered when plaque burden is large and there is a high possibility of distal embolism or no reflow.

\section{Evidences from Japan}

Isshiki et al. reported initial clinical experience with Filtrap $^{\mathrm{TM}}$ distal protection filter [86]. Filtrap ${ }^{\mathrm{TM}}$ was successfully delivered and deployed distal to the lesion in 13 of 14 patients (93\%). Embolic debris was entrapped in $8(62 \%)$ of these cases. All the patients were free from in-hospital events except for one patient with a large anterior AMI who received emergency surgery due to a free wall cardiac rupture. In the ASPARAGUS trial $(n=341)$, patients with AMI were randomized to either stenting with or without GuardWire Plus ${ }^{\mathrm{TM}}$ [87]. The rates of slow flow and no reflow immediately after PCI were 5.3 and $11.4 \%$ in the GuardWire Plus and control groups, respectively $(p=0.05)$. Blush score 3 acquisition rates immediately after PCI were 25.2 and $20.3 \%$ in the GuardWire Plus and control groups, respectively $(p=0.26)$, and the rates at 30 days after PCI were 42.9 and $30.4 \%$, respectively $(p=0.035)$. In the CANARY pilot trial, near-infrared spectroscopy and intravascular ultrasound were performed at baseline, and lesions with a maximal lipid core burden index over any 4-mm length $\left(\operatorname{maxLCBI}_{4 \mathrm{~mm}}\right) \geq 600$ were randomized to PCI with versus without a distal protection filter [88]. Among 31 randomized lesions with maxLCBI $\mathrm{Imm}_{4 \mathrm{~mm}} \geq 600$, there was no difference in the rates of periprocedural MI with versus without the use of a distal protection filter (35.7\% vs. $23.5 \%, p=0.69)$. More recently, the VAMPIRE 3 trial randomized 200 ACS patients who had attenuated plaque with a longitudinal length of $\geq 5 \mathrm{~mm}$ by pre-PCI intravascular ultrasound to either distal protection (DP) by filter or conventional treatment (CT) [89]. The primary endpoint of no-reflow phenomenon occurred in $26.5 \%$ of the DP group $(n=98)$ and $41.7 \%$ of the CT group $(n=96 ; p=0.0261)$ and the corrected TIMI frame count after revascularization was significantly
Table 6 Filter devices for distal protection commercially available in Japan

\begin{tabular}{lllll}
\hline Company & $\begin{array}{l}\text { Product } \\
\text { name }\end{array}$ & $\begin{array}{l}\text { Filter diam- } \\
\text { eter at expan- } \\
\text { sion }(\mathrm{mm})\end{array}$ & $\begin{array}{l}\text { Guidewire } \\
\text { compatibility } \\
\text { (inch) }\end{array}$ & Length $(\mathrm{cm})$ \\
\hline Nipro & Filtrap & 3.5 & 0.014 & 180 \\
& & 5 & 0.014 & 180 \\
& & 6.5 & 0.014 & 180 \\
& & 6.5 & 0.014 & 300 \\
Tri-Med & Parachute & 5 & 0.014 & 180 \\
& & 5 & 0.014 & 300 \\
& & 6.5 & 0.014 & 190 \\
& & 6.5 & 0.014 & 270 \\
& & 8 & 0.014 & 190 \\
& & 8 & 0.014 & 270 \\
& & 8 & 0.014 & 270 \\
& & 6 & 0.014 & 50 \\
\hline
\end{tabular}

lower in the DP group (23 vs 30.5; $p=0.0003$ ). In addition, the incidence of in-hospital adverse cardiac events was significantly lower in the DP group than in the CT group $(0 \%$ vs $5.2 \% ; p=0.028)$. Future studies may further elucidate whether distal protection is beneficial in selected patient.

In contrast, distal embolic protection during PCI of saphenous vein grafts was confirmed in a multicenter randomized controlled trial. In the SAFER randomized trial, a composite of death, myocardial infarction, emergency bypass, or target lesion revascularization by 30 days was observed in $16.5 \%$ in the control group and $9.6 \%$ in the embolic protection device $(p=0.004)$ [90]. This $42 \%$ relative reduction in major adverse cardiac events was driven by myocardial infarction $(8.6 \%$ versus $14.7 \%, p=0.008)$ and "no-reflow" phenomenon (3\% versus $9 \%, p=0.02)$. Clinical benefit was seen even when platelet glycoprotein IIb/IIIa receptor blockers were administered (61\% of patients), with composite end points occurring in $10.7 \%$ of protection device patients versus $19.4 \%$ of control patients $(p=0.008)$. This study demonstrated the importance of prevention of distal embolization in saphenous vein graft.

Currently available filter devices in Japan are tabulated in Table 6.

\section{Recommendations}

Distal protection can be considered in selective cases when plaque burden is large and there is a high possibility of distal embolism or no reflow or cases with myocardial infarction in saphenous vein grafts.

f. Pharmacological intervention for no reflow 
In 2017 ESC guidelines [20], using GP IIb/IIIa inhibitors as bail-out therapy is considered as class IIa indication in the event of angiographic evidence of a large thrombus, slow or no reflow, although this strategy has not been tested in a randomized trial.

\section{Evidence from Japan}

Ishii et al. performed a randomized trial among 368 STEMI patients undergoing primary PCI [the nicorandil group $(n=185)$ or control group $(n=183)$ ] [91]. They reported that intravenous $12 \mathrm{mg}$ of nicorandil before primary PCI significantly improved ST-segment resolution and epicardial coronary flow, resulting in preventing cardiovascular events of long duration and deaths, compared to placebo group.

Miyazawa et al. studied the effect of nicorandil in STEMI, randomizing patients with STEMI to the nicorandil group $(n=35)$ or control group $(n=35)$ [92]. In the nicorandil group, $2 \mathrm{mg}$ of nicorandil was injected directly into the infarct area prior to reperfusion by PCI. With nicorandil infusion, additional ST elevations without chest pain were observed for a few minutes in $94 \%$ of cases. However, no ventricular fibrillation or ventricular tachycardia occurred. TIMI grade 3 rates were significantly higher in the nicorandil group ( $40 \%$ vs. $17 \%, p<0.01)$. Rates of adverse events were similar, however, left ventricular regional wall motion score significantly improved in the nicorandil group $(p<0.05)$. The effect of nicorandil was pronounced in patients without ischemic preconditioning.

Kobatake et al. compared the effects of nitroprusside $(n=25)$ with nicorandil $(n=24)$ on the slow/no-reflow phenomenon during primary PCI [93]. The degree of improvement in TIMI flow grade (post-pre/pre) and TIMI frame count (pre-post/pre) showed that nitroprusside was more effective than nicorandil (nitroprusside vs. nicorandil: $0.88 \pm 0.79,0.37 \pm 0.37, p=0.008 ; 0.59 \pm 0.23,0.36 \pm 0.27$, $p=0.003$, respectively). At 1 year, rate of MACE was not significantly different $(5 / 25$ vs. $9 / 24, p=0.175)$.

Further studies are needed to determine optimal methods of administration and doses of nicorandil because nicorandil has dose-dependent effects on coronary artery diameters and coronary blood flow.

More recently, a network meta-analysis was published comparing the effect of 7 intracoronary agents (adenosine, anisodamine, diltiazem, nicorandil, nitroprusside, urapidil, and verapamil) on the no-reflow phenomenon in patients with STEMI undergoing primary PCI, including 41 randomized control trials with 4,069 patients [94]. Anisodamine ( $\alpha 1$ adrenergic receptor antagonist used in the treatment of acute circulatory shock in China) was associated with improved post-procedural TIMI flow grade, more occurrences of ST-segment resolution, and improvement of LVEF. The cardioprotective effect of anisodamine conferred a MACE-free survival benefit. Additionally, nitroprusside was regarded as efficient in improving coronary flow and clinical outcomes. Compared with standard care, adenosine, nicorandil, and verapamil improved coronary flow but had no corresponding benefits on cardiac function and clinical outcomes.

Considering GP IIb/IIIa inhibitors and anisodamine are not available in Japan, use of nicorandil or nitroprusside prior to reperfusion by primary PCI may be considered reasonable.

\section{Recommendations}

Intravenous nicorandil may be considered for STEMI patients before primary PCI within $12 \mathrm{~h}$ after symptom onset to prevent coronary microvascular impairment.

Intracoronary injection of nicorandil can be considered to bail out in case of slow flow or no reflow.

\section{g. Direct stenting}

Evidence in favor of direct stenting (stenting without predilation) in patients with STEMI comes from several studies [95]. Loubeyre et al. [96] randomized 206 patients with STEMI to direct stenting or stent implantation after balloon predilation. The composite angiographic (corrected TIMI frame count, slow flow/no reflow or distal embolization) endpoint ( $11.7 \%$ vs. $26.9 \% ; p=0.01)$ and ST-segment resolution $(79.8 \%$ vs. $61.9 \% ; p=0.01)$ were better among patients randomized to direct stenting than among those randomized to stent implantation after predilation [96]. In the Harmonizing Outcomes with Revascularization and Stents in Acute Myocardial Infarction (HORIZONS-AMI), direct stenting $(n=698)$ compared with conventional stenting after predilation $(n=1830)$ was associated with better STsegment resolution at $60 \mathrm{~min}$ after the procedure (median: $74.8 \%$ vs. $68.9 \% ; p=0.01)$ and lower 1 -year rates of allcause mortality $(1.6 \%$ vs. $3.8 \% ; p=0.01)$ and stroke $(0.3 \%$ vs. $1.1 \% ; p=0.049)$ [97]. The EUROTRANSFER Registry that included 1,419 patients showed that direct stenting $(n=276)$ was superior to stenting after predilation in terms of post-procedural TIMI flow grade of 3 (94.9\% vs. $91.5 \%$; $p=0.02)$, no reflow ( $1.4 \%$ vs. $3.4 \% ; p=0.035)$, ST-segment resolution of $>50 \%(86.2 \%$ vs. $76.3 \% ; p=0.016)$ and 1 -year mortality ( $2.9 \%$ vs. $6.5 \% ; p=0.047$ after adjustment for propensity score) [98]. Direct stenting may be advantageous over stenting after predilation in several aspects including the use of fewer and shorter stents, shorter fluoroscopy time and less use of contrast media and reduced microvascular dysfunction/obstruction and no reflow by reduced distal embolization. Potential disadvantages of direct stenting may include: failure to reach and/or to cross the lesion, stent loss, 
erroneous estimation of stent length, difficulty with stent positioning (especially in cases of persistent TIMI flow 0-1), underexpansion of the stent in an undilatable (i.e., calcified) lesion and stent undersizing due to underestimation of vessel diameter because of reduced flow [99]. Notwithstanding these disadvantages, direct stenting is now considered as acceptable alternative strategy as compared to conventional stenting during primary PCI.

\section{Recommendations}

Direct stenting is recommended in primary PCI if possible.

\section{h. Balloon angioplasty}

The clinical efficacy of balloon angioplasty for STEMI is limited due to the relatively high percentage of restenosis caused by elastic recoil and late negative remodeling [100]. Several studies showed the need for repeat revascularization was significantly reduced by the use of coronary stents [101-103]. There is also Japanese evidence supporting this fact in patients with AMI [104, 105]. Nonetheless, stent implantation did not result in lower rates of recurrent MI or death, when compared with balloon angioplasty alone. Subsequently, numerous randomized trials demonstrated a further reduction in target lesion revascularization (TLR) could be achieved when using drug-eluting stents (DES) as opposed to bare-metal stents (BMS). Equivalent to studies comparing balloon angioplasty with stenting, though, none of these studies demonstrated a reduction in recurrent MI or death [106-108]. An important limitation of stent usage is a persistent risk of stent thrombosis (ST) and/or in-stent restenosis even years after implantation, particularly in patient subsets as STEMI [109-114].

Considering stent implantation may even induce no reflow and thereby expand infarct size [115-117], it may be reasonable to refrain from stenting if coronary flow is restored and no significant stenosis persists after thrombus aspiration and balloon dilatation. Indeed, recent studies have demonstrated it is safe to defer stent implantation in the acute phase of STEMI $[118,119]$. Considering the absence of superiority with regard to hard clinical end points and the potential shortand long-term disadvantages of stent implantation, angioplasty with a drug-coated balloon (DCB) without stenting may well serve as a therapeutic strategy of choice in STEMI.

The PAPPA pilot study was the first prospective clinical trial studying the efficacy and safety of a DCB only strategy in PPCI for STEMI [120]. Additional stenting was allowed only in case of type $\mathrm{C}$ to $\mathrm{F}$ coronary dissection or residual stenosis $>50 \%$. All patients were treated with intravenous bivalirudin. Of 100 consecutive STEMI patients, 59 patients were treated with a DCB only strategy, whereas bail-out stenting was required in 41 patients. At 1-year, five major adverse cardiac events were reported (5\%). Cardiac death was seen in two patients, while three patients underwent TLR. Although in this pilot study the rate of bail-out stenting was relatively high, the use of a DCB angioplasty-only strategy in the setting of primary PCI seems to be a safe and feasible treatment modality.

The REVELATION trial randomized 120 patients presenting with STEMI either to treatment with a DCB $(N=60)$ or DES $(N=60)$ [121]. No death or recurrent MI was reported, and TLRs were performed in 2 patients of the DCB group and 1 patient in the DES group. The functional assessment of the infarct-related lesion by FFR at 9 months after initial treatment was performed in 34 and 39 patients in the DCB and DES groups, respectively, and their FFR values were similar $(0.92 \pm 0.05$ versus $0.91 \pm 0.06 ; p=0.27)$. These results might suggest that angioplasty with a DCB without stenting could be a therapeutic strategy of choice in STEMI, although larger randomized trial is necessary to confirm the safety and efficacy of a DCB without stenting.

In the INNOVATION study, 114 patients receiving primary PCI for STEMI were randomized into deferred stenting (DS) or immediate stenting (IS) [122]. In the DS group, the primary procedures included thrombus aspiration and balloon angioplasty and the second-stage stenting procedure was scheduled to be performed at 3 to 7 days after primary reperfusion procedure. DS did not significantly reduce infarct size $(15.0 \%$ versus $19.4 \% ; p=0.112)$ and the incidence of microvascular obstruction (MVO; $42.6 \%$ versus $57.4 \% ; p=0.196)$, compared with IS. However, in anterior wall myocardial infarction, infarct size ( $16.1 \%$ versus $22.7 \%$; $p=0.017)$ and the incidence of MVO (43.8\% versus 70.3\%; $p=0.047$ ) were significantly reduced in the DS group.

\section{Recommendations}

Currently, primary PCI using a balloon-only strategy is not recommended over direct stenting.

\section{i. IVUS/ OCT/ OFDI}

\section{Pre-procedural IVUS/ OCT/ OFDI}

In ESC guidelines for myocardial revascularization [123], intravascular imaging is recommended only in cases of restenosis and stent thrombosis to detect stent-related mechanical problems and to assess and guide PCI in the left main stem (IIa). According to the expert consensus document of the European Association of Percutaneous Cardiovascular Interventions (EAPCI) [124], when a culprit lesion attributable to a NSTE-ACS presentation is not evident angiographically, an intravascular imaging-based assessment to guide appropriate management should be considered. Thrombus 
detection, for which OCT/ OFDI is the current gold standard, facilitates identification of an ACS culprit lesion.

\section{Identification of culprit lesion}

Optical coherence tomography (OCT), optical frequency domain imaging (OFDI) and intravascular ultrasound (IVUS) detect plaque ruptures in about half of ST-elevation myocardial infarction. However, the superior resolution and obligatory flushing with OCT sharply outlines the rupture cavity and residual fibrous cap fragment to optimize ruptured plaque identification. de Feyter and Ozaki previously demonstrated plaque rupture and thrombus were more frequently found in ACS than those with stable angina by angioscopy, while IVUS failed to discriminate unstable from stable plaque [125]. More recently, Kubo et al. reported, when compared with the gold standard of angioscopy, OCT can identify thrombus better than IVUS and differentiate between red and white thrombus although red thrombus can shadow and obscure underlying plaque morphology [75].

While pathological studies reported that plaque erosion plays a role in ACS, there was no clear OCT definition of plaque erosion previously. While Ozaki and his colleagues proposed that OCT-derived intact fibrous cap (IFC-ACS) can be plaque erosion for the first time, contrary to ruptured fibrous cap (RFC-ACS), distinct culprit lesion characteristics associated with IFC-ACS mechanisms are not identified by CT angiography or IVUS [74]. OCT has been used to monitor changes in thrombus burden when lesions are treated with thrombus aspiration or with pharmacotherapy [126, 127]. Prati et al. demonstrated in the CLIMA study that the simultaneous presence of four high-risk OCT plaque features [MLA $<3.5 \mathrm{~mm}^{2}$, FCT $<75 \mu \mathrm{m}$, lipid arc circumferential extension $>180^{\circ}$, OCT-defined macrophages] was found to be associated with a higher risk of major coronary events in 1,003 patients undergoing OCT evaluation of the untreated proximal LAD [128].

In addition, combined IVUS and Near-Infrared Spectroscopy (NIRS) imaging, in particular where an increased plaque burden and lipid component present, is able to differentiate culprit lesions from non-culprit lesions with a high accuracy in STEMI $[129,130]$ and NSTEMI [131].

\section{Distal embolization or periprocedural myocardial infarction during stent implantation}

TCFA not only cause plaque rupture and thrombosis but also contribute to myonecrosis during stenting. Findings associated with peri-myocardial infarction are greyscale IVUSattenuated plaques, especially when the amount of attenuated plaque is large and begins closer to the lumen than to the adventitia; when large virtual histology-IVUS necrotic core or a virtual histology-thin-cap fibroatheroma or similar findings with integrated backscatter-IVUS (lipid) or iMap (necrotic core) are present; when an OCT-thin-cap fibroatheroma is present; when large lipid-rich plaques are detected by OCT or NIRS; or when plaque rupture is detected by IVUS or OCT [132, 133]. Furthermore, Ozaki and his colleagues reported that IB-IVUS-identified TCFA as well as OCT-verified TCFA were significant independent predictors of periprocedural myocardial infarction (PMI) after PCI [133]. However, the positive predictive value is poor and one trial [88] did not show superiority of distal protection when treating lipid-rich plaques. Conversely, the absence of these findings indicates a low probability of a peri-myocardial infarction with a high negative predictive value.

\section{Post-procedural lesion assessment, especially OCT/ OFDI}

Prati and his colleagues reported that a total of 1002 lesions (832 patients) were assessed. Appropriate OCT assessment was obtained in $98.2 \%$ of cases and revealed suboptimal stent implantation in $31.0 \%$ of lesions, with increased incidence in patients experiencing major adverse cardiac events (MACE) during follow-up (59.2\% vs. $26.9 \%$; $p<0.001)$. They concluded that suboptimal stent deployment defined according to specific quantitative OCT criteria was associated with an increased risk of MACE during follow-up in CLI-OPCI II study [134]. Prati and his coworkers also indicated that in ACS patients undergoing PCI, a composite of OCT-defined suboptimal stent implantation characteristics at the culprit lesion and residual intrastent plaque/ thrombus protrusion was associated with adverse outcome in CLI-OPCI ACS substudy [135]. Post-procedural assessment especially OCT appears to confer a favorable long-term clinical outcome in patients with ACS.

\section{Recommendations}

IVUS/ OCT/ OFDI should be considered to detect stentrelated mechanical problems.

IVUS can be used to assess severity and optimize treatment of unprotected left main lesions.

Post-procedural OCT/ OFDI assessment including presence of dissection, degree of incomplete stent apposition, and presence of thrombus protrusion and may contribute to reducing MACE in long-term follow-up.

\section{j. Stent}

\section{Drug-eluting stents}

Some meta-analyses suggested the safety and efficacy of second-generation DES in STEMI patients. In a network 
meta-analysis of patients with STEMI undergoing primary PCI (12,453 patients from 22 trials) [136], CoCr-EES were associated with significantly lower rates of cardiac death or MI and ST than BMS. CoCr-EES was also associated with significantly lower rates of 1-year stent thrombosis (ST) than paclitaxel-eluting stents (PES). Sirolimus-eluting stents (SES) were also associated with significantly lower rates of 1 -year cardiac death/myocardial infarction than BMS. CoCrEES, PES, and SES, but not zotarolimus-eluting stents, had significantly lower rates of 1-year target vessel revascularization (TVR) than BMS, with SES also showing lower rates of TVR than PES. Another network meta-analysis with longer follow-up data analyzed twelve trials with 9,673 patients [137]. Second-generation DES were associated with significantly lower incidence of definite or probable ST (OR $0.59,95 \%$ CI $0.39-0.89$ ), MI (OR 0.59, 95\% CI 0.39-0.89), and TVR at 3 years (OR 0.50: 95\% CI 0.31-0.81) compared with BMS. In addition, there was a significantly lower incidence of MACE with second-generation DES versus BMS (OR $0.54,95 \%$ CI $0.34-0.74$ ) at 3 years. In a patient-level network meta-analysis in patients with STEMI undergoing primary PCI with a median follow-up of 3 years $(10,979$ patients from 15 trials) [138], DES were superior to BMS with respect to cardiac death, reinfarction, or target lesion revascularization (TLR), and definite or probable stent thrombosis. Although second-generation DES did not significantly reduce cardiac death, reinfarction, or TLR, compared to first-generation DES (HR 0.98, 95\% CI 0.79-1.21), second-generation DES were better than first-generation DES in the reduction of definite or probable stent thrombosis (HR 0.56, 95\% CI 0.36-0.88).

In terms of long follow-up, recently, the EXAMINATION-EXTEND (10-Years Follow-Up of the EXAMINATION Trial) study demonstrated the superiority of CoCrEES $(N=751)$ in combined patient- and device-oriented composite endpoints, compared with BMS $(N=747)$, in patients with STEMI (patient-oriented composite endpoint: $32.4 \%$ vs. $38.0 \%$, HR $0.81,95 \%$ CI $0.68-0.96, p=0.013$; device-oriented composite endpoint: $13.6 \%$ vs. $18.4 \%$, HR $0.72,95 \%$ CI $0.55-0.93, p=0.012$, respectively) [139]. These results were driven mainly by TLR $(5.7 \%$ vs. $8.8 \%$; $p=0.018)$. The rate of definite stent thrombosis was similar in both the groups $(2.2 \%$ vs. $2.5 \% ; p=0.590)$. No differences were found between the groups in terms of target lesion revascularization $(1.4 \%$ vs. $1.3 \% ; p=0.963)$ and definite or probable stent thrombosis $(0.6 \%$ vs. $0.4 \% ; p=0.703)$ between 5 and 10 years.

The efficacy of a new-generation ultrathin strut DES, Orsiro, was demonstrated in the BIOSTEMI trial [140]. In this trial, 1,300 STEMI patients were enrolled, and the primary endpoint of target lesion failure (TLF: cardiac death, target vessel MI, and clinically indicated TLR) at 1 year was $4 \%$ with Orsiro and 6\% with Xience (RR 0.59, 95\% CI 0.37-0.94).

Overall, use of new-generation DES is encouraged, although the clinical benefit of ultrathin strut DES should be further investigated.

\section{Drug-coated stents}

The LEADERS-FREE (Prospective Randomized Comparison of the BioFreedom Biolimus A9 Drug-Coated Stent versus the Gazelle Bare-Metal Stent in Patients at High Bleeding Risk) study compared the polymer-free biolimuseluting Biofreedom stent with a bare-metal stent (BMS) in a cohort $(N=2466)$ at high risk of bleeding. In a subgroup analysis of 659 ACS patients, treatment with the BioFreedom stent remained more effective (clinically driven target lesion revascularization $3.9 \%$ vs. $9.0 \%, p=0.009$ ) and safer (cumulative incidence of cardiac death, MI, or definite or probable stent thrombosis $9.3 \%$ vs. $18.5 \%, \mathrm{P}=0.001$ ), driven by significantly lower rates of cardiac mortality $(3.4 \%$ vs. $6.9 \%, p=0.049)$ and MI (6.9\% VS $13.8 \%, p=0.005)$ [141].

These results confirm the clinical utility of the drugcoated stents for patients at high bleeding risk and a direct comparison with current generation DES would be of great interest.

\section{Evidence from Japan}

There are scarce randomized studies comparing between stents in Japan. Sawada et al. randomized patients with STEMI to receive EES $(n=23)$ or SES $(n=12)$ and compared arterial healing by OCT [142]. Both the EES and SES showed an excellent suppression of neointimal proliferation in the culprit lesion. The frequency of uncovered and malapposed struts of EES was significantly lower than that of SES $(2.7 \%$ vs. $15.7 \%, p<0.0001,0.7 \%$ vs. $2.3 \%$, $p<0.0001$, respectively). EES may promote better arterial healing response than SES in patients with STEMI. The NAUSICA trial randomized patients with STEMI to Nobori biolimus A9 eluting stent (BES) or BMS and aimed to compare MACE at 1 year. However, the main results have not yet been published.

\section{Recommendations}

- Stenting with recent generation DES is recommended over BMS for primary PCI.

\section{k. Post-procedural IVUS/ OCT/ OFDI}

Post-procedural IVUS/ OCT/ OFDI is used to evaluate stent underexpansion, malapposition, tissue protrusion, 
dissection, geographic miss, and thrombus. In the expert consensus document of the EAPCI [143], a relative stent expansion of $>80 \%$ (minimal stent area [MSA] divided by average reference lumen area), and an MSA of $>5.5 \mathrm{~mm}^{2}$ by IVUS and $>4.5 \mathrm{~mm}^{2}$ by OCT in non-left main lesions are recommended.

In the ULTIMATE trial [144], 1,448 patients were randomized to IVUS versus angiographic guidance. IVUS guidance was associated with a lower target vessel failure rate of $2.9 \%$ versus $5.4 \%(p=0.019)$ at 1 year. In the IVUSXPL trial $[145,146], 1,400$ patients with long lesions were randomized to IVUS versus angiographic guidance. IVUS guidance was associated with a lower MACE rate of 5.6\% versus $10.7 \%(p=0.001)$ at 5 years. In CLI-OPCI observational study $(n=670)$, OCT guidance was associated with a significantly lower risk of cardiac death or MI as compared to angiographic only guidance [adjusted $\mathrm{OR}=0.49$ $(0.25-0.96), p=0.037]$. Intravascular imaging-guided PCI has a potential to reduce cardiac death, major adverse cardiac events, stent thrombosis, and target lesion revascularization as compared with angiography-guided PCI [147]. OCT-guided PCI is noninferior to IVUS-guided PCI in terms of stent expansion in the ILUMIEN III trial [148] and clinical outcome in the OPINION trial [149] from Japan.

In general, a small edge dissection found on OCT which is undetected on angiography most likely does not have a clinical impact [150-153]. However, the following factors need to be considered: longitudinal and circumferential extension of dissection, and the depth of dissection (intima, media or even adventitia). In the ILUMIEN III [148], edge dissections were categorized as major if they constituted $\geq 60$ degrees of the circumference of the vessel at the site of dissection and/or were $\geq 3 \mathrm{~mm}$ in length. In that trial, when the intra-dissection lumen area is $<90 \%$ of the respective reference area, additional stent implantation was considered. In CLI-OPCI-II trial [134], dissection was defined on OCT as a linear rim of tissue with a width of $\geq 0.2 \mathrm{~mm}$ and a clear separation from the vessel wall or underlying plaque. In this retrospective multicenter registry, acute dissection in the distal stent edge was an independent predictor for major adverse cardiac events.

If the malapposition distance from the endoluminal lining of strut to the vessel wall is $<250 \mu \mathrm{m}$, such struts likely come into contact with vessel wall at follow-up. Therefore, such small malappositions may be less clinically relevant $[154,155]$. The clinical relevance of acute malapposition on stent failure is not yet fully established [134, 156-158]. Ozaki et al. reported that acute strut malapposition could persist (persistent malapposition; 4.67\%), or resolve at follow-up (resolved/healed malapposition; 2.48\%), whereas strut malapposition could also develop during follow-up (late acquired malapposition; 0.37\%) [159]. The temporal evolution and disappearance of malapposition makes the investigation of the clinical relevance of strut malapposition more complicated.

\section{Recommendations}

IVUS/ OCT/ OFDI can be used to optimize stent implantation.

A relative stent expansion of $>80 \%$ (MSA divided by average reference lumen area), and an MSA of $>5.5 \mathrm{~mm}^{2}$ by IVUS and $>4.5 \mathrm{~mm}^{2}$ by OCT in non-left main lesions should be achieved.

Acute incomplete stent apposition with a distance of $\leq 250$ micron is likely to be resolved at follow-up. Additional post-dilatation is considered when malapposition distance is $>250$ micron.

Most edge dissection detected on OCT is clinically silent, whereas additional stenting may be performed if the width of distal edge dissection is $\geq 200$ micron [134].

\section{Mechanical hemodynamic support}

Intra-aortic balloon pumping (IABP) counterpulsation is the most widely used mechanical support for the treatment of cardiogenic shock, based on the beneficial effect of aortic diastolic inflation and rapid systolic deflation, improving myocardial and peripheral perfusion and reducing afterload and myocardial oxygen consumption.

The previous ESC guidelines stated that IABP may be considered in cardiogenic shock after STEMI (IIb) [22]. However, IABP counterpulsation does not improve outcomes in patients with STEMI and cardiogenic shock without mechanical complications [160, 161], nor does it significantly limit infarct size in those with potentially large anterior MIs [162]. The latest ESC guidelines no longer recommend routine IABP counterpulsation in cardiogenic shock except selected patients (i.e., severe mitral insufficiency or ventricular septal defect).

In other countries, mechanical LV assist devices (LVADs), including percutaneous short-term mechanical circulatory support devices (i.e., intra-cardiac axial flow pumps and arterial-venous extracorporeal membrane oxygenation) have been used in patients not responding to standard therapy, including inotropes, fluids, and IABP, but evidence regarding their benefits is limited [163]. A small exploratory trial studying the Impella CP percutaneous circulatory support device did not find any benefit compared with IABP in AMI complicated by cardiogenic shock [164]. Therefore, short-term mechanical circulatory support may be considered as a rescue therapy to stabilize patients and preserve organ perfusion (oxygenation) as a bridge to recovery of myocardial function, cardiac transplantation, or even LV assist device destination therapy on an individual basis $[165,166]$. 
Table 7 Comparison of mechanical circulatory support system

\begin{tabular}{|c|c|c|c|}
\hline & IABP & IMPELLA & VA-ECMO \\
\hline Cardiac flow & $0.3-0.5 \mathrm{~L} / \mathrm{min}$ & $\begin{array}{l}\text { 1-5 L/min (Impella 2.5, Impella } \\
\text { CP, Impella 5) }\end{array}$ & $3-7 \mathrm{~L} / \mathrm{min}$ \\
\hline Mechanism & Aorta & $\mathrm{LV} \rightarrow$ Ao & $\mathrm{RA} \rightarrow$ Ao \\
\hline Maximum implant days & Weeks & 7 days & Weeks \\
\hline Sheath size & $7-8 \mathrm{Fr}$ & $\begin{array}{l}\text { 13-14 Fr } \\
\text { Impella } 5.0-21 \mathrm{Fr}\end{array}$ & $\begin{array}{l}14-16 \mathrm{Fr} \text { arterial } \\
18-21 \mathrm{Fr} \text { venous }\end{array}$ \\
\hline Femoral artery size & $>4 \mathrm{~mm}$ & $\begin{array}{l}\text { Impella } 2.5 \text { and CP: } 5-5.5 \mathrm{~mm} \\
\text { Impella 5: } 8 \mathrm{~mm}\end{array}$ & $8 \mathrm{~mm}$ \\
\hline Cardiac synchrony or stable rhythm & Yes & No & No \\
\hline Afterload & $\downarrow$ & $\downarrow$ & $\uparrow \uparrow \uparrow$ \\
\hline Mean arterial pressure & $\uparrow$ & $\uparrow \uparrow$ & $\uparrow \uparrow$ \\
\hline LVEDP & $\downarrow$ & $\downarrow \downarrow$ & $\longleftrightarrow$ \\
\hline PCWP & $\downarrow$ & $\downarrow \downarrow$ & $\longleftrightarrow$ \\
\hline LV preload & - & $\downarrow \downarrow$ & $\downarrow$ \\
\hline Coronary perfusion & $\uparrow$ & $\uparrow$ & - \\
\hline Myocardial oxygen demand & $\downarrow$ & $\downarrow \downarrow$ & $\longleftrightarrow$ \\
\hline
\end{tabular}

Modified from [167]

Ao aorta, $I A B P$ intra-aortic balloon pump, $L A$ left atrium, $L V$ left ventricle, $L V E D P$ left ventricular end diastolic pressure, $R A$ right atrium, $P C W P$ pulmonary capillary wedge pressure, VA-ECMO venoarterial extracorporeal membrane oxygenation
A structured approach to determine the best adjunctive mechanical circulatory support device requires understanding the mechanisms, technical requirements, and hemodynamic responses of each device [167] (Table 7). Device escalation is often required if the initial support device (usually IABP) does not improve hemodynamics and end-organ perfusion. Venoarterial extracorporeal membrane oxygenation (VA-ECMO) is often used in a combination with IABP to reduce the afterload increased by the retrograde flow. In a retrospective cohort study using propensity score matching in the Japanese Diagnosis Procedure Combination national inpatient database [168], all-cause 28-day mortality and in-hospital mortality were significantly lower in the IABP combined with VA-ECMO group than the VA-ECMO-alone group (48.4\% vs $58.2 \%$; $p=0.001$ and $55.9 \%$ vs $64.5 \% ; p=0.004$, respectively). The proportion of patients weaned from VA-ECMO was significantly higher in the IABP combined with VAECMO group than in the VA-ECMO-alone group $(82.6 \%$ vs $73.4 \%$; $p<0.001)$.

There have been several clinical reports suggesting the combined use of Impella with IABP [169, 170]. However, this combination may decrease Impella forward flow during diastole due to diastolic pressure augmentation from the IABP [171].

The ongoing STEMI DTU (ST-elevation myocardial infarction door-to-unloading) trial (NCT03947619) will compare primary left ventricular unloading by Impella and a 30-min delay to reperfusion vs current standard of care in reducing infarct size and heart failure-related clinical events in patients presenting with anterior STEMI. The STEMI DTU trial will demonstrate whether Impella unloading of the left ventricle prior to reperfusion therapy reduces infarct size and thereby improves the prognosis of high-risk STEMI patients.

The latest guidelines for ACS from Japanese Circulation Society recommended IABP use as class I with level of evidence $C$ [172], considering that percutaneous LVADs are not broadly available in Japan. However, the Impella 2.5 and Impella 5.0 heart pumps received Pharmaceuticals and Medical Devices Agency (PMDA) approval from the Japanese Ministry of Health, Labor \& Welfare (MHLW) in September 2016 and received reimbursement, effective as of September 2017. Proper selection of patients and institutional criteria are being reviewed in J-PVAD (http://j-pvad.jp), and Impella has now been introduced in approximately 200 sites in Japan.

\section{Recommendations}

Routine intra-aortic balloon pumping is not indicated.

Intra-aortic balloon pumping should be considered in patients with hemodynamic instability/cardiogenic shock due to mechanical complications.

In patients presenting refractory shock, short-term mechanical support (Impella or ECMO) may be considered in selected institutes. 
m. DAPT in maintenance phase

\section{Risk stratification for bleeding}

The PRECISE-DAPT score (age, creatinine clearance, hemoglobin, white-blood-cell count, and previous spontaneous bleeding) was derived from 14,963 patients treated with different durations of DAPT (mainly aspirin and clopidogrel) after coronary stenting and showed a c-index for out-of hospital TIMI major or minor bleeding of $0.73(95 \%$ CI 0.61-0.85) [173]. A longer DAPT duration significantly increased bleeding in patients at high risk (score $\sim 25)$, but did not in those with lower bleeding risk profiles, and exerted a significant ischemic benefit only in this latter group. As stated in the new ESC/EACTS Consensus document on DAPT, the use of risk scores such as PRECISEDAPT designed to evaluate the benefits and risks of different DAPT durations 'may be considered' to support decision making [174].

Yoshikawa et al. reported that, in a pooled cohort of three studies conducted in Japan (12,223 patients from the CREDO Kyoto registry cohort-2, RESET and NEXT), the DAPT score successfully stratified ischemic and bleeding risks, although the ischemic event rate was remarkably low even with high-DAPT score [175].

\section{DAPT duration}

Recent trials demonstrated the safety and efficacy of short DAPT followed by P2Y12 inhibitor monotherapy in ACS patients.

In the GLOBAL LEADERS trial, 1-month DAPT followed by ticagrelor monotherapy (experimental group) and 12-month DAPT (reference group) were compared [176]. In 7,487 patients with ACS, the primary outcome of death or new Q wave MI occurred in 55 patients (1.5\%) in the experimental group and in 75 patients $(2.0 \%)$ in the reference group between 31 and 365 days after randomization (HR 0.73, 95\% CI $0.51-1.03 ; p=0.07$ ) [177]. BARC 3 or 5 bleeding happened in 28 patients $(0.8 \%)$ in the experimental group and in 54 patients $(1.5 \%)$ in the reference arm (HR $0.52,95 \% \mathrm{CI}$ $0.33-0.81 ; p=0.004)$. These findings suggested that between 1 and 12 months after PCI in ACS, aspirin was associated with increased bleeding risk and appeared not to add to the benefit of ticagrelor on ischemic events. In the SMARTCHOICE trial [178], 1498 patients were randomized to either DAPT for 3 months followed by P2Y12 inhibitor (clopidogrel, prasugrel, or ticagrelor) monotherapy or DAPT for 12 months, in which 314 STEMI and 469 NSTEMI patients were included. The rate of BARC 2-5 bleeding was significantly lower in the P2Y12 inhibitor monotherapy group than in the DAPT group $(2.0 \%$ vs $3.4 \%$, HR $0.58,95 \%$ CI $0.36-0.92, p=0.02)$, and MACE rates were similar $(2.9 \%$ vs $2.5 \%$ ). The TWILIGHT trial examined the effect of ticagrelor alone after 3-month DAPT vs. ticagrelor plus aspirin among patients at high risk for bleeding or ischemic events after PCI [179]. Among patients with NSTE-ACS $(n=4614)$, ticagrelor monotherapy reduced BARC 2, 3, or 5 bleeding by $53 \%$ (3.6\% vs. 7.6\%, HR 0.47, 95\% CI 0.36-0.61, $p<0.001$ ). Rates of all-cause death, MI, or stroke were similar (4.3\% vs. $4.4 \%$, HR $0.97,95 \%$ CI $0.74-1.28, p=0.84$ ) [180]. The TICO trial also compared ticagrelor monotherapy after 3-month DAPT vs. 12-month DAPT [181]. In 1,103 STEMI patients, ticagrelor monotherapy significantly reduced TIMI major bleeding (HR 0.32, 95\% CI 0.12-0.87) without significant increase of MACE (HR 1.10, 95\% CI 0.53-2.27). In 1,027 NSTEMI patients, ticagrelor monotherapy tended to reduce TIMI major bleeding (HR 0.69, 95\% CI 0.34-0.143) and MACE (HR 0.58, 95\% CI 0.30-1.13) [182]. These results corroborate the potential benefit of ticagrelor monotherapy after short DAPT in ACS patients.

Regarding the comparison between potent P2Y12 inhibitors, the ISAR-REACT 5 trial compared prasugrel plus aspirin vs. ticagrelor plus aspirin in ACS patients, and demonstrated that treatment with prasugrel, compared to ticagrelor, significantly reduced the composite rate of death, MI, or stroke (6.9\% vs. $9.3 \%, p=0.006)$ without any increase in bleeding complications ( $4.8 \%$ vs. $5.4 \%, p=0.46)$ [55].

Recently, MASTER DAPT trial compared with 1-month DAPT and at least 6-month for patients without anticoagulation (at least 3-month for patients with anticoagulation) in high bleeding risk population, in which ACS patients were included. The rates of both net adverse clinical events (NACE) and major adverse cardiac or cerebrovascular events (MACCE) were similar (7.5\% vs $7.7 \%$ and $6.1 \%$ vs $5.9 \%$ ) and met the trial definition for non-inferiority. However, the rate of major and clinically relevant nonmajor bleeding was significantly lower in the abbreviated 1-month DAPT group, compared to the prolonged DAPT group $(6.5 \%$ vs 9.4\%, $p<0.001)$ [183, 184].

It is well known that aspirin induces gastrointestinal ulceration and erosion [185]. In the Management of Aspirin-induced Gastrointestinal Complications (MAGIC) study, patients receiving PPI had lower risk of gastrointestinal ulcer or erosion [186, 187] Therefore, PPI should be more constantly used in patients with aspirin to reduce gastrointestinal toxicity during long-term prevention of cardiovascular events.

\section{DAPT dosage}

Both prasugrel and ticagrelor are available, but the dose of prasugrel is different in Japan. While $60 \mathrm{mg}$ loading dose and $10 \mathrm{mg}$ maintenance dose are applied in Europe and US, $20 \mathrm{mg}$ loading dose and $3.75 \mathrm{mg}$ maintenance dose are used in Japan. Although clopidogrel is dominantly used around the world, smaller dose of prasugrel including loading 
conveys less bleeding events associated without increase of ischemic events in Japan [52] (Table 1).

\section{Evidence from Japan}

The STOP-DAPT 2 trial randomized 3,045 patients either to 1-month of DAPT followed by clopidogrel monotherapy or 12 months of DAPT with aspirin and clopidogrel [188]. One-month DAPT was superior to 12-month DAPT for the primary end point of all-cause death and new Q-wave MI, occurring in $2.36 \%$ with 1 -month DAPT and $3.70 \%$ with 12-month DAPT (HR 0.64, 95\% CI 0.42-0.98, $p=0.04$ ). TIMI major or minor bleeding occurred in $0.41 \%$ with 1-month DAPT and $1.54 \%$ with 12-month DAPT (HR 0.26 , $95 \%$ CI $0.11-0.64, p=0.004)$. The results of the STOPDAPT 2 ACS trial were presented in the ESC congress 2021 , in which randomized 4,169 ACS patients with the same antiplatelet therapy regimen as the STOP-DAPT 2 trial were analyzed. The same primary endpoint as the STOPDAPT 2 trial were applied to the ACS patients, and cumulative event rates were $3.2 \%$ in the 1-month DAPT group and $2.83 \%$ in the 12-month group, which did not meet the statistical significance for non-inferiority (HR 1.14, 95\% CI $0.80-1.62$, p non-inferiority 0.06 ), although cumulative rates of TIMI major and minor bleeding were significantly lower with 1 -month DAPT $(0.54 \%$ vs $1.17 \%$, HR $0.46,95 \%$ CI $0.23-0.94)$.

The STOP-DAPT-3 (NCT04609111) started for patients with high bleeding risk or ACS, in which 1-month prasugrel monotherapy followed by clopidogrel monotherapy (no aspirin) vs 1-month DAPT comprising of aspirin and prasugrel followed by aspirin monotherapy after PCI will be investigated. In terms of an aspirin-free strategy, the safety and efficacy of prasugrel monotherapy after PCI in selected patients with stable $\mathrm{CAD}$ and low ischemic and bleeding risk were investigated in ASET trial [189]. The primary ischemic and bleeding endpoints occurred in 1 patient $(0.5 \%)$, and no stent thrombosis events occurred. To investigate the additional application of prasugrel monotherapy after PCI, the safety and efficacy of Japanese low-dose prasugrel monotherapy $(3.5 \mathrm{mg}$ ) after PCI in patients with CCS (phase 1) and NSTE-ACS (phase 2) has been evaluated in 400 patients in the ASET-JAPAN trial (NCT05117866).

\section{Patients with atrial fibrillation}

In patients with atrial fibrillation, after a short period of triple therapy up to 1 week from the acute event, 1-year combination therapy with direct oral anticoagulant (DOAC) and P2Y12 inhibitor, followed by DOAC/novel oral anticoagulant (NOAC) monotherapy could be recommended, but for high thrombotic risk patients, a period of triple therapy might be extended to 3-6 months [21, 190].
In patients with atrial fibrillation, the large 4 trials, WOEST, PIONEER AF, RE-DUAL PCI, and AUGUSTUS trials and their network meta-analysis demonstrate that the treatment with DOAC and P2Y12 inhibitor could reduce bleeding risk without an increased risk of ischemic events up to 1 year after PCI, compared to vitamin K-antagonist plus DAPT (i.e., triple therapy) [191-195]. In these 4 trials, approximately half of patients presented with ACS. Clopidogrel was used as a P2Y12 inhibitor in more than $90 \%$ patients. Recently, MASTER DAPT study comparing abbreviated and prolonged DAPT following Ultimaster stent ${ }^{\mathrm{TM}}$ implantation in high bleeding risk (HBR) patients indicated that abbreviated therapy resulted in a lower incidence of major or clinically relevant nonmajor bleeding[183]. Furthermore, a substudy of MASTER DAPT using clopidogrel in patients with oral anticoagulant $(\mathrm{OAC})$ revealed that it is safe and beneficial to stop DAPT at 1 month in HBR patients with or without an indication for OAC, while an abbreviated antiplatelet therapy strategy significantly reduced clinically relevant bleeding risk in HBR patients without OAC but no such significant reduction was obtained in the OAC population [184].

The AFIRE trial demonstrated that DOAC monotherapy was noninferior to combination therapy with DOAC and single antiplatelet therapy for efficacy (stroke, systemic embolism, MI, unstable angina requiring revascularization, or all-cause death; HR $0.72,95 \%$ CI $0.55-0.95$ ) and superior for safety (major bleeding; HR 0.59, 95\% CI 0.39-0.89) in patients with atrial fibrillation and stable coronary artery disuse including prior PCI more than 1 year earlier [196]. Although 4 major DOAC studies (i.e., WOEST, PIONEER AF, RE-DUAL PCI, and AUGUSTUS) clearly indicated the superiority of DOAC over warfarin, patients with impaired kidney function were exclude from such trial because DOAC are not recommended in patients with significant renal dysfunction. To address such real-world limitations, Ozaki and his colleagues performed REWRAPS study (NCT02024230) involving all comer patients regardless of kidney function. While all the patients had coronary stenting and AF in the REWRAPS study, 250 patients were assigned to Rivaroxaban and 245 patients were allocated to Warfarin associated with a minimum 3-year follow-up. Renal function appears to play a major role in prognosis of patients with impaired renal function. Furthermore, Hashimoto and Ozaki and his coworkers recently reported that 3-year mortality and MACE significantly deteriorated from $5.09 \%$ and $15.8 \%$ in no CKD through $16.3 \%$ and $38.2 \%$ in moderate CKD to $36.7 \%$ and $57.9 \%$ in severe CKD, respectively $(p<0.0001)$, based on 3,281 patients with AMI enrolled in the J-MINUET registry associated with primary PCI of $93.1 \%$ in STEMI [197]. They concluded that CKD remains a useful predictor of inhospital and 3-year mortality as well as MACE after AMI in the modern PCI and optimal medical therapy era [197]. 
Recently, Collet JP and the task force for the management of ACS of the European Society of Cardiology (ESC) recommended in patients with atrial fibrillation and high bleeding risk, triple antithrombotic therapy with DOAC, aspirin, and clopidogrel should be given in a short period up to 1 week followed by double therapy using DOAC and clopidogrel for 6 months then DOAC monotherapy after the 6 months, while in those with atrial fibrillation and high ischemic risk, triple antithrombotic therapy including DOAC, aspirin, and clopidogrel should be provided up to 1 month followed by double therapy consisting of DOAC and clopidogrel for 12 months then DOAC monotherapy after the 12 months [21].

\section{Field of still lack of evidence in DAPT duration}

While TWILIGHT, GLOBAL LEADERS, STOP-DAPT-2 and MASTER DAPT trials have proved the superiority of shorter DAPT strategy in various clinical setting, the scientific direction surely is moving towards to shorter and abbreviated DAPT duration to reduce bleeding events $[176,179,183$, 188]. Recently two new advance trials such as ASET Japan and STOP-DAPT-3 have launched to confirm "aspirin is only before stenting but not after stenting" strategy in chronic coronary syndrome and subsequently acute coronary syndrome. In ASET Japan patients was only enrolled with optimal stenting results confirmed by OCT/ OFDI/ IVUS. However, no trial has not yet done in comparison with shorter abbreviated and longer standard DAPT in bifurcation two stenting including LMT, fill mental jacket and a history of stent thrombosis. While imaging-guided stent optimization can be a solution to reduce the ischemic complications in such complex PCI in long-term follow-up, non-uniform DAPT duration should be considered to account for complexity such as bifurcation two stenting including LMT, fill mental jacket and stent thrombosis. However, even in such cases, shortening the DAPT duration should always be kept in mind to reduce bleeding events.

\section{Recommendations}

Short DAPT (1 month) followed by a potent P2Y12 inhibitor (possibly prasugrel or ticagrelor) monotherapy should be considered after PCI in patients with high bleeding risk based on recent publications including the GLOBAL LEADERS, STOP-DAPT2 and MASTER DAPT trials.

One-month DAPT followed by clopidogrel monotherapy may be not recommended in patients with ACS.

Prolonged DAPT (at least 6 months) should only be considered for patients with high thrombotic risk such as patients with ACS or history of stent thrombosis as well as lesions with bifurcated two stenting or full mental jacket.

In patients with atrial fibrillation and high bleeding risk, triple antithrombotic therapy with DOAC, aspirin, and clopidogrel should be given in a short period up to 1 week followed by double therapy using DOAC and clopidogrel for 6 months, while in those with atrial fibrillation and high ischemic risk, triple antithrombotic therapy including DOAC, aspirin, and clopidogrel should be given up to 1 month followed by double therapy consisting of DOAC and clopidogrel for 12 months then DOAC monotherapy after the 12 months.

A proton pump inhibitor (PPI) in combination with DAPT is recommended in patients at high risk of gastrointestinal bleeding.

In patients with LV thrombus, anticoagulation should be administered for at least 6 months guided by repeated ultrasound or CT/MRI imaging.

\section{Treatment of non-infarcted-related artery}

\section{General recommendation in revascularization of non-infarct-related artery in acute MI}

In the guidelines released by the European Society of Cardiology in 2017 on the management of patients with ST-segment elevation MI Complete revascularization for ST-segment elevation MI patients with multivessel disease was upgraded from III to IIa with the level of evidence A.

In the Compare-Acute trial, 885 patients with ST-segment elevation MI and multivessel disease who underwent primary PCI were randomized in a 1:2 fashion to complete revascularization of non-infarct-related coronary arteries guided by FFR or no revascularization of non-infarct-related coronary arteries [198, 199]. There was a significant reduction in MACE at 3 years with FFRguided complete revascularization $(15.6 \%$ vs $30.2 \%$, HR $0.46,95 \%$ CI 0.33 to $0.64, p<0.001)$. The benefit was mostly driven by a reduced risk of revascularization. In the COMPLETE trial, 4041 patients with ST-segment elevation MI and MVD who underwent primary PCI were randomized in a 1:1 fashion to complete revascularization of non-infarct-related coronary arteries guided by FFR or no revascularization of non-infarct-related coronary arteries [200]. At 5 years, FFR-guided complete revascularization significantly reduced cardiovascular death or MI (7.8\% vs $10.5 \%$, HR $0.74,95 \%$ CI 0.60 to $0.91, p=0.004$ ). In a meta-analysis published in 2020, these trials are included, and complete revascularization had a benefit for cardiovascular death (odds ratio 0.69, 95\% CI 0.48-0.99) [201].

In the setting of cardiogenic shock, the efficacy and safety of treating non-infarct-related coronary arteries in the context of primary PCI has been a matter of debate. In the CULPRIT-SHOCK (Culprit Lesion Only PCI versus Multivessel PCI in Cardiogenic Shock) trial $(N=706)$, the 30-day risk of a composite of death or severe renal failure leading to renal-replacement therapy was lower in patients who underwent initial PCI of the culprit lesion 
only compared with those who underwent immediate multivessel PCI [202]. Between 30 days and 1 year, there was no significant difference in all-cause death between the two groups [203].

In 2017 ESC guidelines, published 2 months before the CULPRIT-SHOCK trial, Grade IIa recommendation with level of evidence $\mathrm{C}$ was applied for complete revascularization in ST-segment elevation MI at patients with multivessel disease who present with cardiogenic shock. However, in 2018 ESC guidelines on myocardial revascularization [123], routine revascularization of non-IRA lesions is not recommended during primary PCI in patients with cardiogenic shock (Class III).

In 2020 ESC guidelines for NSTE-ACS, complete revascularization in NSTE-ACS patients without cardiogenic shock and with multivessel CAD is recommended as Class IIa [21]. Data from the British Cardiac Intervention Society PCI database showed significantly lower mortality rates with single-stage complete revascularization compared to culpritlesion-only PCI (adjusted HR $0.90,95 \%$ CI $0.85-0.97$ ) at a median follow-up of 4.6 years among 21,857 NSTE-ACS patients with multivessel CAD undergoing PCI [204]. In the Alberta COAPT registry, complete revascularization significantly reduced all-cause death or new MI, compared to incomplete revascularization (inverse probability-weighted HR 0.78, 95\% CI 0.73-0.84) in patients with ACS and MVD [205]. The significant reduction was observed regardless of ACS type (STEMII, NSTEMI, or unstable angina).

In terms of the timing of non-culprit lesion PCI, a substudy in the COMPLETE trial investigated the timing of non-culprit lesion PCI [206], and PCI during index hospitalization or after discharge conferred similar benefits on major cardiovascular events. The SMILE trial randomized 500 NSTE-ACS patients to immediate complete revascularization vs staged complete revascularization. Immediate complete revascularization significantly reduced MACE (13.6\% vs $23.2 \%$, HR 0.55 , 95\% CI 0.36-0.83) [207]. We still need dedicated randomized trials for the best timing of non-culprit lesion PCI.

\section{Recommendations}

Complete revascularization should be considered in STEMI or NSTEMI patients with multivessel disease.

Non-IRA PCI during the index procedure is not recommended in patients with cardiogenic shock.

\section{Physiological assessment of non-infarct-related artery}

The Compare-Acute and COMPLETE trials applied fractional flow reserve (FFR) guide assessment of non-infarctedrelated artery for complete revascularization in STEMI patients, and in both trials, FFR-guide complete revascularization significantly reduced cardiovascular events, compared to culprit-lesion-only PCI.

Regarding the impact of physiological assessment for complete revascularization, 306 STEMI patients were randomized to angiography-guided or stress echo-guided PCI for non-infarct-related lesions in the CROSS-AMI [208]. The primary endpoint of cardiovascular mortality, nonfatal reinfarction, coronary revascularization, or readmission because of heart failure occurred in $14 \%$ in both groups $(p=0.85)$. However, this trial had a rather small sample size.

Direct comparison between angiography-guided and FFR-guided complete revascularization was performed in the FLOWER-MI study [209]. The primary outcome was a composite of death from any cause, nonfatal myocardial infarction, or unplanned hospitalization leading to urgent revascularization at 1 year, and a primary outcome event occurred in 32 of 586 patients (5.5\%) in the FFR-guided group and in 24 of 577 patients $(4.2 \%)$ in the angiography-guided group (HR 1.32, 95\% CI 0.78-2.23; $p=0.31$ ). Although an FFR-guided strategy failed to show a significant benefit over an angiography-guided strategy, considering the given the wide CIs for the estimate of effect we still need the evidence for physiological assessment of non-infarctedrelated artery in acute setting.

\section{Summary (Fig. 1)}

The Task Force on Primary PCI of the CVIT society has updated this expert consensus document for the management of AMI in 2022 version based on the new evidence (Fig. 1). Our team would like to recommend the following strategies in STEMI: (1) primary PCI should be done within $90 \mathrm{~min}$; (2) radial access and drug-eluting stent (DES) over baremetal stent (BMS) are recommended; (3) complete revascularization before hospital discharge (either immediate or staged) is now preferred. For patients with NSTEMI, we also now recommend an early invasive strategy within $24 \mathrm{~h}$, and complete revascularization in NSTEMI patients without cardiogenic shock.

Although in ESC guidelines [123] intravascular imaging is recommended only in case of restenosis and stent thrombosis to detect stent-related mechanical problems and to assess and guide PCI in left main stem, in the recent expert consensus document of the European Association of Percutaneous Cardiovascular Interventions (EAPCI) [124], an intravascular imaging-based assessment to guide appropriate management should be considered when a culprit lesion is not evident angiographically in NSTE-ACS. Furthermore, thrombus detection where OCT/ OFDI is the current gold standard facilitates identification of an ACS culprit lesion. IVUS/ OCT/ OFDI should be considered to detect stentrelated mechanical problems. IVUS can be used to assess 
Fig. 1 Summary of recommendations in primary PCI. *Urgent coronary angiography $(<2 \mathrm{~h})$ is recommended in very high-risk patients. $†$ Cases with large thrombus formation or plaque burden with a high possibility of distal embolism or slow/no flow; or cases with MI in SVG. DAPT dual antiplatelet therapy; $D E S$ drug-eluting stent; GI gastrointestinal; ISR in-stent restenosis; IVUS intravascular ultrasound; NSTEMI non-STsegment elevation myocardial infarction; $O C T$ optical coherence tomography; $P C I$ percutaneous coronary intervention; $P P I$ proton pump inhibitor; $S T$ stent thrombosis; STEMI STsegment elevation myocardial infarction; and $U F H$ unfractionated heparin

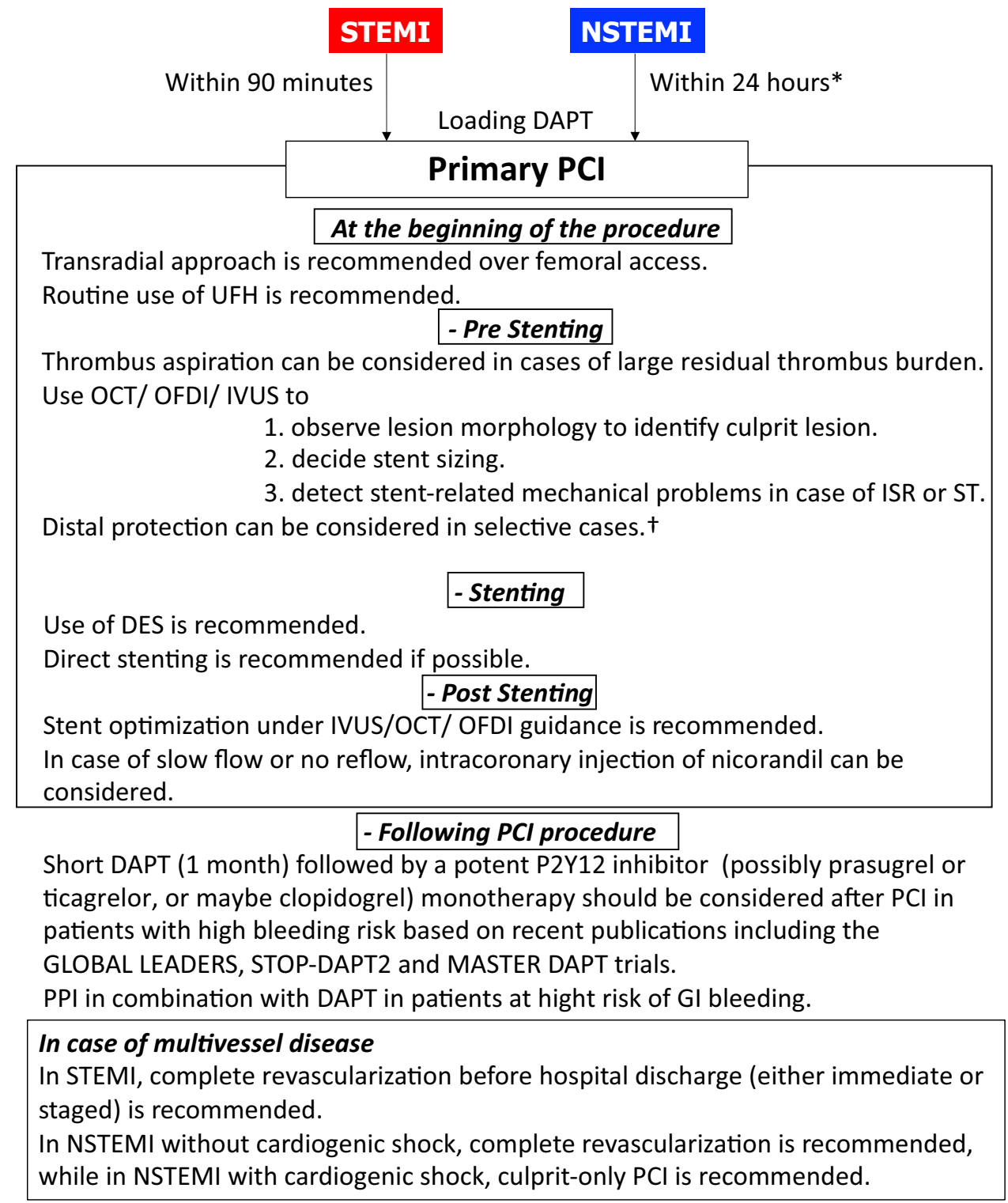

severity and optimize treatment of unprotected left main lesions. Post-procedural OCT/OFDI assessment including presence of dissection, degree of incomplete stent apposition, and presence of thrombus protrusion could contribute to reducing MACE in long-term follow-up.

Furthermore, although earlier studies have shown the benefit of thrombus aspiration in primary PCI published in New England Journal Medicine and European Heart Journal from the Dutch group [78, 79], routine use of mechanical thrombus aspiration is no longer recommended due to the safety concerns regarding the risk of stroke. However, in the subgroup with high thrombus burden, thrombus aspiration was associated with fewer cardiovascular deaths but with more strokes or transient ischemic attacks [77]. Futhermore, there are several studies in Japan showing the benefit of thrombus aspiration in primary PCI. Therefore, in the absence of
GP IIb/IIIa inhibitors, careful thrombus aspiration may be considered in primary PCI, especially in patients with high thrombus burden.

Concerning the duration of antiplatelet therapy, short DAPT (1 month) followed by P2Y12 inhibitor has become the first choice in patients with high bleeding risk, however in the near future P2Y12 inhibitor monotherapy might be enough after PCI in patients without atrial fibrillation. Furthermore, although clopidogrel is dominantly used around the world, smaller dose of prasugrel including loading confers fewer bleeding complications associated without increased risk of ischemic events in Japan. In patients with atrial fibrillation and high bleeding risk, following a short period of triple antithrombotic therapy (up to 1 week from the acute event), dual antithrombotic therapy (e.g., DOAC and single oral antiplatelet agent preferably 
clopidogrel) is recommended with cessation of antiplatelet therapy after 6 months. In patients with atrial fibrillation and high ischemic risk, triple antithrombotic therapy including DOAC, aspirin, and clopidogrel should be given up to 1 month followed by double therapy consisting of DOAC and clopidogrel for 12 months then DOAC monotherapy after the 12 months.

While the Compare-Acute and COMPLETE trials applied FFR-guide assessment of non-infarcted-related artery for complete revascularization in STEMI patients, FFR-guide complete revascularization significantly reduced cardiovascular events compared to culprit-lesion-only PCI. However, the FLOWER-MI study performed a direct comparison between angiography-guided and FFR-guided complete revascularization and failed to show a significant benefit over an angiography-guided strategy. We still need the evidence for physiological assessment of non-infarcted-related artery in acute setting. Furthermore, in the near future, such physiological assessment will be preferred to be less invasive manner including QFR or FFR-CT especially in non-culprit vessels.

Open Access This article is licensed under a Creative Commons Attribution 4.0 International License, which permits use, sharing, adaptation, distribution and reproduction in any medium or format, as long as you give appropriate credit to the original author(s) and the source, provide a link to the Creative Commons licence, and indicate if changes were made. The images or other third party material in this article are included in the article's Creative Commons licence, unless indicated otherwise in a credit line to the material. If material is not included in the article's Creative Commons licence and your intended use is not permitted by statutory regulation or exceeds the permitted use, you will need to obtain permission directly from the copyright holder. To view a copy of this licence, visit http://creativecommons.org/licenses/by/4.0/.

\section{References}

1. Hochman JS, Sleeper LA, Webb JG, Sanborn TA, White HD, Talley JD, Buller CE, Jacobs AK, Slater JN, Col J, Mckinlay $\mathrm{SM}$, Lejemtel TH. Early revascularization in acute myocardial infarction complicated by cardiogenic shock. SHOCK Investigators. Should We Emergently Revascularize Occluded Coronaries for Cardiogenic Shock. N Engl J Med. 1999;341:625-34. https:// doi.org/10.1056/nejm199908263410901.

2. Bonnefoy E, Lapostolle F, Leizorovicz A, Steg G, Mcfadden EP, Dubien PY, Cattan S, Boullenger E, Machecourt J, Lacroute JM, Cassagnes J, Dissait F, Touboul P. Primary angioplasty versus prehospital fibrinolysis in acute myocardial infarction: a randomised study. Lancet (London, England). 2002;360:825-9. https://doi.org/10.1016/s0140-6736(02)09963-4.

3. Widimsky P, Budesinsky T, Vorac D, Groch L, Zelizko M, Aschermann M, Branny M, St' asek J, Formanek P. Long distance transport for primary angioplasty vs immediate thrombolysis in acute myocardial infarction. Final results of the randomized national multicentre trial-PRAGUE-2. Eur Heart J. 2003;24:94-104.

4. Steg PG, Bonnefoy E, Chabaud S, Lapostolle F, Dubien PY, Cristofini P, Leizorovicz A, Touboul P. Impact of time to treatment on mortality after prehospital fibrinolysis or primary angioplasty: data from the CAPTIM randomized clinical trial. Circulation. 2003;108:2851-6. https://doi.org/10.1161/01.cir.0000103122. 10021.f2.

5. Lincoff AM, Califf RM, Van De Werf F, Willerson JT, White HD, Armstrong PW, Guetta V, Gibler WB, Hochman JS, Bode C, Vahanian A, Steg PG, Ardissino D, Savonitto S, Bar F, Sadowski Z, Betriu A, Booth JE, Wolski K, Waller M, Topol EJ. Mortality at 1 year with combination platelet glycoprotein IIb/IIIa inhibition and reduced-dose fibrinolytic therapy vs conventional fibrinolytic therapy for acute myocardial infarction: GUSTO V randomized trial. JAMA. 2002;288:2130-5.

6. Zijlstra F, Beukema WP, Vant Hof AW, Liem A, Reiffers S, Hoorntje JC, Suryapranata H, De Boer MJ. Randomized comparison of primary coronary angioplasty with thrombolytic therapy in low risk patients with acute myocardial infarction. J Am Coll Cardiol. 1997;29:908-12.

7. Zijlstra F, De Boer MJ, Hoorntje JC, Reiffers S, Reiber JH, Suryapranata H. A comparison of immediate coronary angioplasty with intravenous streptokinase in acute myocardial infarction. N Engl J Med. 1993;328:680-4. https://doi.org/10.1056/ nejm199303113281002.

8. Widimsky P, Groch L, Zelizko M, Aschermann M, Bednar $F$, Suryapranata H. Multicentre randomized trial comparing transport to primary angioplasty vs immediate thrombolysis vs combined strategy for patients with acute myocardial infarction presenting to a community hospital without a catheterization laboratory. PRAGUE Study Eur Heart J. 2000;21:823-31. https:// doi.org/10.1053/euhj.1999.1993.

9. De Boer MJ, Ottervanger JP, Van Hof AW, Hoorntje JC, Suryapranata H, Zijlstra F. Reperfusion therapy in elderly patients with acute myocardial infarction: a randomized comparison of primary angioplasty and thrombolytic therapy. J Am Coll Cardiol. 2002;39:1723-8.

10. Grines CL, Browne KF, Marco J, Rothbaum D, Stone GW, Okeefe J, Overlie P, Donohue B, Chelliah N, Timmis GC, et al. A comparison of immediate angioplasty with thrombolytic therapy for acute myocardial infarction. The primary angioplasty in myocardial infarction study group. N Engl J Med. 1993;328:673-9. https://doi.org/10.1056/nejm199303113281001.

11. Ribichini F, Steffenino G, Dellavalle A, Ferrero V, Vado A, Feola $\mathrm{M}$, Uslenghi E. Comparison of thrombolytic therapy and primary coronary angioplasty with liberal stenting for inferior myocardial infarction with precordial ST-segment depression: immediate and long-term results of a randomized study. J Am Coll Cardiol. 1998;32:1687-94.

12. Garcia E, Elizaga J, Perez-Castellano N, Serrano JA, Soriano J, Abeytua M, Botas J, Rubio R, Lopez De Sa E, Lopez-Sendon JL, Delcan JL. Primary angioplasty versus systemic thrombolysis in anterior myocardial infarction. J Am Coll Cardiol. 1999;33:605-11.

13. Investigators. GUOSTOOCaIaCSGIaS,. A clinical trial comparing primary coronary angioplasty with tissue plasminogen activator for acute myocardial infarction. N Engl J Med. 1997;336:1621-8. https://doi.org/10.1056/nejm19970605336 2301.

14. Schomig A, Kastrati A, Dirschinger J, Mehilli J, Schricke U, Pache J, Martinoff S, Neumann FJ, Schwaiger M. Coronary stenting plus platelet glycoprotein IIb/IIIa blockade compared with tissue plasminogen activator in acute myocardial infarction. Stent versus Thrombolysis for Occluded Coronary Arteries in Patients with Acute Myocardial Infarction Study Investigators. N Engl J Med. 2000;343:385-91. https://doi.org/10.1056/nejm200008 103430602.

15. Vermeer F, Oude Ophuis AJ, Vd Berg EJ, Brunninkhuis LG, Werter CJ, Boehmer AG, Lousberg AH, Dassen WR, Bar FW. 
Prospective randomised comparison between thrombolysis, rescue PTCA, and primary PTCA in patients with extensive myocardial infarction admitted to a hospital without PTCA facilities: a safety and feasibility study. Heart (Br Card Soc). 1999;82:426-31.

16. Kastrati A, Mehilli J, Dirschinger J, Schricke U, Neverve J, Pache J, Martinoff S, Neumann FJ, Nekolla S, Blasini R, Seyfarth M, Schwaiger M, Schomig A. Myocardial salvage after coronary stenting plus abciximab versus fibrinolysis plus abciximab in patients with acute myocardial infarction: a randomised trial. Lancet (Lond, Engl). 2002;359:920-5. https://doi.org/10.1016/ s0140-6736(02)08022-4.

17. Aversano T, Aversano LT, Passamani E, Knatterud GL, Terrin ML, Williams DO, Forman SA. Thrombolytic therapy vs primary percutaneous coronary intervention for myocardial infarction in patients presenting to hospitals without on-site cardiac surgery: a randomized controlled trial. JAMA. 2002;287:1943-51.

18. Grines CL, Westerhausen DR Jr, Grines LL, Hanlon JT, Logemann TL, Niemela M, Weaver WD, Graham M, Boura J, Oneill WW, Balestrini C. A randomized trial of transfer for primary angioplasty versus on-site thrombolysis in patients with high-risk myocardial infarction: the Air Primary Angioplasty in Myocardial Infarction study. J Am Coll Cardiol. 2002;39:1713-9.

19. Andersen HR, Nielsen TT, Rasmussen K, Thuesen L, Kelbaek $\mathrm{H}$, Thayssen P, Abildgaard U, Pedersen F, Madsen JK, Grande P, Villadsen AB, Krusell LR, Haghfelt T, Lomholt P, Husted SE, Vigholt E, Kjaergard HK, Mortensen LS. A comparison of coronary angioplasty with fibrinolytic therapy in acute myocardial infarction. N Engl J Med. 2003;349:733-42. https://doi.org/ 10.1056/NEJMoa025142.

20. Ibanez B, James S, Agewall S, Antunes MJ, Bucciarelli-Ducci C, Bueno H, Caforio ALP, Crea F, Goudevenos JA, Halvorsen S, Hindricks G, Kastrati A, Lenzen MJ, Prescott E, Roffi M, Valgimigli M, Varenhorst C, Vranckx P, Widimsky P. 2017 ESC Guidelines for the management of acute myocardial infarction in patients presenting with ST-segment elevation: the Task Force for the management of acute myocardial infarction in patients presenting with ST-segment elevation of the European Society of Cardiology (ESC). Eur Heart J. 2017. https://doi.org/10.1093/ eurheartj/ehx393.

21. Collet JP, Thiele H, Barbato E, Barthelemy O, Bauersachs J, Bhatt DL, Dendale P, Dorobantu M, Edvardsen T, Folliguet T, Gale CP, Gilard M, Jobs A, Juni P, Lambrinou E, Lewis BS, Mehilli J, Meliga E, Merkely B, Mueller C, Roffi M, Rutten FH, Sibbing D, Siontis GCM, Group ESCSD. 2020 ESC Guidelines for the management of acute coronary syndromes in patients presenting without persistent ST-segment elevation. Eur Heart J. 2021;42:1289-367. https://doi.org/10.1093/eurheartj/ehaa575.

22. Steg PG, James SK, Atar D, Badano LP, Blomstrom-Lundqvist C, Borger MA, Di Mario C, Dickstein K, Ducrocq G, FernandezAviles F, Gershlick AH, Giannuzzi P, Halvorsen S, Huber K, Juni P, Kastrati A, Knuuti J, Lenzen MJ, Mahaffey KW, Valgimigli M, Vant Hof A, Widimsky P, Zahger D. ESC Guidelines for the management of acute myocardial infarction in patients presenting with ST-segment elevation. Eur Heart J. 2012;33:2569-619. https://doi.org/10.1093/eurheartj/ehs215.

23. Ibanez B, James S, Agewall S, Antunes MJ, Bucciarelli-Ducci C, Bueno H, Caforio ALP, Crea F, Goudevenos JA, Halvorsen S, Hindricks G, Kastrati A, Lenzen MJ, Prescott E, Roffi M, Valgimigli M, Varenhorst C, Vranckx P, Widimsky P, Group ESCSD. 2017 ESC Guidelines for the management of acute myocardial infarction in patients presenting with ST-segment elevation: the Task Force for the management of acute myocardial infarction in patients presenting with ST-segment elevation of the European Society of Cardiology (ESC). Eur Heart J. 2018;39:119-77. https://doi.org/10.1093/eurheartj/ehx393.
24. Steg PG, James SK, Atar D, Badano LP, Blömstrom-Lundqvist C, Borger MA, Di Mario C, Dickstein K, Ducrocq G, FernandezAviles F, Gershlick AH, Giannuzzi P, Halvorsen S, Huber K, Juni P, Kastrati A, Knuuti J, Lenzen MJ, Mahaffey KW, Valgimigli M, Vant Hof A, Widimsky P, Zahger D. ESC Guidelines for the management of acute myocardial infarction in patients presenting with ST-segment elevation. Eur Heart J. 2012;33:2569-619. https://doi.org/10.1093/eurheartj/ehs215.

25. Oikawa J, Fukaya H, Ako J, Nakao K, Ozaki Y, Kimura K, Noguchi T, Suwa S, Fujimoto K, Nakama Y, Morita T, Shimizu W, Saito Y, Hirohata A, Morita Y, Inoue T, Okamura A, Mano T, Miyamoto Y, Ogawa H, Ishihara M. Risk factors of in-hospital lethal arrhythmia following acute myocardial infarction in patients undergoing primary percutaneous coronary intervention - insight from the J-MINUET study. Circ Rep. 2019;2:17-23. https://doi.org/10.1253/circrep.CR-19-0081.

26. Okuno T, Aoki J, Tanabe K, Nakao K, Ozaki Y, Kimura K, Ako J, Noguchi T, Yasuda S, Suwa S, Fujimoto K, Nakama Y, Morita T, Shimizu W, Saito Y, Hirohata A, Morita Y, Inoue T, Okamura A, Mano T, Hirata K, Shibata Y, Owa M, Tsujita K, Funayama H, Kokubu N, Kozuma K, Uemura S, Tobaru T, Saku K, Ohshima S, Nishimura K, Miyamoto Y, Ogawa H, Ishihara M. Association of onset-season with characteristics and long-term outcomes in acute myocardial infarction patients: results from the Japanese registry of acute myocardial infarction diagnosed by universal definition (J-MINUET) substudy. Heart Vessels. 2019;34:1899908. https://doi.org/10.1007/s00380-019-01426-w.

27. Ishihara M, Fujino M, Ogawa H, Yasuda S, Noguchi T, Nakao K, Ozaki Y, Kimura K, Suwa S, Fujimoto K, Nakama Y, Morita T, Shimizu W, Saito Y, Tsujita K, Nishimura K, Miyamoto Y. Clinical presentation, management and outcome of Japanese patients with acute myocardial infarction in the troponin era - Japanese Registry of Acute Myocardial Infarction Diagnosed by Universal Definition (J-MINUET). Circ J. 2015;79:1255-62. https://doi. org/10.1253/circj.CJ-15-0217.

28. Ishihara M, Nakao K, Ozaki Y, Kimura K, Ako J, Noguchi T, Fujino M, Yasuda S, Suwa S, Fujimoto K, Nakama Y, Morita T, Shimizu W, Saito Y, Hirohata A, Morita Y, Inoue T, Okamura A, Uematsu M, Hirata K, Tanabe K, Shibata Y, Owa M, Tsujita K, Funayama H, Kokubu N, Kozuma K, Tobaru T, Oshima S, Nakai M, Nishimura K, Miyamoto Y, Ogawa H. Long-term outcomes of non-ST-elevation myocardial infarction without creatine kinase elevation: the J-MINUET study. Circ J. 2017;81:958-65. https:// doi.org/10.1253/circj.CJ-17-0033.

29. Daida H, Miyauchi K, Ogawa H, Yokoi H, Matsumoto M, Kitakaze M, Kimura T, Matsubara T, Ikari Y, Kimura K, Tsukahara K, Origasa H, Morino Y, Tsutsui H, Kobayashi M, Isshiki T. Management and two-year long-term clinical outcome of acute coronary syndrome in Japan: prevention of atherothrombotic incidents following ischemic coronary attack (PACIFIC) registry. Circ J. 2013;77:934-43.

30. Miyachi H, Takagi A, Miyauchi K, Yamasaki M, Tanaka H, Yoshikawa M, Saji M, Suzuki M, Yamamoto T, Shimizu W, Nagao K, Takayama M. Current characteristics and management of ST elevation and non-ST elevation myocardial infarction in the Tokyo metropolitan area: from the Tokyo CCU network registered cohort. Heart Vessels. 2016;31:1740-51. https://doi.org/ 10.1007/s00380-015-0791-9.

31. Kojima S, Nishihira K, Takegami M, Nakao YM, Honda S, Takahashi J, Takayama M, Shimokawa H, Sumiyoshi T, Ogawa H, Kimura K, Yasuda S. Nationwide real-world database of 20,462 patients enrolled in the Japanese Acute Myocardial Infarction Registry (JAMIR): impact of emergency coronary intervention in a super-aging population. Int J Cardiol Heart Vasc. 2018;20:1-6. https://doi.org/10.1016/j.ijcha.2018.06.003. 
32. Honda S, Nishihira K, Kojima S, Takegami M, Asaumi Y, Suzuki M, Kosuge M, Takahashi J, Sakata Y, Takayama M, Sumiyoshi T, Ogawa H, Kimura K, Yasuda S. Rationale, design, and baseline characteristics of the prospective japan acute myocardial infarction registry (JAMIR). Cardiovasc Drugs Ther. 2019;33:97-103. https://doi.org/10.1007/s10557-018-6839-1.

33. Yasuda S, Honda S, Takegami M, Nishihira K, Kojima S, Asaumi Y, Suzuki M, Kosuge M, Takahashi J, Sakata Y, Takayama M, Sumiyoshi T, Ogawa H, Kimura K. Contemporary antiplatelet therapy and clinical outcomes of japanese patients with acute myocardial infarction: results from the prospective Japan Acute Myocardial Infarction Registry (JAMIR). Circ J. 2019;83:163343. https://doi.org/10.1253/circj.CJ-19-0145.

34. Suzuki M, Nishihira K, Takegami M, Honda S, Kojima S, Takayama M, Sumiyoshi T, Ogawa H, Kimura K, Yasuda S. Clinical profiles and outcomes in the treatment of acute myocardial infarction in Japan of aging society. Heart Vessels. 2020;35:1681-8. https://doi.org/10.1007/s00380-020-01654-5.

35. Mori H, Suzuki H, Nishihira K, Honda S, Kojima S, Takegami M, Takahashi J, Itoh T, Watanabe T, Takenaka T, Ito M, Takayama M, Kario K, Sumiyoshi T, Kimura K, Yasuda S. Inhospital morality associated with acute myocardial infarction was inversely related with the number of coronary risk factors in patients from a Japanese nation-wide real-world database. Int J Cardiol Hypertens. 2020;6: 100039. https://doi.org/10.1016/j. ijchy.2020.100039.

36. Kanaoka K, Okayama S, Yoneyama K, Nakai M, Nishimura K, Kawata H, Horii M, Kawakami R, Okura H, Miyamoto Y, Akashi Y, Saito Y. Number of board-certified cardiologists and acute myocardial infarction-related mortality in Japan - JROAD and JROAD-DPC registry analysis. Circ J. 2018;82:2845-51. https:// doi.org/10.1253/circj.CJ-18-0487.

37. Uemura S, Okamoto H, Nakai M, Nishimura K, Miyamoto Y, Yasuda S, Tanaka N, Kohsaka S, Kadota K, Saito Y, Tsutsui H, Komuro I, Ikari Y, Ogawa H, Nakamura M. Primary percutaneous coronary intervention in elderly patients with acute myocardial infarction - an analysis from a japanese nationwide claim-based database. Circ J. 2019;83:1229-38. https://doi.org/ 10.1253/circj.CJ-19-0004.

38. Matoba T, Sakamoto K, Nakai M, Ichimura K, Mohri M, Tsujita Y, Yamasaki M, Ueki Y, Tanaka N, Hokama Y, Fukutomi M, Hashiba K, Fukuhara R, Suwa S, Matsuura H, Hosoda H, Nakashima T, Tahara Y, Sumita Y, Nishimura K, Miyamoto Y, Yonemoto N, Yagi T, Tachibana E, Nagao K, Ikeda T, Sato N, Tsutsui H. Institutional characteristics and prognosis of acute myocardial infarction with cardiogenic shock in Japan: analysis from the JROAD/JROAD-DPC database. Circ J. 2021. https:// doi.org/10.1253/circj.CJ-20-0655.

39. Sakakura K, Inohara T, Kohsaka S, Amano T, Uemura S, Ishii H, Kadota K, Nakamura M, Funayama H, Fujita H, Momomura SI. Incidence and determinants of complications in rotational atherectomy: insights from the national clinical data (J-PCI Registry). Circulation. 2016. https://doi.org/10.1161/circinterventio ns.116.004278.

40. Numasawa Y, Inohara T, Ishii H, Kuno T, Kodaira M, Kohsaka S, Fujii K, Uemura S, Amano T, Kadota K, Nakamura M. Comparison of outcomes of women versus men with non-st-elevation acute coronary syndromes undergoing percutaneous coronary intervention (from the Japanese Nationwide Registry). Am J Cardiol. 2017;119:826-31. https://doi.org/10.1016/j.amjcard.2016. 11.034.

41. Yamaji K, Kohsaka S, Morimoto T, Fujii K, Amano T, Uemura S, Akasaka T, Kadota K, Nakamura M, Kimura T. Relation of ST-segment elevation myocardial infarction to daily ambient temperature and air pollutant levels in a Japanese nationwide percutaneous coronary intervention registry. Am J Cardiol.
2017;119:872-80. https://doi.org/10.1016/j.amjcard.2016.11. 041.

42. Inohara T, Kohsaka S, Yamaji K, Amano T, Fujii K, Oda H, Uemura S, Kadota K, Miyata H, Nakamura M. Impact of institutional and operator volume on short-term outcomes of percutaneous coronary intervention: a report from the japanese nationwide registry. JACC Cardiovasc Interv. 2017;10:918-27. https://doi. org/10.1016/j.jcin.2017.02.015.

43. Levine GN, Bates ER, Blankenship JC, Bailey SR, Bittl JA, Cercek B, Chambers CE, Ellis SG, Guyton RA, Hollenberg SM, Khot UN, Lange RA, Mauri L, Mehran R, Moussa ID, Mukherjee D, Ting HH, Ogara PT, Kushner FG, Ascheim DD, Brindis RG, Casey DE, Chung MK, De Lemos JA, Diercks DB, Fang JC, Franklin BA, Granger CB, Krumholz HM, Linderbaum JA, Morrow DA, Newby LK, Ornato JP, Ou N, Radford MJ, TamisHolland JE, Tommaso CL, Tracy CM, Woo YJ, Zhao DX. ACC/ AHA/SCAI focused update on primary percutaneous coronary intervention for patients with ST-elevation myocardial infarction: an update of the 2011 ACCF/AHA/SCAI guideline for percutaneous coronary intervention and the $2013 \mathrm{ACCF} / \mathrm{AHA}$ guideline for the management of ST-elevation myocardial infarction. J Am Coll Cardiol. 2016;67:1235-50. https://doi.org/10.1016/j.jacc. 2015.10.005.

44. Fox KA, Clayton TC, Damman P, Pocock SJ, De Winter RJ, Tijssen JG, Lagerqvist B, Wallentin L. Long-term outcome of a routine versus selective invasive strategy in patients with nonST-segment elevation acute coronary syndrome a meta-analysis of individual patient data. J Am Coll Cardiol. 2010;55:2435-45. https://doi.org/10.1016/j.jacc.2010.03.007.

45. Wallentin L, Lindhagen L, Arnstrom E, Husted S, Janzon M, Johnsen SP, Kontny F, Kempf T, Levin LA, Lindahl B, Stridsberg M, Stahle E, Venge P, Wollert KC, Swahn E, Lagerqvist B. Early invasive versus non-invasive treatment in patients with non-ST-elevation acute coronary syndrome (FRISC-II): 15 year follow-up of a prospective, randomised, multicentre study. Lancet (Lond, Engl). 2016;388:1903-11. https://doi.org/10.1016/ s0140-6736(16)31276-4.

46. Kofoed KF, Kelbæk H, Hansen PR, Torp-Pedersen C, Høfsten D, Kløvgaard L, Holmvang L, Helqvist S, Jørgensen E, Galatius S, Pedersen F, Bang L, Saunamaki K, Clemmensen P, Linde JJ, Heitmann M, Wendelboe Nielsen O, Raymond IE, Kristiansen OP, Svendsen IH, Bech J, Dominguez Vall-Lamora MH, Kragelund C, Hansen TF, Dahlgaard Hove J, Jørgensen T, Fornitz GG, Steffensen R, Jurlander B, Abdulla J, Lyngbæk S, Elming H, Therkelsen SK, Abildgaard U, Jensen JS, Gislason G, Køber LV, Engstrøm T. Early versus standard care invasive examination and treatment of patients with non-st-segment elevation acute coronary syndrome. Circulation. 2018;138:2741-50. https://doi. org/10.1161/circulationaha.118.037152.

47. Komiyama K, Nakamura M, Tanabe K, Niikura H, Fujimoto H, Oikawa K, Daida H, Yamamoto T, Nagao K, Takayama M. In-hospital mortality analysis of Japanese patients with acute coronary syndrome using the Tokyo CCU Network database: applicability of the GRACE risk score. J Cardiol. 2017. https:// doi.org/10.1016/j.jjcc.2017.09.006.

48. Ozaki Y, Nakao K, Kimura K, Jynya A, Noguchi T, Yasuda S, Takahashi H, Nishimura K, Miyamoto Y, Ishihara M. Impact of chronic kidney disease (Ckd) on in-hospital and 3-year clinical outcomes in patients with acute myocardial infarction (Ami) treated by contemporary pci and optimal medical therapy (Omt): insights from the J-Minuet study. J Am Coll Cardiol. 2018;71:1391-1391. https://doi.org/10.1016/S0735-1097(18) 31932-6.

49. Lemkes JS, Janssens GN, Van Der Hoeven NW, Jewbali LSD, Dubois EA, Meuwissen M, Rijpstra TA, Bosker HA, Blans MJ, Bleeker GB, Baak R, Vlachojannis GJ, Eikemans BJW, Van Der 
Harst P, Van Der Horst ICC, Voskuil M, Van Der Heijden JJ, Beishuizen A, Stoel M, Camaro C, Van Der Hoeven H, Henriques JP, Vlaar APJ, Vink MA, Van Den Bogaard B, Heestermans T, De Ruijter W, Delnoij TSR, Crijns H, GaJ J, Oemrawsingh PV, Gosselink MTM, Plomp K, Magro M, Elbers PWG, Van De Ven PM, Oudemans-Van Straaten HM, Van Royen N. Coronary angiography after cardiac arrest without ST-segment elevation. N Engl J Med. 2019;380:1397-407. https://doi.org/10. 1056/NEJMoa1816897.

50. Lemkes JS, Janssens GN, Van Der Hoeven NW, Jewbali LSD, Dubois EA, Meuwissen MM, Rijpstra TA, Bosker HA, Blans MJ, Bleeker GB, Baak RR, Vlachojannis GJ, Eikemans BJW, Van Der Harst P, Van Der Horst ICC, Voskuil M, Van Der Heijden JJ, Beishuizen A, Stoel M, Camaro C, Van Der Hoeven H, Henriques JP, Vlaar APJ, Vink MA, Van Den Bogaard B, Heestermans T, De Ruijter W, Delnoij TSR, Crijns H, GaJ J, Oemrawsingh PV, Gosselink MTM, Plomp K, Magro M, Elbers PWG, Spoormans EM, Van De Ven PM, Oudemans-Van Straaten HM, Van Royen N. Coronary angiography after cardiac arrest without ST segment elevation: one-year outcomes of the COACT randomized clinical trial. JAMA Cardiol. 2020;5:1-8. https://doi. org/10.1001/jamacardio.2020.3670.

51. Wiviott SD, Braunwald E, Mccabe CH, Montalescot G, Ruzyllo W, Gottlieb S, Neumann FJ, Ardissino D, De Servi S, Murphy SA, Riesmeyer J, Weerakkody G, Gibson CM, Antman EM. Prasugrel versus clopidogrel in patients with acute coronary syndromes. N Engl J Med. 2007;357:2001-15. https://doi.org/ 10.1056/NEJMoa0706482.

52. Saito S, Isshiki T, Kimura T, Ogawa H, Yokoi H, Nanto S, Takayama M, Kitagawa K, Nishikawa M, Miyazaki S, Nakamura M. Efficacy and safety of adjusted-dose prasugrel compared with clopidogrel in Japanese patients with acute coronary syndrome: the PRASFIT-ACS study. Circ J. 2014;78:1684-92.

53. Sahlen A, Varenhorst C, Lagerqvist B, Renlund H, Omerovic E, Erlinge D, Wallentin L, James SK, Jernberg T. Outcomes in patients treated with ticagrelor or clopidogrel after acute myocardial infarction: experiences from SWEDEHEART registry. Eur Heart J. 2016;37:3335-42. https://doi.org/10.1093/eurheartj/ ehw284.

54. Wallentin L, Becker RC, Budaj A, Cannon CP, Emanuelsson H, Held C, Horrow J, Husted S, James S, Katus H, Mahaffey KW, Scirica BM, Skene A, Steg PG, Storey RF, Harrington RA, Freij A, Thorsen M. Ticagrelor versus clopidogrel in patients with acute coronary syndromes. N Engl J Med. 2009;361:1045-57. https://doi.org/10.1056/NEJMoa0904327.

55. Schupke S, Neumann FJ, Menichelli M, Mayer K, Bernlochner I, Wohrle J, Richardt G, Liebetrau C, Witzenbichler B, Antoniucci D, Akin I, Bott-Flugel L, Fischer M, Landmesser U, Katus HA, Sibbing D, Seyfarth M, Janisch M, Boncompagni D, Hilz R, Rottbauer W, Okrojek R, Mollmann H, Hochholzer W, Migliorini A, Cassese S, Mollo P, Xhepa E, Kufner S, Strehle A, Leggewie S, Allali A, Ndrepepa G, Schuhlen H, Angiolillo DJ, Hamm CW, Hapfelmeier A, Tolg R, Trenk D, Schunkert H, Laugwitz KL, Kastrati A. Ticagrelor or prasugrel in patients with acute coronary syndromes. N Engl J Med. 2019;381:1524-34. https://doi. org/10.1056/NEJMoa1908973.

56. Montalescot G, Zeymer U, Silvain J, Boulanger B, Cohen M, Goldstein P, Ecollan P, Combes X, Huber K, Pollack C Jr, Benezet JF, Stibbe O, Filippi E, Teiger E, Cayla G, Elhadad S, Adnet F, Chouihed T, Gallula S, Greffet A, Aout M, Collet JP, Vicaut E. Intravenous enoxaparin or unfractionated heparin in primary percutaneous coronary intervention for ST-elevation myocardial infarction: the international randomised open-label ATOLL trial. Lancet (Lond, Engl). 2011;378:693-703. https://doi.org/10.1016/ s0140-6736(11)60876-3.
57. Silvain J, Beygui F, Barthelemy O, Pollack C Jr, Cohen M, Zeymer U, Huber K, Goldstein P, Cayla G, Collet JP, Vicaut E, Montalescot G. Efficacy and safety of enoxaparin versus unfractionated heparin during percutaneous coronary intervention: systematic review and meta-analysis. BMJ (Clin Res ed). 2012;344: e553. https://doi.org/10.1136/bmj.e553.

58. Capodanno D, Gargiulo G, Capranzano P, Mehran R, Tamburino $\mathrm{C}$, Stone GW. Bivalirudin versus heparin with or without glycoprotein IIb/IIIa inhibitors in patients with STEMI undergoing primary PCI: An updated meta-analysis of 10,350 patients from five randomized clinical trials. Eur Heart J Acute Cardiovasc Care. 2016;5:253-62. https://doi.org/10.1177/2048872615572599.

59. Valgimigli M, Frigoli E, Leonardi S, Rothenbuhler M, Gagnor A, Calabro P, Garducci S, Rubartelli P, Briguori C, Ando G, Repetto A, Limbruno U, Garbo R, Sganzerla P, Russo F, Lupi A, Cortese B, Ausiello A, Ierna S, Esposito G, Presbitero P, Santarelli A, Sardella G, Varbella F, Tresoldi S, De Cesare N, Rigattieri S, Zingarelli A, Tosi P, Vant Hof A, Boccuzzi G, Omerovic E, Sabate M, Heg D, Juni P, Vranckx P. Bivalirudin or unfractionated heparin in acute coronary syndromes. N Engl J Med. 2015;373:997-1009. https://doi.org/10.1056/NEJMoa1507854.

60. Stone GW, Witzenbichler B, Guagliumi G, Peruga JZ, Brodie BR, Dudek D, Kornowski R, Hartmann F, Gersh BJ, Pocock SJ, Dangas G, Wong SC, Kirtane AJ, Parise H, Mehran R. Bivalirudin during primary PCI in acute myocardial infarction. $\mathrm{N}$ Engl J Med. 2008;358:2218-30. https://doi.org/10.1056/NEJMoa0708 191.

61. Kastrati A, Neumann FJ, Mehilli J, Byrne RA, Iijima R, Buttner HJ, Khattab AA, Schulz S, Blankenship JC, Pache J, Minners J, Seyfarth M, Graf I, Skelding KA, Dirschinger J, Richardt G, Berger PB, Schomig A. Bivalirudin versus unfractionated heparin during percutaneous coronary intervention. N Engl J Med. 2008;359:688-96. https://doi.org/10.1056/NEJMoa0802944.

62. Ndrepepa G, Schulz S, Keta D, Mehilli J, Birkmeier A, Massberg S, Laugwitz KL, Neumann FJ, Seyfarth M, Berger PB, Schomig A, Kastrati A. Bleeding after percutaneous coronary intervention with Bivalirudin or unfractionated Heparin and one-year mortality. Am J Cardiol. 2010;105:163-7. https://doi.org/10.1016/j. amjcard.2009.08.668.

63. Erlinge D, Omerovic E, Frobert O, Linder R, Danielewicz M, Hamid M, Swahn E, Henareh L, Wagner H, Hardhammar P, Sjogren I, Stewart J, Grimfjard P, Jensen J, Aasa M, Robertsson L, Lindroos P, Haupt J, Wikstrom H, Ulvenstam A, Bhiladvala $\mathrm{P}$, Lindvall $\mathrm{B}$, Lundin $\mathrm{A}$, Todt $\mathrm{T}$, Ioanes $\mathrm{D}$, Ramunddal T, Kellerth T, Zagozdzon L, Gotberg M, Andersson J, Angeras O, Ostlund O, Lagerqvist B, Held C, Wallentin L, Schersten F, Eriksson P, Koul S, James S. Bivalirudin versus heparin monotherapy in myocardial infarction. N Engl J Med. 2017;377:1132-42. https://doi.org/10.1056/NEJMoa1706443.

64. Nakagawa Y, Nobuyoshi M, Yamaguchi T, Meguro T, Yokoi H, Kimura T, Hosoda S, Kanmatsuse K, Matsumori A, Sasayama S. Efficacy of abciximab for patients undergoing balloon angioplasty: data from Japanese evaluation of c7E3 Fab for elective and primary PCI organization in randomized trial (JEPPORT). Circ J. 2009;73:145-51.

65. Romagnoli E, Biondi-Zoccai G, Sciahbasi A, Politi L, Rigattieri S, Pendenza G, Summaria F, Patrizi R, Borghi A, Di Russo C, Moretti C, Agostoni P, Loschiavo P, Lioy E, Sheiban I, Sangiorgi G. Radial versus femoral randomized investigation in ST-segment elevation acute coronary syndrome: the RIFLESTEACS (Radial Versus Femoral Randomized Investigation in ST-Elevation Acute Coronary Syndrome) study. J Am Coll Cardiol. 2012;60:2481-9. https://doi.org/10.1016/j.jacc.2012. 06.017 .

66. Jolly SS, Yusuf S, Cairns J, Niemela K, Xavier D, Widimsky P, Budaj A, Niemela M, Valentin V, Lewis BS, Avezum A, 
Steg PG, Rao SV, Gao P, Afzal R, Joyner CD, Chrolavicius S, Mehta SR. Radial versus femoral access for coronary angiography and intervention in patients with acute coronary syndromes (RIVAL): a randomised, parallel group, multicentre trial. Lancet (Lond, Engl). 2011;377:1409-20. https://doi.org/10.1016/s01406736(11)60404-2.

67. Vranckx P, Frigoli E, Rothenbuhler M, Tomassini F, Garducci S, Ando G, Picchi A, Sganzerla P, Paggi A, Ugo F, Ausiello A, Sardella G, Franco N, Nazzaro M, De Cesare N, Tosi P, Falcone C, Vigna C, Mazzarotto P, Di Lorenzo E, Moretti C, Campo G, Penzo C, Pasquetto G, Heg D, Juni P, Windecker S, Valgimigli M. Radial versus femoral access in patients with acute coronary syndromes with or without ST-segment elevation. Eur Heart J. 2017;38:1069-80. https://doi.org/10.1093/eurheartj/ehx048.

68. Saito S, Tanaka S, Hiroe Y, Miyashita Y, Takahashi S, Tanaka K, Satake S. Comparative study on transradial approach vs. transfemoral approach in primary stent implantation for patients with acute myocardial infarction: results of the test for myocardial infarction by prospective unicenter randomization for access sites (TEMPURA) trial. Catheter Cardiovasc Interv. 2003;59:26-33. https://doi.org/10.1002/ccd.10493.

69. Saito S, Isshiki T, Kimura T, Ogawa H, Yokoi H, Nishikawa M, Miyazaki S, Tanaka Y, Nakamura M. Impact of arterial access route on bleeding complications in japanese patients undergoing percutaneous coronary intervention- insight from the PRASFIT trial. Circ J. 2015;79:1928-37. https://doi.org/10.1253/circj. CJ-15-0276.

70. Yamashita Y, Shiomi H, Morimoto T, Yaku H, Kaji S, Furukawa Y, Nakagawa Y, Ando K, Kadota K, Abe M, Akao M, Nagao K, Shizuta S, Ono K, Kimura T. Transradial versus transfemoral approach in patients undergoing primary percutaneous coronary intervention for ST-elevation acute myocardial infarction: insight from the CREDO-Kyoto AMI registry. Heart Vessels. 2017;32:1448-57. https://doi.org/10.1007/s00380-017-1021-4.

71. Schaar JA, Muller JE, Falk E, Virmani R, Fuster V, Serruys PW, Colombo A, Stefanadis C, Ward Casscells S, Moreno PR, Maseri A, Van Der Steen AF. Terminology for high-risk and vulnerable coronary artery plaques. Report of a meeting on the vulnerable plaque, June 17 and 18, 2003, Santorini. Greece Eur Heart J. 2004;25:1077-82. https://doi.org/10.1016/j.ehj.2004.01.002.

72. Arbustini E, Dal Bello B, Morbini P, Burke AP, Bocciarelli M, Specchia G, Virmani R. Plaque erosion is a major substrate for coronary thrombosis in acute myocardial infarction. Heart. 1999;82:269-72. https://doi.org/10.1136/hrt.82.3.269.

73. Jia H, Abtahian F, Aguirre AD, Lee S, Chia S, Lowe H, Kato K, Yonetsu T, Vergallo R, Hu S, Tian J, Lee H, Park SJ, Jang YS, Raffel OC, Mizuno K, Uemura S, Itoh T, Kakuta T, Choi SY, Dauerman HL, Prasad A, Toma C, Mcnulty I, Zhang S, Yu B, Fuster V, Narula J, Virmani R, Jang IK. In vivo diagnosis of plaque erosion and calcified nodule in patients with acute coronary syndrome by intravascular optical coherence tomography. J Am Coll Cardiol. 2013;62:1748-58. https://doi.org/10.1016/j. jacc.2013.05.071.

74. Ozaki Y, Okumura M, Ismail TF, Motoyama S, Naruse H, Hattori K, Kawai H, Sarai M, Takagi Y, Ishii J, Anno H, Virmani R, Serruys PW, Narula J. Coronary CT angiographic characteristics of culprit lesions in acute coronary syndromes not related to plaque rupture as defined by optical coherence tomography and angioscopy. Eur Heart J. 2011;32:2814-23. https://doi.org/10. 1093/eurheartj/ehr189.

75. Kubo T, Imanishi T, Takarada S, Kuroi A, Ueno S, Yamano T, Tanimoto T, Matsuo Y, Masho T, Kitabata H, Tsuda K, Tomobuchi Y, Akasaka T. Assessment of culprit lesion morphology in acute myocardial infarction: ability of optical coherence tomography compared with intravascular ultrasound and coronary angioscopy. J Am Coll Cardiol. 2007;50:933-9. https://doi.org/ 10.1016/j.jacc.2007.04.082.

76. Nijssen EC, Rennenberg RJ, Nelemans PJ, Essers BA, Janssen MM, Vermeeren MA, Ommen VV, Wildberger JE. Prophylactic hydration to protect renal function from intravascular iodinated contrast material in patients at high risk of contrast-induced nephropathy (AMACING): a prospective, randomised, phase 3, controlled, open-label, non-inferiority trial. Lancet (Lond, Engl). 2017;389:1312-22. https://doi.org/10.1016/s0140-6736(17) 30057-0.

77. Jolly SS, James S, Dzavik V, Cairns JA, Mahmoud KD, Zijlstra F, Yusuf S, Olivecrona GK, Renlund H, Gao P, Lagerqvist B, Alazzoni A, Kedev S, Stankovic G, Meeks B, Frobert O. Thrombus aspiration in ST-segment-elevation myocardial infarction: an individual patient meta-analysis: thrombectomy trialists collaboration. Circulation. 2017;135:143-52. https://doi.org/10.1161/ circulationaha.116.025371.

78. Svilaas T, Vlaar PJ, Van Der Horst IC, Diercks GF, De Smet BJ, Van Den Heuvel AF, Anthonio RL, Jessurun GA, Tan ES, Suurmeijer AJ, Zijlstra F. Thrombus aspiration during primary percutaneous coronary intervention. N Engl J Med. 2008;358:557-67. https://doi.org/10.1056/NEJMoa0706416.

79. Burzotta F, De Vita M, Gu YL, Isshiki T, Lefevre T, Kaltoft A, Dudek D, Sardella G, Orrego PS, Antoniucci D, De Luca L, Biondi-Zoccai GG, Crea F, Zijlstra F. Clinical impact of thrombectomy in acute ST-elevation myocardial infarction: an individual patient-data pooled analysis of 11 trials. Eur Heart J. 2009;30:2193-203. https://doi.org/10.1093/eurheartj/ehp348.

80. Ikari Y, Sakurada M, Kozuma K, Kawano S, Katsuki T, Kimura K, Suzuki T, Yamashita T, Takizawa A, Misumi K, Hashimoto H, Isshiki $\mathrm{T}$. Upfront thrombus aspiration in primary coronary intervention for patients with ST-segment elevation acute myocardial infarction: report of the VAMPIRE (VAcuuM asPIration thrombus REmoval) trial. JACC Cardiovasc Interv. 2008;1:424-31. https://doi.org/10.1016/j.jcin.2008.06.004.

81. Nakatani D, Sato H, Sakata Y, Mizuno H, Shimizu M, Suna S, Nanto S, Hirayama A, Ito H, Fujii K, Hori M. Effect of intracoronary thrombectomy on 30-day mortality in patients with acute myocardial infarction. Am J Cardiol. 2007;100:1212-7. https:// doi.org/10.1016/j.amjcard.2007.05.040.

82. Hara H, Nakamura M, Komatsu H, Ikeda N, Shinji H, Makino K, Itaya $\mathrm{H}$, Yamamoto M, Itou N, Tsunoda T, Sugi K. Comparison of the in vitro performance of 6 and 7 French aspiration catheters. EuroIntervention. 2007;2:487-92.

83. Anzai H, Yoneyama S, Tsukagoshi M, Miyake T, Kikuchi T, Sakurada M. Rescue percutaneous thrombectomy system provides better angiographic coronary flow and does not increase the in-hospital cost in patients with acute myocardial infarction. Circ J. 2003;67:768-74.

84. Stone GW, Webb J, Cox DA, Brodie BR, Qureshi M, Kalynych A, Turco M, Schultheiss HP, Dulas D, Rutherford BD, Antoniucci D, Krucoff MW, Gibbons RJ, Jones D, Lansky AJ, Mehran R. Distal microcirculatory protection during percutaneous coronary intervention in acute ST-segment elevation myocardial infarction: a randomized controlled trial. JAMA. 2005;293:106372. https://doi.org/10.1001/jama.293.9.1063.

85. Bavry AA, Kumbhani DJ, Bhatt DL. Role of adjunctive thrombectomy and embolic protection devices in acute myocardial infarction: a comprehensive meta-analysis of randomized trials. Eur Heart J. 2008;29:2989-3001. https://doi.org/10.1093/ eurheartj/ehn421.

86. Isshiki T, Kozuma K, Kyono H, Suzuki N, Yokoyama N, Yamamoto Y. Initial clinical experience with distal embolic protection using "Filtrap", a novel filter device with a self-expandable spiral basket in patients undergoing percutaneous coronary 
intervention. Cardiovasc Interv Ther. 2011;26:12-7. https://doi. org/10.1007/s12928-010-0027-y.

87. Muramatsu T, Kozuma K, Tsukahara R, Ito Y, Fujita N, Suwa S, Koyama S, Saitoh M, Kamiya H, Nakamura M. Comparison of myocardial perfusion by distal protection before and after primary stenting for acute myocardial infarction: angiographic and clinical results of a randomized controlled trial. Catheter Cardiovasc Interv. 2007;70:677-82. https://doi.org/10.1002/ccd. 21190.

88. Stone GW, Maehara A, Muller JE, Rizik DG, Shunk KA, BenYehuda O, Genereux P, Dressler O, Parvataneni R, Madden S, Shah P, Brilakis ES, Kini AS. Plaque characterization to inform the prediction and prevention of periprocedural myocardial infarction during percutaneous coronary intervention: the CANARY trial (coronary assessment by near-infrared of atherosclerotic rupture-prone yellow). JACC Cardiovasc Interv. 2015;8:927-36. https://doi.org/10.1016/j.jcin.2015.01.032.

89. Hibi K, Kozuma K, Maejima N, Sonoda S, Endo T, Tanaka H, Kyono H, Koshida R, Ishihara T, Awata M, KumeT, Tanabe K, Morino Y, Tsukahara K, Ikari Y, Fujii K, Yamasaki M, Yamanaka T, Sumiyoshi T, Yoshino H, KimuraK, Isshiki T; VAMPIRE 3 Investigators. Long-term clinical outcomes after filter protection during percutaneouscoronary intervention in patients with attenuated plaque - 1-year follow up of the VAMPIRE 3 (VacuumAspiration Thrombus Reemoval 3) Trial. Circ J. 2020;85(1):44-49. https://doi.org/10.1253/circj.CJ-20-0449.

90. Baim DS, Wahr D, George B, Leon MB, Greenberg J, Cutlip DE, Kaya U, Popma JJ, Ho KK, Kuntz RE. Randomized trial of a distal embolic protection device during percutaneous intervention of saphenous vein aorto-coronary bypass grafts. Circulation. 2002;105:1285-90.

91. Ishii H, Ichimiya S, Kanashiro M, Amano T, Imai K, Murohara $\mathrm{T}$, Matsubara T. Impact of a single intravenous administration of nicorandil before reperfusion in patients with ST-segmentelevation myocardial infarction. Circulation. 2005;112:1284-8. https://doi.org/10.1161/circulationaha.104.530329.

92. Miyazawa A, Ikari Y, Tanabe K, Nakajima H, Aoki J, Iijima R, Nakayama T, Hatori M, Nakazawa G, Tanimoto S, Onuma Y, Hara K. Intracoronary nicorandil prior to reperfusion in acute myocardial infarction. EuroIntervention. 2006;2:211-7.

93. Kobatake R, Sato T, Fujiwara Y, Sunami H, Yoshioka R, Ikeda T, Saito H, Ujihira T. Comparison of the effects of nitroprusside versus nicorandil on the slow/no-reflow phenomenon during coronary interventions for acute myocardial infarction. Heart Vessels. 2011;26:379-84. https://doi.org/10.1007/ s00380-010-0065-5.

94. Niu X, Zhang J, Bai M, Peng Y, Sun S, Zhang Z. Effect of intracoronary agents on the no-reflow phenomenon during primary percutaneous coronary intervention in patients with ST-elevation myocardial infarction: a network meta-analysis. BMC Cardiovasc Disord. 2018;18:3. https://doi.org/10.1186/ s12872-017-0722-z.

95. Ndrepepa G, Kastrati A. Mechanical strategies to enhance myocardial salvage during primary percutaneous coronary intervention in patients with STEMI. EuroIntervention. 2016;12:319-28. https://doi.org/10.4244/eijv12i3a52.

96. Loubeyre C, Morice MC, Lefevre T, Piechaud JF, Louvard Y, Dumas P. A randomized comparison of direct stenting with conventional stent implantation in selected patients with acute myocardial infarction. J Am Coll Cardiol. 2002;39:15-21.

97. Mockel M, Vollert J, Lansky AJ, Witzenbichler B, Guagliumi G, Peruga JZ, Brodie BR, Kornowski R, Dudek D, Farkouh ME, Parise H, Mehran R, Stone GW. Comparison of direct stenting with conventional stent implantation in acute myocardial infarction. Am J Cardiol. 2011;108:1697-703. https://doi.org/10. 1016/j.amjcard.2011.07.040.
98. Dziewierz A, Siudak Z, Rakowski T, Kleczynski P, Zasada W, Dubiel JS, Dudek D. Impact of direct stenting on outcome of patients with ST-elevation myocardial infarction transferred for primary percutaneous coronary intervention (from the EUROTRANSFER registry). Catheter Cardiovasc Interv. 2014;84:92531. https://doi.org/10.1002/ccd.25266.

99. Barbato E, Marco J, Wijns W. Direct stenting. Eur Heart J. 2003;24:394-403.

100. Mintz GS. Remodeling and restenosis: observations from serial intravascular ultrasound studies. Curr Interv Cardiol Rep. 2000;2:316-25.

101. Ozaki Y, Violaris AG, Hamburger JN, Melkert R, Foley D, Keane D, de Feyter PJ, Serruys PW. Short- and long-term clinical and quantitative angiographic results with the new less shortening Wallstent for vessel reconstruction in chronic total occlusion. J Am Coll Cardiol 1996;28:354-360.

102. De Luca G, Suryapranata H, Stone GW, Antoniucci D, BiondiZoccai G, Kastrati A, Chiariello M, Marino P. Coronary stenting versus balloon angioplasty for acute myocardial infarction: a meta-regression analysis of randomized trials. Int J Cardiol. 2008;126:37-44. https://doi.org/10.1016/j.ijcard.2007.03.112.

103. Suryapranata H, De Luca G, Vant Hof AW, Ottervanger JP, Hoorntje JC, Dambrink JH, Gosselink AT, Zijlstra F, De Boer MJ. Is routine stenting for acute myocardial infarction superior to balloon angioplasty? A randomised comparison in a large cohort of unselected patients. Heart (Br Card Soc). 2005;91:641-5. https:// doi.org/10.1136/hrt.2004.056705.

104. Saito S, Hosokawa G, Tanaka S, Nakamura S. Primary stent implantation is superior to balloon angioplasty in acute myocardial infarction: final results of the primary angioplasty versus stent implantation in acute myocardial infarction (PASTA) trial. PASTA Trial Investigators. Catheter Cardiovasc Interv. 1999;48:262-8.

105. Tsuchihashi M, Tsutsui H, Shihara M, Tada H, Kono S, Takeshita A. Comparison of outcomes for patients undergoing balloon angioplasty vs coronary stenting for acute myocardial infarction. Circ J. 2003;67:369-74.

106. Laarman GJ, Suttorp MJ, Dirksen MT, Van Heerebeek L, Kiemeneij F, Slagboom T, Van Der Wieken LR, Tijssen JG, Rensing BJ, Patterson M. Paclitaxel-eluting versus uncoated stents in primary percutaneous coronary intervention. $\mathrm{N}$ Engl $\mathrm{J}$ Med. 2006;355:1105-13. https://doi.org/10.1056/NEJMoa062598.

107. Kastrati A, Dibra A, Spaulding C, Laarman GJ, Menichelli M, Valgimigli M, Di Lorenzo E, Kaiser C, Tierala I, Mehilli J, Seyfarth M, Varenne O, Dirksen MT, Percoco G, Varricchio A, Pittl U, Syvanne M, Suttorp MJ, Violini R, Schomig A. Meta-analysis of randomized trials on drug-eluting stents vs. bare-metal stents in patients with acute myocardial infarction. Eur Heart J. 2007;28:2706-13. https://doi.org/10.1093/eurheartj/ehm402.

108. De Luca G, Stone GW, Suryapranata H, Laarman GJ, Menichelli M, Kaiser C, Valgimigli M, Di Lorenzo E, Dirksen MT, Spaulding C, Pittl U, Violini R, Percoco G, Marino P. Efficacy and safety of drug-eluting stents in ST-segment elevation myocardial infarction: a meta-analysis of randomized trials. Int J Cardiol. 2009;133:213-22. https://doi.org/10.1016/j.ijcard.2007.12.040.

109. Degertekin M, Serruys PW, Tanabe K, Lee CH, Sousa JE, Colombo A, Morice MC, Ligthart JM, De Feyter PJ. Long-term follow-up of incomplete stent apposition in patients who received sirolimus-eluting stent for de novo coronary lesions: an intravascular ultrasound analysis. Circulation. 2003;108:2747-50. https://doi.org/10.1161/01.cir.0000103666.25660.77.

110. Mcfadden EP, Stabile E, Regar E, Cheneau E, Ong AT, Kinnaird T, Suddath WO, Weissman NJ, Torguson R, Kent KM, Pichard AD, Satler LF, Waksman R, Serruys PW. Late thrombosis in drug-eluting coronary stents after discontinuation of antiplatelet 
therapy. Lancet (Lond, Engl). 2004;364:1519-21. https://doi.org/ 10.1016/s0140-6736(04)17275-9.

111. Nakazawa G, Finn AV, Joner M, Ladich E, Kutys R, Mont EK, Gold HK, Burke AP, Kolodgie FD, Virmani R. Delayed arterial healing and increased late stent thrombosis at culprit sites after drug-eluting stent placement for acute myocardial infarction patients: an autopsy study. Circulation. 2008;118:1138-45. https://doi.org/10.1161/circulationaha.107.762047.

112. Vink MA, Dirksen MT, Suttorp MJ, Tijssen JG, Van Etten J, Patterson MS, Slagboom T, Kiemeneij F, Laarman GJ. 5-year follow-up after primary percutaneous coronary intervention with a paclitaxel-eluting stent versus a bare-metal stent in acute STsegment elevation myocardial infarction: a follow-up study of the PASSION (Paclitaxel-Eluting Versus Conventional Stent in Myocardial Infarction with ST-Segment Elevation) trial. JACC Cardiovasc Interv. 2011;4:24-9. https://doi.org/10.1016/j.jcin. 2010.11.003.

113. Stone SG, Serrao GW, Mehran R, Tomey MI, Witzenbichler B, Guagliumi G, Peruga JZ, Brodie BR, Dudek D, Mockel M, Brener SJ, Dangas G, Stone GW. Incidence, predictors, and implications of reinfarction after primary percutaneous coronary intervention in ST-segment-elevation myocardial infarction: the Harmonizing Outcomes with Revascularization and Stents in Acute Myocardial Infarction Trial. Circ Cardiovasc Interv. 2014;7:543-51. https://doi.org/10.1161/circinterventions.114. 001360 .

114. Gonzalo N, Barlis P, Serruys PW, Garcia-Garcia HM, Onuma Y, Ligthart J, Regar E. Incomplete stent apposition and delayed tissue coverage are more frequent in drug-eluting stents implanted during primary percutaneous coronary intervention for STsegment elevation myocardial infarction than in drug-eluting stents implanted for stable/unstable angina: insights from optical coherence tomography. JACC Cardiovasc Interv. 2009;2:445-52. https://doi.org/10.1016/j.jcin.2009.01.012.

115. Jaffe R, Charron T, Puley G, Dick A, Strauss BH. Microvascular obstruction and the no-reflow phenomenon after percutaneous coronary intervention. Circulation. 2008;117:3152-6. https://doi. org/10.1161/circulationaha.107.742312.

116. Ndrepepa G, Tiroch K, Keta D, Fusaro M, Seyfarth M, Pache J, Mehilli J, Schomig A, Kastrati A. Predictive factors and impact of no reflow after primary percutaneous coronary intervention in patients with acute myocardial infarction. Circ Cardiovasc Interv. 2010;3:27-33. https://doi.org/10.1161/circinterventions. 109.896225 .

117. Harrison RW, Aggarwal A, Ou FS, Klein LW, Rumsfeld JS, Roe MT, Wang TY. Incidence and outcomes of no-reflow phenomenon during percutaneous coronary intervention among patients with acute myocardial infarction. Am J Cardiol. 2013;111:17884. https://doi.org/10.1016/j.amjcard.2012.09.015.

118. Kelbaek H, Engstrom T, Ahtarovski KA, Lonborg J, Vejlstrup N, Pedersen F, Holmvang L, Helqvist S, Saunamaki K, Jorgensen E, Clemmensen P, Klovgaard L, Tilsted HH, Raungaard B, Ravkilde J, Aaroe J, Eggert S, Kober L. Deferred stent implantation in patients with ST-segment elevation myocardial infarction: a pilot study. EuroIntervention. 2013;8:1126-33. https://doi.org/ 10.4244/eijv8i10a175.

119. Carrick D, Oldroyd KG, Mcentegart M, Haig C, Petrie MC, Eteiba H, Hood S, Owens C, Watkins S, Layland J, Lindsay M, Peat E, Rae A, Behan M, Sood A, Hillis WS, Mordi I, Mahrous A, Ahmed N, Wilson R, Lasalle L, Genereux P, Ford I, Berry C. A randomized trial of deferred stenting versus immediate stenting to prevent no- or slow-reflow in acute ST-segment elevation myocardial infarction (DEFER-STEMI). J Am Coll Cardiol. 2014;63:2088-98. https://doi.org/10.1016/j.jacc.2014.02.530.

120. Vos NS, Dirksen MT, Vink MA, Van Nooijen FC, Amoroso G, Herrman JP, Kiemeneij F, Patterson MS, Slagboom T, Van Der
Schaaf RJ. Safety and feasibility of a PAclitaxel-eluting balloon angioplasty in Primary Percutaneous coronary intervention in Amsterdam (PAPPA): one-year clinical outcome of a pilot study. EuroIntervention : journal of EuroPCR in collaboration with the Working Group on Interventional Cardiology of the European Society of Cardiology. 2014;10:584-90. https://doi.org/10.4244/ eijv10i5a101.

121. Vos NS, Fagel ND, Amoroso G, Herrman JR, Patterson MS, Piers LH, Van Der Schaaf RJ, Slagboom T, Vink MA. Paclitaxelcoated balloon angioplasty versus drug-eluting stent in acute myocardial infarction: the REVELATION randomized trial. JACC Cardiovasc Interv. 2019;12:1691-9. https://doi.org/10. 1016/j.jcin.2019.04.016.

122. Kim JS, Lee HJ, Woong YuC, Kim YM, Hong SJ, Park JH, Choi RK, Choi YJ, Park JS, Kim TH, Jang HJ, Joo HJ, Cho SA, Ro YM, Lim DS. INNOVATION study (impact of immediate stent implantation versus deferred stent implantation on infarct size and microvascular perfusion in patients with st-segment-elevation myocardial infarction). Circulation. 2016. https://doi.org/10. 1161/circinterventions.116.004101.

123. Neumann FJ, Sousa-Uva M, Ahlsson A, Alfonso F, Banning AP, Benedetto U, Byrne RA, Collet JP, Falk V, Head SJ, Juni P, Kastrati A, Koller A, Kristensen SD, Niebauer J, Richter DJ, Seferovic PM, Sibbing D, Stefanini GG, Windecker S, Yadav R, Zembala MO, Group ESCSD. 2018 ESC/EACTS guidelines on myocardial revascularization. Eur Heart J. 2019;40:87-165. https://doi.org/10.1093/eurheartj/ehy394.

124. Johnson TW, Räber L, Di Mario C, Bourantas C, Jia H, Mattesini A, Gonzalo N, De La Torre Hernandez JM, Prati F, Koskinas K, Joner M, Radu MD, Erlinge D, Regar E, Kunadian V, Maehara A, Byrne RA, Capodanno D, Akasaka T, Wijns W, Mintz GS, Guagliumi G. Clinical use of intracoronary imaging. Part 2: acute coronary syndromes, ambiguous coronary angiography findings, and guiding interventional decision-making: an expert consensus document of the European Association of Percutaneous Cardiovascular Interventions. Eur Heart J. 2019;40:2566-84. https:// doi.org/10.1093/eurheartj/ehz332.

125. De Feyter PJ, Ozaki Y, Baptista J, Escaned J, Di Mario C, De Jaegere PP, Serruys PW, Roelandt JR. Ischemia-related lesion characteristics in patients with stable or unstable angina. A study with intracoronary angioscopy and ultrasound. Circulation. 1995;92:1408-13.

126. Prati F, Uemura S, Souteyrand G, Virmani R, Motreff P, Di Vito L, Biondi-Zoccai G, Halperin J, Fuster V, Ozaki Y, Narula J. OCT-based diagnosis and management of STEMI associated with intact fibrous cap. JACC Cardiovasc Imaging. 2013;6:2837. https://doi.org/10.1016/j.jcmg.2012.12.007.

127. Jia H, Dai J, Hou J, Xing L, Ma L, Liu H, Xu M, Yao Y, Hu S, Yamamoto E, Lee H, Zhang S, Yu B, Jang IK. Effective anti-thrombotic therapy without stenting: intravascular optical coherence tomography-based management in plaque erosion (the EROSION study). Eur Heart J. 2017;38:792-800. https://doi.org/ 10.1093/eurheartj/ehw381.

128. Prati F, Romagnoli E, Gatto L, La Manna A, Burzotta F, Ozaki Y, Marco V, Boi A, Fineschi M, Fabbiocchi F, Taglieri N, Niccoli G, Trani C, Versaci F, Calligaris G, Ruscica G, Di Giorgio A, Vergallo R, Albertucci M, Biondi-Zoccai G, Tamburino C, Crea F, Alfonso F, Arbustini E. Relationship between coronary plaque morphology of the left anterior descending artery and 12 months clinical outcome: the CLIMA study. Eur Heart J. 2020;41:383-91. https://doi.org/10.1093/eurheartj/ehz520.

129. Madder RD, Goldstein JA, Madden SP, Puri R, Wolski K, Hendricks M, Sum ST, Kini A, Sharma S, Rizik D, Brilakis ES, Shunk KA, Petersen J, Weisz G, Virmani R, Nicholls SJ, Maehara A, Mintz GS, Stone GW, Muller JE. Detection by nearinfrared spectroscopy of large lipid core plaques at culprit sites 
in patients with acute ST-segment elevation myocardial infarction. JACC Cardiovasc Interv. 2013;6:838-46. https://doi.org/10. 1016/j.jcin.2013.04.012.

130. Madder RD, Puri R, Muller JE, Harnek J, Gotberg M, Vanoosterhout S, Chi M, Wohns D, Mcnamara R, Wolski K, Madden S, Sidharta S, Andrews J, Nicholls SJ, Erlinge D. Confirmation of the Intracoronary Near-Infrared Spectroscopy Threshold of Lipid-Rich Plaques That Underlie ST-Segment-Elevation Myocardial Infarction. Arterioscler Thromb Vasc Biol. 2016;36:1010-5. https://doi.org/10.1161/ATVBAHA.115. 306849 .

131. Madder RD, Husaini M, Davis AT, Van Oosterhout S, Harnek J, Gotberg M, Erlinge D. Detection by near-infrared spectroscopy of large lipid cores at culprit sites in patients with non-st-segment elevation myocardial infarction and unstable angina. Catheter Cardiovasc Interv. 2014. https://doi.org/10.1002/ccd.25754.

132. Kini AS, Motoyama S, Vengrenyuk Y, Feig JE, Pena J, Baber U, Bhat AM, Moreno P, Kovacic JC, Narula J, Sharma SK. Multimodality intravascular imaging to predict periprocedural myocardial infarction during percutaneous coronary intervention. JACC Cardiovasc Interv. 2015;8:937-45. https://doi.org/10.1016/j.jcin. 2015.03.016

133. Ozaki Y, Ohota M, Ismail TF, Okumura M, Ishikawa M, Muramatsu T. Thin cap fibroatheroma defined as lipid core abutting lumen (LCAL) on integrated backscatter intravascular ultrasound - comparison with optical coherence tomography and correlation with peri-procedural myocardial infarction. Circ J. 2015;79:80817. https://doi.org/10.1253/circj.CJ-14-0758.

134. Prati F, Romagnoli E, Burzotta F, Limbruno U, Gatto L, La Manna A, Versaci F, Marco V, Di Vito L, Imola F, Paoletti G, Trani C, Tamburino C, Tavazzi L, Mintz GS. Clinical Impact of OCT Findings During PCI: The CLI-OPCI II Study. JACC Cardiovasc Imaging. 2015;8:1297-305. https://doi.org/10.1016/j. jcmg.2015.08.013.

135. Prati F, Romagnoli E, Gatto L, La Manna A, Burzotta F, Limbruno U, Versaci F, Fabbiocchi F, Di Giorgio A, Marco V, Ramazzotti V, Di Vito L, Trani C, Porto I, Boi A, Tavazzi L, Mintz GS. Clinical impact of suboptimal stenting and residual intrastent plaque/thrombus protrusion in patients with acute coronary syndrome: the CLI-OPCI ACS substudy (centro per la lotta contro l'infarto-optimization of percutaneous coronary intervention in acute coronary syndrome). Circ Cardiovasc Interv. 2016. https://doi.org/10.1161/circinterventions.115.003726.

136. Palmerini T, Biondi-Zoccai G, Della Riva D, Mariani A, Sabate M, Valgimigli M, Frati G, Kedhi E, Smits PC, Kaiser C, Genereux P, Galatius S, Kirtane AJ, Stone GW. Clinical outcomes with drug-eluting and bare-metal stents in patients with ST-segment elevation myocardial infarction: evidence from a comprehensive network meta-analysis. J Am Coll Cardiol. 2013;62:496-504. https://doi.org/10.1016/j.jacc.2013.05.022.

137. Philip F, Stewart S, Southard JA. Very late stent thrombosis with second generation drug eluting stents compared to bare metal stents: Network meta-analysis of randomized primary percutaneous coronary intervention trials. Catheter Cardiovasc Interv. 2016;88:38-48. https://doi.org/10.1002/ccd.26458.

138. Chichareon P, Modolo R, Collet C, Tenekecioglu E, Vink MA, Oh PC, Ahn JM, Musto C, Díaz De La Llera LS, Cho YS, Violini R, Park SJ, Suryapranata H, Piek JJ, De Winter RJ, Wykrzykowska JJ, Spaulding C, Kang WC, Slagboom T, Hofma SH, Wijnbergen IF, Di Lorenzo E, Pijls NH, Räber L, Brugaletta S, Sabaté M, Stoll HP, Stone GW, Windecker S, Onuma Y, Serruys PW. Efficacy and safety of stents in st-segment elevation myocardial infarction. J Am Coll Cardiol. 2019;74:2572-84. https:// doi.org/10.1016/j.jacc.2019.09.038.

139. Brugaletta S, Gomez-Lara J, Ortega-Paz L, Jimenez-Diaz V, Jimenez M, Jiménez-Quevedo P, Diletti R, Mainar V, Campo G,
Silvestro A, Maristany J, Flores X, Oyarzabal L, De Miguel-Castro A, Iñiguez A, Serra A, Nombela-Franco L, Ielasi A, Tespili M, Lenzen M, Gonzalo N, Bordes P, Tebaldi M, Biscaglia S, Rodriguez-Arias JJ, Al-Shaibani S, Arevalos V, Romaguera R, Gomez-Hospital JA, Serruys PW, Sabaté M. 10-year follow-up of patients with everolimus-eluting versus bare-metal stents after st-segment elevation myocardial infarction. J Am Coll Cardiol. 2021;77:1165-78. https://doi.org/10.1016/j.jacc.2020.12.059.

140. Iglesias JF, Muller O, Heg D, Roffi M, Kurz DJ, Moarof I, Weilenmann D, Kaiser C, Tapponnier M, Stortecky S, Losdat S, Eeckhout E, Valgimigli M, Odutayo A, Zwahlen M, Jüni $\mathrm{P}$, Windecker S, Pilgrim T. Biodegradable polymer sirolimuseluting stents versus durable polymer everolimus-eluting stents in patients with ST-segment elevation myocardial infarction (BIOSTEMI): a single-blind, prospective, randomised superiority trial. Lancet. 2019;394:1243-53. https://doi.org/10.1016/ s0140-6736(19)31877-x.

141. Naber CK, Urban P, Ong PJ, Valdes-Chavarri M, Abizaid AA, Pocock SJ, Fabbiocchi F, Dubois C, Copt S, Greene S, Morice MC. Biolimus-A9 polymer-free coated stent in high bleeding risk patients with acute coronary syndrome: a Leaders Free ACS sub-study. Eur Heart J. 2017;38:961-9. https://doi.org/10.1093/ eurheartj/ehw203.

142. Sawada T, Shinke T, Otake H, Mizoguchi T, Iwasaki M, Emoto T, Terashita D, Mizuguchi T, Okamoto H, Matsuo Y, Kim SK, Takarada A, Yokoyama M. Comparisons of detailed arterial healing response at seven months following implantation of an everolimus- or sirolimus-eluting stent in patients with ST-segment elevation myocardial infarction. Int J Cardiol. 2013;168:960-6. https://doi.org/10.1016/j.ijcard.2012.10.043.

143. Raber L, Mintz GS, Koskinas KC, Johnson TW, Holm NR, Onuma Y, Radu MD, Joner M, Yu B, Jia H, Meneveau N, De La Torre Hernandez JM, Escaned J, Hill J, Prati F, Colombo A, Di Mario C, Regar E, Capodanno D, Wijns W, Byrne RA, Guagliumi G, Group ESCSD. Clinical use of intracoronary imaging. Part 1: guidance and optimization of coronary interventions. An expert consensus document of the European Association of Percutaneous Cardiovascular Interventions. Eur Heart J. 2018;39:3281-300. https://doi.org/10.1093/eurheartj/ehy285.

144. Zhang J, Gao X, Kan J, Ge Z, Han L, Lu S, Tian N, Lin S, Lu Q, Wu X, Li Q, Liu Z, Chen Y, Qian X, Wang J, Chai D, Chen C, Li X, Gogas BD, Pan T, Shan S, Ye F, Chen SL. Intravascular ultrasound versus angiography-guided drug-eluting stent implantation: the ULTIMATE trial. J Am Coll Cardiol. 2018;72:3126-37. https://doi.org/10.1016/j.jacc.2018.09.013.

145. Hong SJ, Kim BK, Shin DH, Nam CM, Kim JS, Ko YG, Choi D, Kang TS, Kang WC, Her AY, Kim YH, Hur SH, Hong BK, Kwon $\mathrm{H}$, Jang Y, Hong MK. Effect of intravascular ultrasound-guided vs angiography-guided everolimus-eluting stent implantation: the IVUS-XPL randomized clinical trial. JAMA. 2015;314:2155-63. https://doi.org/10.1001/jama.2015.15454.

146. Hong SJ, Mintz GS, Ahn CM, Kim JS, Kim BK, Ko YG, Kang TS, Kang WC, Kim YH, Hur SH, Hong BK, Choi D, Kwon $\mathrm{H}$, Jang Y, Hong MK. Effect of intravascular ultrasound-guided drug-eluting stent implantation: 5-year follow-up of the IVUSXPL randomized trial. JACC Cardiovasc Interv. 2020;13:62-71. https://doi.org/10.1016/j.jcin.2019.09.033.

147. Zhang Y, Farooq V, Garcia-Garcia HM, Bourantas CV, Tian N, Dong S, Li M, Yang S, Serruys PW, Chen SL. Comparison of intravascular ultrasound versus angiography-guided drug-eluting stent implantation: a meta-analysis of one randomised trial and ten observational studies involving 19,619 patients. EuroIntervention. 2012;8:855-65. https://doi.org/10.4244/eijv8i7a129.

148. Ali ZA, Maehara A, Genereux P, Shlofmitz RA, Fabbiocchi F, Nazif TM, Guagliumi G, Meraj PM, Alfonso F, Samady H, Akasaka T, Carlson EB, Leesar MA, Matsumura M, Ozan MO, Mintz 
GS, Ben-Yehuda O, Stone GW. Optical coherence tomography compared with intravascular ultrasound and with angiography to guide coronary stent implantation (ILUMIEN III: OPTIMIZE PCI): a randomised controlled trial. Lancet (Lond, Engl). 2016;388:2618-28. https://doi.org/10.1016/s0140-6736(16) 31922-5.

149. Kubo T, Shinke T, Okamura T, Hibi K, Nakazawa G, Morino Y, Shite J, Fusazaki T, Otake H, Kozuma K, Ioji T, Kaneda H, Serikawa T, Kataoka T, Okada H, Akasaka T. Optical frequency domain imaging vs. intravascular ultrasound in percutaneous coronary intervention (OPINION trial): one-year angiographic and clinical results. Eur Heart J. 2017;38:3139-47. https://doi. org/10.1093/eurheartj/ehx351.

150. Radu MD, Raber L, Heo J, Gogas BD, Jorgensen E, Kelbaek H, Muramatsu T, Farooq V, Helqvist S, Garcia-Garcia HM, Windecker S, Saunamaki K, Serruys PW. Natural history of optical coherence tomography-detected non-flow-limiting edge dissections following drug-eluting stent implantation. EuroIntervention. 2014;9:1085-94. https://doi.org/10.4244/eijv9i9a183.

151. De Cock D, Bennett J, Ughi GJ, Dubois C, Sinnaeve P, Dhooge J, Desmet W, Belmans A, Adriaenssens T. Healing course of acute vessel wall injury after drug-eluting stent implantation assessed by optical coherence tomography. Eur Heart J Cardiovasc Imaging. 2014;15:800-9. https://doi.org/10.1093/ehjci/jeu003.

152. Bouki KP, Sakkali E, Toutouzas K, Vlad D, Barmperis D, Phychari S, Riga M, Apostolou T, Stefanadis C. Impact of coronary artery stent edge dissections on long-term clinical outcome in patients with acute coronary syndrome: an optical coherence tomography study. Catheter Cardiovasc Interv. 2015;86:237-46. https://doi.org/10.1002/ccd.25855.

153. Chamie D, Bezerra HG, Attizzani GF, Yamamoto H, Kanaya T, Stefano GT, Fujino Y, Mehanna E, Wang W, Abdul-Aziz A, Dias M, Simon DI, Costa MA. Incidence, predictors, morphological characteristics, and clinical outcomes of stent edge dissections detected by optical coherence tomography. JACC Cardiovasc Interv. 2013;6:800-13. https://doi.org/10.1016/j.jcin.2013.03. 019.

154. Kawamori H, Shite J, Shinke T, Otake H, Matsumoto D, Nakagawa M, Nagoshi R, Kozuki A, Hariki H, Inoue T, Osue T, Taniguchi Y, Nishio R, Hiranuma N, Hirata K. Natural consequence of post-intervention stent malapposition, thrombus, tissue prolapse, and dissection assessed by optical coherence tomography at mid-term follow-up. Eur Heart J Cardiovasc Imaging. 2013;14:865-75. https://doi.org/10.1093/ehjci/jes299.

155. Taniwaki M, Radu MD, Zaugg S, Amabile N, Garcia-Garcia HM, Yamaji K, Jorgensen E, Kelbaek H, Pilgrim T, Caussin C, Zanchin T, Veugeois A, Abildgaard U, Juni P, Cook S, Koskinas KC, Windecker S, Raber L. Mechanisms of very late drug-eluting stent thrombosis assessed by optical coherence tomography. Circulation. 2016;133:650-60. https://doi. org/10.1161/circulationaha.115.019071.

156. Steinberg DH, Mintz GS, Mandinov L, Yu A, Ellis SG, Grube E, Dawkins KD, Ormiston J, Turco MA, Stone GW, Weissman NJ. Long-term impact of routinely detected early and late incomplete stent apposition: an integrated intravascular ultrasound analysis of the TAXUS IV, V, and VI and TAXUS ATLAS workhorse, long lesion, and direct stent studies. JACC Cardiovasc Interv. 2010;3:486-94. https://doi.org/10.1016/j. jcin.2010.03.007.

157. Guo N, Maehara A, Mintz GS, He Y, Xu K, Wu X, Lansky AJ, Witzenbichler B, Guagliumi G, Brodie B, Kellett MA Jr, Dressler $\mathrm{O}$, Parise H, Mehran R, Stone GW. Incidence, mechanisms, predictors, and clinical impact of acute and late stent malapposition after primary intervention in patients with acute myocardial infarction: an intravascular ultrasound substudy of the Harmonizing Outcomes with Revascularization and Stents in Acute
Myocardial Infarction (HORIZONS-AMI) trial. Circulation. 2010;122:1077-84. https://doi.org/10.1161/circulationaha.109. 906040 .

158. Romagnoli E, Gatto L, La Manna A, Burzotta F, Taglieri N, Saia F, Amico F, Marco V, Ramazzotti V, Di Giorgio A, Di Vito L, Boi A, Contarini M, Castriota F, Mintz GS, Prati F. Role of residual acute stent malapposition in percutaneous coronary interventions. Catheter Cardiovasc Interv. 2017. https://doi.org/ 10.1002/ccd.26974.

159. Ozaki Y, Okumura M, Ismail TF, Naruse H, Hattori K, Kan S, Ishikawa M, Kawai T, Takagi Y, Ishii J, Prati F, Serruys PW. The fate of incomplete stent apposition with drug-eluting stents: an optical coherence tomography-based natural history study. Eur Heart J. 2010;31:1470-6. https://doi.org/10.1093/eurheartj/ ehq066.

160. Thiele H, Zeymer U, Neumann FJ, Ferenc M, Olbrich HG, Hausleiter J, Richardt G, Hennersdorf M, Empen K, Fuernau G, Desch S, Eitel I, Hambrecht R, Fuhrmann J, Bohm M, Ebelt H, Schneider S, Schuler G, Werdan K. Intraaortic balloon support for myocardial infarction with cardiogenic shock. N Engl J Med. 2012;367:1287-96. https://doi.org/10.1056/NEJMoa1208410.

161. Thiele H, Zeymer U, Neumann FJ, Ferenc M, Olbrich HG, Hausleiter J, De Waha A, Richardt G, Hennersdorf M, Empen K, Fuernau G, Desch S, Eitel I, Hambrecht R, Lauer B, Bohm M, Ebelt H, Schneider S, Werdan K, Schuler G. Intra-aortic balloon counterpulsation in acute myocardial infarction complicated by cardiogenic shock (IABP-SHOCK II): final 12 month results of a randomised, open-label trial. Lancet (Lond, Engl). 2013;382:1638-45. https://doi.org/10.1016/s0140-6736(13) 61783-3.

162. Patel MR, Smalling RW, Thiele H, Barnhart HX, Zhou Y, Chandra P, Chew D, Cohen M, French J, Perera D, Ohman EM. Intraaortic balloon counterpulsation and infarct size in patients with acute anterior myocardial infarction without shock: the CRISP AMI randomized trial. JAMA. 2011;306:1329-37. https://doi. org/10.1001/jama.2011.1280.

163. Cheng JM, Den Uil CA, Hoeks SE, Van Der Ent M, Jewbali LS, Van Domburg RT, Serruys PW. Percutaneous left ventricular assist devices vs. intra-aortic balloon pump counterpulsation for treatment of cardiogenic shock: a meta-analysis of controlled trials. Eur Heart J. 2009;30:2102-8. https://doi.org/10.1093/eurhe $\operatorname{artj} / \mathrm{ehp} 292$.

164. Ouweneel DM, Eriksen E, Sjauw KD, Van Dongen IM, Hirsch A, Packer EJ, Vis MM, Wykrzykowska JJ, Koch KT, Baan J, De Winter RJ, Piek JJ, Lagrand WK, De Mol BA, Tijssen JG, Henriques JP. Percutaneous mechanical circulatory support versus intra-aortic balloon pump in cardiogenic shock after acute myocardial infarction. J Am Coll Cardiol. 2017;69:278-87. https:// doi.org/10.1016/j.jacc.2016.10.022.

165. Starling RC, Naka Y, Boyle AJ, Gonzalez-Stawinski G, John R, Jorde U, Russell SD, Conte JV, Aaronson KD, Mcgee EC Jr, Cotts WG, Denofrio D, Pham DT, Farrar DJ, Pagani FD. Results of the post-U.S. Food and Drug Administration-approval study with a continuous flow left ventricular assist device as a bridge to heart transplantation: a prospective study using the INTERMACS (Interagency Registry for Mechanically Assisted Circulatory Support). J Am Coll Cardiol. 2011;57:1890-8. https://doi. org/10.1016/j.jacc.2010.10.062.

166. Sheu JJ, Tsai TH, Lee FY, Fang HY, Sun CK, Leu S, Yang CH, Chen SM, Hang CL, Hsieh YK, Chen CJ, Wu CJ, Yip HK. Early extracorporeal membrane oxygenator-assisted primary percutaneous coronary intervention improved 30-day clinical outcomes in patients with ST-segment elevation myocardial infarction complicated with profound cardiogenic shock. Crit Care Med. 2010;38:1810-7. https://doi.org/10.1097/CCM.0b013e3181 e8acf7. 
167. Atkinson TM, Ohman EM, Oneill WW, Rab T, Cigarroa JE. A practical approach to mechanical circulatory support in patients undergoing percutaneous coronary intervention: an interventional perspective. JACC Cardiovasc Interv. 2016;9:871-83. https://doi.org/10.1016/j.jcin.2016.02.046.

168. Aso S, Matsui H, Fushimi K, Yasunaga H. The effect of intraaortic balloon pumping under venoarterial extracorporeal membrane oxygenation on mortality of cardiogenic patients: an analysis using a nationwide inpatient database. Crit Care Med. 2016;44:1974-9. https://doi.org/10.1097/ccm.0000000000 001828 .

169. Cubeddu RJ, Lago R, Horvath SA, Vignola PA, Oneill W, Palacios IF. Use of the Impella 2.5 system alone, after and in combination with an intra-aortic balloon pump in patients with cardiogenic shock: case description and review of the literature. EuroIntervention. 2012;7:1453-60. https://doi.org/10.4244/eijv7 i12a226.

170. Wiktor DM, Sawlani N, Kanthi Y, Sipahi I, Fang JC, Blitz A. Successful combined use of Impella Recover 2.5 device and intra-aortic balloon pump support in cardiogenic shock from acute myocardial infarction. ASAIO J. 2010;56:519-21. https:// doi.org/10.1097/MAT.0b013e3181f7478e.

171. Burzotta F, Trani C, Doshi SN, Townend J, Van Geuns RJ, Hunziker P, Schieffer B, Karatolios K, Moller JE, Ribichini FL, Schafer A, Henriques JP. Impella ventricular support in clinical practice: collaborative viewpoint from a European expert user group. Int J Cardiol. 2015;201:684-91. https://doi.org/10.1016/j. ijcard.2015.07.065.

172. Kimura K, Kimura T, Ishihara M, Nakagawa Y, Nakao K, Miyauchi K, Sakamoto T, Tsujita K, Hagiwara N, Miyazaki S, Ako J, Arai H, Ishii H, Origuchi H, Shimizu W, Takemura H, Tahara Y, Morino Y, Ino K, Itoh T, Iwanaga Y, Uchida K, Endo H, Kongoji K, Sakamoto K, Shiomi H, Shimohama T, Suzuki A, Takahashi J, Takeuchi I, Tanaka A, Tamura T, Nakashima T, Noguchi T, Fukamachi D, Mizuno T, Yamaguchi J, Yodogawa K, Kosuge M, Kohsaka S, Yoshino H, Yasuda S, Shimokawa H, Hirayama A, Akasaka T, Haze K, Ogawa H, Tsutsui H, Yamazaki T. JCS 2018 guideline on diagnosis and treatment of acute coronary syndrome. Circ J. 2019;83:1085-196. https://doi.org/10. 1253/circj.CJ-19-0133.

173. Costa F, Van Klaveren D, James S, Heg D, Raber L, Feres F, Pilgrim T, Hong MK, Kim HS, Colombo A, Steg PG, Zanchin T, Palmerini T, Wallentin L, Bhatt DL, Stone GW, Windecker S, Steyerberg EW, Valgimigli M. Derivation and validation of the predicting bleeding complications in patients undergoing stent implantation and subsequent dual antiplatelet therapy (PRECISE-DAPT) score: a pooled analysis of individualpatient datasets from clinical trials. Lancet (Lond, Engl). 2017;389:1025-34. https://doi.org/10.1016/s0140-6736(17) 30397-5.

174. Valgimigli M, Bueno H, Byrne RA, Collet JP, Costa F, Jeppsson A, Juni P, Kastrati A, Kolh P, Mauri L, Montalescot G, Neumann FJ, Petricevic M, Roffi M, Steg PG, Windecker S, Zamorano JL, Levine GN. ESC focused update on dual antiplatelet therapy in coronary artery disease developed in collaboration with EACTS: the Task Force for dual antiplatelet therapy in coronary artery disease of the European Society of Cardiology (ESC) and of the European Association for Cardio-Thoracic Surgery (EACTS). Eur Heart J. 2017. https://doi.org/10.1093/eurheartj/ehx419.

175. Yoshikawa Y, Shiomi H, Watanabe H, Natsuaki M, Kondo H, Tamura T, Nakagawa Y, Morimoto T, Kimura T. Validating utility of dual antiplatelet therapy score in a large pooled cohort from 3 japanese percutaneous coronary intervention studies. Circulation. 2018;137:551-62. https://doi.org/10.1161/circulatio naha.117.028924.
176. Vranckx P, Valgimigli M, Juni P, Hamm C, Steg PG, Heg D, Van Es GA, Mcfadden EP, Onuma Y, Van Meijeren C, Chichareon P, Benit E, Mollmann H, Janssens L, Ferrario M, Moschovitis A, Zurakowski A, Dominici M, Van Geuns RJ, Huber K, Slagboom T, Serruys PW, Windecker S, Investigators GL. Ticagrelor plus aspirin for 1 month, followed by ticagrelor monotherapy for 23 months vs aspirin plus clopidogrel or ticagrelor for 12 months, followed by aspirin monotherapy for 12 months after implantation of a drug-eluting stent: a multicentre, open-label, randomised superiority trial. Lancet. 2018;392:940-9. https:// doi.org/10.1016/S0140-6736(18)31858-0.

177. Tomaniak M, Chichareon P, Onuma Y, Deliargyris EN, Takahashi K, Kogame N, Modolo R, Chang CC, Rademaker-Havinga T, Storey RF, Dangas GD, Bhatt DL, Angiolillo DJ, Hamm C, Valgimigli M, Windecker S, Steg PG, Vranckx P, Serruys PW. Benefit and risks of aspirin in addition to ticagrelor in acute coronary syndromes: a Post Hoc analysis of the randomized GLOBAL LEADERS trial. JAMA Cardiol. 2019. https://doi. org/10.1001/jamacardio.2019.3355.

178. Hahn JY, Song YB, Oh JH, Chun WJ, Park YH, Jang WJ, Im ES, Jeong JO, Cho BR, Oh SK, Yun KH, Cho DK, Lee JY, Koh YY, Bae JW, Choi JW, Lee WS, Yoon HJ, Lee SU, Cho JH, Choi WG, Rha SW, Lee JM, Park TK, Yang JH, Choi JH, Choi SH, Lee SH, Gwon HC, Investigators S-C. Effect of P2Y12 inhibitor monotherapy vs dual antiplatelet therapy on cardiovascular events in patients undergoing percutaneous coronary intervention: the SMART-CHOICE randomized clinical trial. JAMA. 2019;321:2428-37. https://doi.org/10.1001/jama.2019.8146.

179. Mehran R, Baber U, Sharma SK, Cohen DJ, Angiolillo DJ, Briguori C, Cha JY, Collier T, Dangas G, Dudek D, Dzavik V, Escaned J, Gil R, Gurbel P, Hamm CW, Henry T, Huber K, Kastrati A, Kaul U, Kornowski R, Krucoff M, Kunadian V, Marx SO, Mehta SR, Moliterno D, Ohman EM, Oldroyd K, Sardella G, Sartori S, Shlofmitz R, Steg PG, Weisz G, Witzenbichler B, Han YL, Pocock S, Gibson CM. Ticagrelor with or without aspirin in high-risk patients after PCI. N Engl J Med. 2019;381:2032-42. https://doi.org/10.1056/NEJMoa1908419.

180. Baber U, Dangas G, Angiolillo DJ, Cohen DJ, Sharma SK, Nicolas J, Briguori C, Cha JY, Collier T, Dudek D, Džavik V, Escaned J, Gil R, Gurbel P, Hamm CW, Henry T, Huber K, Kastrati A, Kaul U, Kornowski R, Krucoff M, Kunadian V, Marx SO, Mehta S, Moliterno D, Ohman EM, Oldroyd K, Sardella G, Sartori S, Shlofmitz R, Steg PG, Weisz G, Witzenbichler B, Han YL, Pocock S, Gibson CM, Mehran R. Ticagrelor alone vs. ticagrelor plus aspirin following percutaneous coronary intervention in patients with non-ST-segment elevation acute coronary syndromes: TWILIGHT-ACS. Eur Heart J. 2020;41:3533-45. https://doi.org/10.1093/eurheartj/ehaa670.

181. Kim BK, Hong SJ, Cho YH, Yun KH, Kim YH, Suh Y, Cho JY, Her AY, Cho S, Jeon DW, Yoo SY, Cho DK, Hong BK, Kwon H, Ahn CM, Shin DH, Nam CM, Kim JS, Ko YG, Choi D, Hong MK, Jang Y. Effect of ticagrelor monotherapy vs ticagrelor with aspirin on major bleeding and cardiovascular events in patients with acute coronary syndrome: the TICO randomized clinical trial. JAMA. 2020;323:2407-16. https://doi.org/10.1001/jama. 2020.7580 .

182. Lee SJ, Cho JY, Kim BK, Yun KH, Suh Y, Cho YH, Kim YH, Her AY, Cho S, Jeon DW, Yoo SY, Cho DK, Hong BK, Kwon HM, Hong SJ, Ahn CM, Shin DH, Nam CM, Kim JS, Ko YG, Choi D, Hong MK, Jang Y. Ticagrelor monotherapy versus ticagrelor with aspirin in patients with ST-segment elevation myocardial infarction. JACC Cardiovasc Interv. 2021;14:431-40. https://doi.org/10.1016/j.jcin.2020.11.036.

183. Valgimigli M, Frigoli E, Heg D, Tijssen J, Juni P, Vranckx P, Ozaki Y, Morice MC, Chevalier B, Onuma Y, Windecker S, Pal T, Roffi M, Lesiak M, Mahfoud F, Bartunek J, Hildick-Smith D, 
Colombo A, Stankovic G, Iniguez A, Schultz C, Kornowski R, Ong PJL, Alasnag M, Rodriguez AE, Moschovitis A, Laanmets P, Donahue M, Leonardi S, Smits PC, Investigators MD. Dual antiplatelet therapy after PCI in patients at high bleeding risk. N Engl J Med. 2021. https://doi.org/10.1056/NEJMoa2108749.

184. Smits PC, Frigoli E, Tijssen J, Jüni P, Vranckx P, Ozaki Y, Morice MC, Chevalier B, Onuma Y, Windecker S, PaL T, Roffi M, Lesiak M, Mahfoud F, Bartunek J, Hildick-Smith D, Colombo A, Stankovic G, Iñiguez A, Schultz C, Kornowski R, Ong PJL, Alasnag M, Rodriguez AE, Moschovitis A, Laanmets P, Heg D, Valgimigli M. Abbreviated antiplatelet therapy in patients at high bleeding risk with or without oral anticoagulant therapy after coronary stenting: an open-label, randomized, controlled trial. Circulation. 2021. https://doi.org/10.1161/circulationaha. 121.056680 .

185. Cryer B, Bhatt DL, Lanza FL, Dong JF, Lichtenberger LM, Marathi UK. Low-dose aspirin-induced ulceration is attenuated by aspirin-phosphatidylcholine: a randomized clinical trial. Am J Gastroenterol. 2011;106:272-7. https://doi.org/10.1038/ajg. 2010.436

186. Uchiyama S, Goto S, Origasa H, Uemura N, Sugano K, Hiraishi H, Shimada K, Okada Y, Ikeda Y. Major cardiovascular and bleeding events with long-term use of aspirin in patients with prior cardiovascular diseases: 1-year follow-up results from the Management of Aspirin-induced Gastrointestinal Complications (MAGIC) study. Heart Vessels. 2020;35:170-6. https://doi.org/ 10.1007/s00380-019-01484-0.

187. Uemura N, Sugano K, Hiraishi H, Shimada K, Goto S, Uchiyama S, Okada Y, Origasa H, Ikeda Y. Risk factor profiles, drug usage, and prevalence of aspirin-associated gastroduodenal injuries among high-risk cardiovascular Japanese patients: the results from the MAGIC study. J Gastroenterol. 2014;49:814-24. https:// doi.org/10.1007/s00535-013-0839-5.

188. Watanabe H, Domei T, Morimoto T, Natsuaki M, Shiomi H, Toyota T, Ohya M, Suwa S, Takagi K, Nanasato M, Hata Y, Yagi M, Suematsu N, Yokomatsu T, Takamisawa I, Doi M, Noda T, Okayama H, Seino Y, Tada T, Sakamoto H, Hibi K, Abe M, Kawai K, Nakao K, Ando K, Tanabe K, Ikari Y, Hanaoka KI, Morino Y, Kozuma K, Kadota K, Furukawa Y, Nakagawa Y, Kimura T, Investigators S-C. Effect of 1-month dual antiplatelet therapy followed by clopidogrel vs 12-month dual antiplatelet therapy on cardiovascular and bleeding events in patients receiving pci: the stopdapt-2 randomized clinical trial. JAMA. 2019;321:2414-27. https://doi.org/10.1001/jama.2019.8145.

189. Kogame N, Guimaraes PO, Modolo R, De Martino F, Tinoco J, Ribeiro EE, Kawashima H, Ono M, Hara H, Wang R, Cavalcante R, Moulin B, BaA F, Leite RS, De Almeida Sampaio FB, Morais GR, Meireles GC, Campos CM, Onuma Y, Serruys PW, Lemos PA. Aspirin-free prasugrel monotherapy following coronary artery stenting in patients with stable CAD: the ASET Pilot Study. JACC Cardiovasc Interv. 2020;13:2251-62. https://doi.org/10.1016/j.jcin.2020.06.023.

190. Rubboli A, Valgimigli M, Capodanno D, Lip GYH. Choices in antithrombotic management for patients with atrial fibrillation undergoing percutaneous coronary intervention: questions (and answers) in chronological sequence. Eur Heart J Cardiovasc Pharmacother. 2021;7:68-73. https://doi.org/10.1093/ehjcvp/ pvaa047.

191. Dewilde WJ, Oirbans T, Verheugt FW, Kelder JC, De Smet BJ, Herrman JP, Adriaenssens T, Vrolix M, Heestermans AA, Vis MM, Tijsen JG, Vant Hof AW, Ten Berg JM. Use of clopidogrel with or without aspirin in patients taking oral anticoagulant therapy and undergoing percutaneous coronary intervention: an open-label, randomised, controlled trial. Lancet. 2013;381:1107-15. https://doi.org/10.1016/s0140-6736(12) 62177-1.
192. Gibson CM, Mehran R, Bode C, Halperin J, Verheugt FW, Wildgoose P, Birmingham M, Ianus J, Burton P, Van Eickels M, Korjian S, Daaboul Y, Lip GY, Cohen M, Husted S, Peterson ED, Fox KA. Prevention of Bleeding in Patients with Atrial Fibrillation Undergoing PCI. N Engl J Med. 2016;375:2423-34. https:// doi.org/10.1056/NEJMoa1611594.

193. Cannon CP, Bhatt DL, Oldgren J, Lip GYH, Ellis SG, Kimura T, Maeng M, Merkely B, Zeymer U, Gropper S, Nordaby M, Kleine E, Harper R, Manassie J, Januzzi JL, Ten Berg JM, Steg PG, Hohnloser SH, Committee R-DPS, Investigators. Dual antithrombotic therapy with dabigatran after PCI in atrial fibrillation. N Engl J Med. 2017;377:1513-24. https://doi.org/10.1056/NEJMo a1708454.

194. Lopes RD, Heizer G, Aronson R, Vora AN, Massaro T, Mehran R, Goodman SG, Windecker S, Darius H, Li J, Averkov O, Bahit MC, Berwanger O, Budaj A, Hijazi Z, Parkhomenko A, Sinnaeve P, Storey RF, Thiele H, Vinereanu D, Granger CB, Alexander JH, Investigators A. Antithrombotic therapy after acute coronary syndrome or PCI in atrial fibrillation. N Engl J Med. 2019;380:1509-24. https://doi.org/10.1056/NEJMoa1817083.

195. Lopes RD, Hong H, Harskamp RE, Bhatt DL, Mehran R, Cannon CP, Granger CB, Verheugt FWA, Li J, Ten Berg JM, Sarafoff N, Gibson CM, Alexander JH. Safety and efficacy of antithrombotic strategies in patients with atrial fibrillation undergoing percutaneous coronary intervention: a network meta-analysis of randomized controlled trials. JAMA Cardiol. 2019;4:747-55. https:// doi.org/10.1001/jamacardio.2019.1880.

196. Yasuda S, Kaikita K, Akao M, Ako J, Matoba T, Nakamura M, Miyauchi K, Hagiwara N, Kimura K, Hirayama A, Matsui $\mathrm{K}$, Ogawa $\mathrm{H}$, Investigators A. Antithrombotic therapy for atrial fibrillation with stable coronary disease. N Engl J Med. 2019;381:1103-13. https://doi.org/10.1056/NEJMoa1904143.

197. Hashimoto Y, Ozaki Y, Kan S, Nakao K, Kimura K, Ako J, Noguchi T, Suwa S, Fujimoto K, Dai K, Morita T, Shimizu W, Saito Y, Hirohata A, Morita Y, Inoue T, Okamura A, Mano T, Wake M, Tanabe K, Shibata Y, Owa M, Tsujita K, Funayama H, Kokubu N, Kozuma K, Uemura S, Tobaru T, Saku K, Oshima S, Yasuda S, Ismail TF, Muramatsu T, Izawa H, Takahashi H, Nishimura K, Miyamoto Y, Ogawa H, Ishihara M. Impact of chronic kidney disease on in-hospital and 3-year clinical outcomes in patients with acute myocardial infarction treated by contemporary percutaneous coronary intervention and optimal medical therapy insights from the J-MINUET study. Circ J. 2021. https://doi.org/10.1253/circj.CJ-20-1115.

198. Smits PC, Abdel-Wahab M, Neumann FJ, Boxma-De Klerk BM, Lunde K, Schotborgh CE, Piroth Z, Horak D, Wlodarczak A, Ong PJ, Hambrecht R, Angeras O, Richardt G, Omerovic E. Fractional Flow Reserve-guided multivessel angioplasty in myocardial infarction. N Engl J Med. 2017;376:1234-44. https:// doi.org/10.1056/NEJMoa1701067.

199. Smits PC, Laforgia PL, Abdel-Wahab M, Neumann FJ, Richardt G, Boxma-De Klerk B, Lunde K, Schotborgh CE, Piroth Z, Horak D, Wlodarczak A, Frederix GW, Omerovic E. Fractional flow reserve-guided multivessel angioplasty in myocardial infarction: three-year follow-up with cost benefit analysis of the Compare-Acute trial. EuroIntervention. 2020;16:225-32. https:// doi.org/10.4244/eij-d-20-00012.

200. Mehta SR, Wood DA, Storey RF, Mehran R, Bainey KR, Nguyen H, Meeks B, Di Pasquale G, López-Sendón J, Faxon DP, Mauri L, Rao SV, Feldman L, Steg PG, Avezum Á, Sheth T, PinillaEcheverri N, Moreno R, Campo G, Wrigley B, Kedev S, Sutton A, Oliver R, Rodés-Cabau J, Stanković G, Welsh R, Lavi S, Cantor WJ, Wang J, Nakamya J, Bangdiwala SI, Cairns JA. Complete revascularization with multivessel pci for myocardial infarction. N Engl J Med. 2019;381:1411-21. https://doi.org/10. 1056/NEJMoa1907775. 
201. Bainey KR, Engstrøm T, Smits PC, Gershlick AH, James SK, Storey RF, Wood DA, Mehran R, Cairns JA, Mehta SR. Complete vs culprit-lesion-only revascularization for st-segment elevation myocardial infarction: a systematic review and metaanalysis. JAMA Cardiol. 2020;5:1-9. https://doi.org/10.1001/ jamacardio.2020.1251.

202. Thiele H, Akin I, Sandri M, Fuernau G, De Waha S, MeyerSaraei R, Nordbeck P, Geisler T, Landmesser U, Skurk C, Fach A, Lapp H, Piek JJ, Noc M, Goslar T, Felix SB, Maier LS, Stepinska J, Oldroyd K, Serpytis P, Montalescot G, Barthelemy O, Huber K, Windecker S, Savonitto S, Torremante P, Vrints C, Schneider S, Desch S, Zeymer U. PCI Strategies in Patients with Acute Myocardial Infarction and Cardiogenic Shock. N Engl J Med. 2017;5:5. https://doi.org/10.1056/NEJMoa171026.

203. Thiele H, Akin I, Sandri M, De Waha-Thiele S, Meyer-Saraei R, Fuernau G, Eitel I, Nordbeck P, Geisler T, Landmesser U, Skurk C, Fach A, Jobs A, Lapp H, Piek JJ, Noc M, Goslar T, Felix SB, Maier LS, Stepinska J, Oldroyd K, Serpytis P, Montalescot G, Barthelemy O, Huber K, Windecker S, Hunziker L, Savonitto S, Torremante P, Vrints C, Schneider S, Zeymer U, Desch S. One-year outcomes after PCI Strategies In Cardiogenic Shock. N Engl J Med. 2018;379:1699-710. https://doi.org/10.1056/NEJMo a1808788.

204. Rathod KS, Koganti S, Jain AK, Astroulakis Z, Lim P, Rakhit R, Kalra SS, Dalby MC, Omahony C, Malik IS, Knight CJ, Mathur A, Redwood S, Sirker A, Maccarthy PA, Smith EJ, Wragg A, Jones DA. Complete versus culprit-only lesion intervention in patients with acute coronary syndromes. J Am Coll Cardiol. 2018;72:1989-99. https://doi.org/10.1016/j.jacc.2018.07.089.

205. Bainey KR, Alemayehu W, Armstrong PW, Westerhout CM, Kaul P, Welsh RC. Long-term outcomes of complete revascularization with percutaneous coronary intervention in acute coronary syndromes. JACC Cardiovasc Interv. 2020;13:1557-67. https:// doi.org/10.1016/j.jcin.2020.04.034.

206. Wood DA, Cairns JA, Wang J, Mehran R, Storey RF, Nguyen H, Meeks B, Kunadian V, Tanguay JF, Kim HH, Cheema A, Dehghani P, Natarajan MK, Jolly SS, Amerena J, Keltai M,
James S, Hlinomaz O, Niemela K, Alhabib K, Lewis BS, Nguyen M, Sarma J, Dzavik V, Della Siega A, Mehta SR. Timing of Staged Nonculprit Artery Revascularization In Patients With StSegment Elevation Myocardial Infarction: COMPLETE trial. J Am Coll Cardiol. 2019;74:2713-23. https://doi.org/10.1016/j. jacc.2019.09.051.

207. Sardella G, Lucisano L, Garbo R, Pennacchi M, Cavallo E, Stio RE, Calcagno S, Ugo F, Boccuzzi G, Fedele F, Mancone M. Single-staged compared with multi-staged pci in multivessel nstemi patients: the SMILE trial. J Am Coll Cardiol. 2016;67:264-72. https://doi.org/10.1016/j.jacc.2015.10.082.

208. Calviño-Santos R, Estévez-Loureiro R, Peteiro-Vázquez J, Salgado-Fernández J, Rodríguez-Vilela A, Franco-Gutiérrez R, Bouzas-Mosquera A, Rodríguez-Fernández J, Mesías-Prego A, González-Juanatey C, Aldama-López G, Piñón-Esteban P, Flores-Ríos X, Soler-Martín R, Seoane-Pillado T, VázquezGonzález N, Muñiz J, Vázquez-Rodríguez JM. Angiographically guided complete revascularization versus selective stress echocardiography-guided revascularization in patients with st-segment-elevation myocardial infarction and multivessel disease: the CROSS-AMI randomized clinical trial. Circ Cardiovasc Interv. 2019;12: e007924. https://doi.org/10.1161/circinterventio ns.119.007924.

209. Puymirat E, Cayla G, Simon T, Steg PG, Montalescot G, DurandZaleski I, Le Bras A, Gallet R, Khalife K, Morelle JF, Motreff P, Lemesle G, Dillinger JG, Lhermusier T, Silvain J, Roule V, Labèque JN, Rangé G, Ducrocq G, Cottin Y, Blanchard D, Charles Nelson A, De Bruyne B, Chatellier G, Danchin N. Multivessel PCI guided by FFR or angiography for myocardial infarction. N Engl J Med. 2021. https://doi.org/10.1056/NEJMoa2104 650.

Publisher's Note Springer Nature remains neutral with regard to jurisdictional claims in published maps and institutional affiliations.

\section{Authors and Affiliations}

Yukio Ozaki $^{1} \cdot$ Hironori Haraa ${ }^{2,3} \cdot$ Yoshinobu Onuma $^{2} \cdot$ Yuki Katagiri $^{4} \cdot$ Tetsuya Amano $^{5} \cdot$ Yoshio Kobayashi $^{6}$. Takashi Muramatsu $^{1} \cdot$ Hideki Ishii $^{7} \cdot$ Ken Kozuma $^{8} \cdot$ Nobuhiro Tanaka $^{9} \cdot$ Hitoshi Matsuo $^{10} \cdot$ Shiro Uemura ${ }^{11}$. Kazushige Kadota ${ }^{12}$. Yutaka Hikichi ${ }^{13} \cdot$ Kenichi Tsujita $^{14}$. Junya Ako ${ }^{15}$. Yoshihisa Nakagawa ${ }^{16}$. Yoshihiro Morino ${ }^{17}$. Ichiro Hamanaka ${ }^{18}$. Nobuo Shiode ${ }^{19}$. Junya Shite ${ }^{20}$. Junko Honye ${ }^{21} \cdot$ Tetsuo Matsubara $^{22} \cdot K_{\text {Kazuya Kawai }}{ }^{23}$. Yasumi Igarashi ${ }^{24}$. Atsunori Okamura ${ }^{25}$. Takayuki Ogawa ${ }^{26} \cdot$ Yoshisato Shibata $^{27}$. Takafumi Tsuji ${ }^{28}$. Junji Yajima ${ }^{29}$. Kaoru Iwabuchi ${ }^{30}$. Nobuo Komatsu ${ }^{31} \cdot$ Teruyasu Sugano $^{32}$ - Masaru Yamaki ${ }^{33}$. Shinichiro Yamada ${ }^{34}$. Hiroaki Hirase $\mathrm{e}^{35}$. Yuusuke Miyashita ${ }^{36} \cdot$ Fuminobu Yoshimachi $^{37}$. Masakazu Kobayashi ${ }^{1}$. Jiro Aoki ${ }^{38}$. Hirotaka Oda ${ }^{39}$. Yoshiaki Katahira ${ }^{40} \cdot$ Kinzo Ueda $^{41} \cdot$ Masami Nishino $^{42} \cdot$ Koichi Nakao $^{43} \cdot$ Ichiro Michishita $^{44}$. Takafumi Ueno $^{45}$. Taku Inohara ${ }^{46}$. Shun Kohsaka ${ }^{46}$. Tevfik F. Ismail ${ }^{1,47}$. Patrick W. Serruys ${ }^{2,48}$. Masato Nakamura ${ }^{49}$. Hiroyoshi Yokoi ${ }^{50} \cdot$ Yuji Ikari $^{51}$. The Task Force on Primary Percutaneous Coronary Intervention (PCI) of the Japanese Cardiovascular Interventional Therapeutics (CVIT)

1 Department of Cardiology, Fujita Health University School of Medicine, Aichi, Japan

2 Department of Cardiology, National University of Ireland, Galway (NUIG), Galway, Ireland

3 Department of Cardiology, Academic Medical Center, University of Amsterdam, Amsterdam, The Netherlands
4 Department of Cardiology, Sapporo Higashi Tokushukai Hospital, Sapporo, Japan

5 Department of Cardiology, Aichi Medical University, Aichi, Japan

6 Department of Cardiovascular Medicine, Chiba University Graduate School of Medicine, Chiba, Japan 
7 Department of Cardiovascular Medicine, Gunma University Graduate School of Medicine, Gunma, Japan

8 Department of Cardiology, Teikyo University Hospital, Tokyo, Japan

9 Division of Cardiology, Tokyo Medical University Hachioji Medical Center, Tokyo, Japan

10 Gifu Heart Center, Gifu, Japan

11 Cardiovascular Medicine, Kawasaki Medical School, Kurashiki, Japan

12 Kurashiki Central Hospital, Kurashiki, Japan

13 Heart Center, Saga Medical Center Koseikan, Saga, Japan

14 Department of Cardiovascular Medicine, Graduate School of Medical Sciences, Kumamoto University, Kumamoto, Japan

15 Department of Cardiology, Kitasato University Hospital, Sagamihara, Japan

16 Division of Cardiovascular Medicine, Department of Internal Medicine, Shiga University of Medical Science, Otsu, Japan

17 Department of Cardiology, Iwate Medical University Hospital, Morioka, Japan

18 Cardiovascular Intervention Center, Rakuwakai Marutamachi Hospital, Kyoto, Japan

19 Division of Cardiology, Hiroshima City Hiroshima Citizens Hospital, Hiroshima, Japan

20 Cardiology Division, Osaka Saiseikai Nakatsu Hospital, Osaka, Japan

2 Kikuna Memorial Hospital, Yokohama, Japan

22 Toyohashi Heart Center, Toyohashi, Japan

( Tardiology, The Jikei University School of Medicine, Tokyo, Japan

27 Miyazaki Medical Association Hospital, Miyazaki, Japan
40 Department of Cardiology, Katta General Hospital, Shiroishi, Japan

41 Takase Clinic, Takasaki, Japan

42 Division of Cardiology, Osaka Rosai Hospital, Osaka, Japan

43 Division of Cardiology, Saiseikai Kumamoto Hospital, Cardiovascular Center, Kumamoto, Japan

44 Yokohama Sakae Kyosai Hospital, Yokohama, Japan

45 Fukuoka Kinen Hospital, Fukuoka, Japan

46 Keio University School of Medicine, Tokyo, Japan

47 King's College London \& Guy's and St Thomas' Hospital NHS Foundation Trust, London, UK

48 NHLI, Imperial College London, London, UK

49 Division of Cardiovascular Medicine, Ohashi Medical Center, Toho University School of Medicine, Tokyo, Japan

50 Cardiovascular Center, Fukuoka Sanno Hospital, Fukuoka, Japan

51 Department of Cardiology, Tokai University School of Medicine, Isehara, Japan 